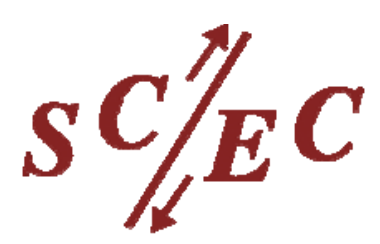
an NSF+USCScenter
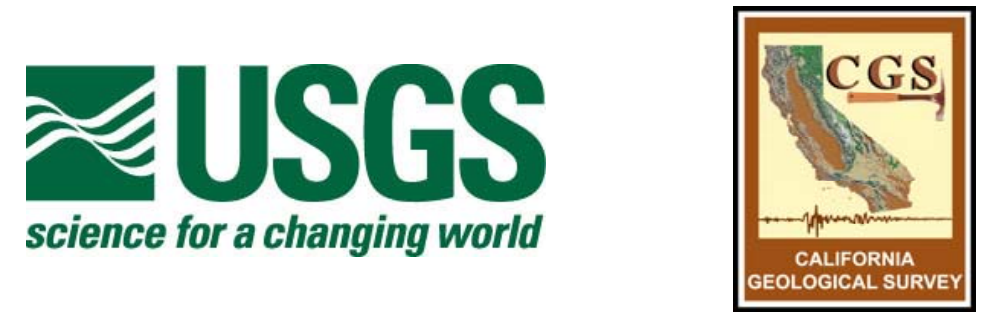

\title{
The Uniform California Earthquake Rupture Forecast, Version 2 (UCERF 2)
}

By 2007 Working Group on California Earthquake Probabilities*

USGS Open File Report 2007-1437

CGS Special Report 203

SCEC Contribution \#1138

Version 1.0

2008

* Edward H. Field, Timothy E. Dawson, Karen R. Felzer, Arthur D. Frankel, Vipin Gupta, Thomas H. Jordan, Tom Parsons, Mark D. Petersen, Ross S. Stein, Ray J. Weldon I I, and Chris J. Wills

U.S. Department of the Interior

U.S. Geological Survey

California Department of Conservation

California Geological Survey 


\title{
U.S. Department of the Interior \\ DIRK KEMPTHORNE, Secretary
}

\author{
U.S. Geological Survey \\ Mark D. Myers, Director
}

State of California

ARNOLD SCHWARZENEGGER, Governor

The Resources Agency

MIKE CHRISMAN, Secretary for Resources

Department of Conservation

Bridgett Luther, Director

California Geological Survey

John G. Parrish, Ph.D., State Geologist

U.S. Geological Survey, Reston, Virginia 2008

For product and ordering information:

World Wide Web: http://www.usgs.gov/pubprod

Telephone: 1-888-ASK-USGS

For more information on the USGS - the Federal source for science about the Earth, its natural and living resources, natural hazards, and the environment:

World Wide Web: http://www.usgs.gov

Telephone: 1-888-ASK-USGS

Suggested citation:

2007 Working Group on California Earthquake Probabilities, 2008, The Uniform California Earthquake Rupture Forecast, Version 2 (UCERF 2): U.S. Geological Survey Open-File Report 2007-1437 and California Geological Survey Special Report 203

[http://pubs.usgs.gov/of/2007/1091/].

Any use of trade, product, or firm names is for descriptive purposes only and does not imply endorsement by the U.S. Government.

Although this report is in the public domain, permission must be secured from the individual copyright owners to reproduce any copyrighted material contained within this report. 


\title{
Executive Committee (ExCom)
}

\author{
Edward H. Field (Chair) U. S. Geological Survey, Pasadena, Calif. \\ Tom Parsons U. S. Geological Survey, Menlo Park, Calif. \\ Mark D. Petersen U. S. Geological Survey, Golden, Colo. \\ Ross S. Stein U. S. Geological Survey, Menlo Park, Calif. \\ Ray J. Weldon II SCEC, University of Oregon, Eugene, Oreg. \\ Chris J. Wills California Geological Survey
}

\section{Scientific Review Panel (SRP)}

$\begin{array}{ll}\text { William L. Ellsworth (Chair) } & \text { U. S. Geological Survey, Menlo Park, Calif. } \\ \text { Michael L. Blanpied } & \text { U. S. Geological Survey, Reston, Virg. } \\ \text { Lloyd C. Cluff } & \text { Pacific Gas and Electric Company } \\ \text { C. Allin Cornell } & \text { Stanford University, Stanford, Calif. } \\ \text { Arthur D. Frankel } & \text { U. S. Geological Survey, Golden, Colo. } \\ \text { David D. Jackson } & \text { University of California, Los Angeles, Los Angeles, Calif. } \\ \text { David P. Schwartz } & \text { U. S. Geological Survey, Menlo Park, Calif. } \\ \text { Steve G. Wesnousky } & \text { University of Nevada, Reno, Reno, Nev. }\end{array}$

\section{Management Oversight Committee (MOC)}

$\begin{array}{ll}\text { Thomas H. Jordan (Chair) } & \text { SCEC Director, University of Southern California } \\ \text { Rufus D. Catchings } & \text { U. S. Geological Survey, Menlo Park, Calif. } \\ \text { Jill R. McCarthy } & \text { U. S. Geological Survey, Golden, Colo. } \\ \text { Michael S. Reichle } & \text { California Geological Survey }\end{array}$




\section{Authors and Co-authors of Appendices}

\author{
Glenn P. Biasi \\ William A. Bryant \\ Tianqing Cao \\ Timothy E. Dawson \\ Karen R. Felzer \\ Edward H. Field \\ Arthur D. Frankel \\ Thomas E. Fumal \\ Vipin Gupta \\ Katherine J. Kendrick \\ Charles S. Mueller \\ Tom Parsons \\ Mark D. Petersen \\ David A. Schmidt \\ Ross S. Stein \\ Tom K. Rockwell \\ Ray J. Weldon II \\ Chris J. Wills \\ Beth A. Wisely \\ Yuehua Zeng
}

University of Nevada, Reno, Reno, Nev.

California Geological Survey

California Geological Survey

U. S. Geological Survey, Menlo Park, Calif.

U. S. Geological Survey, Pasadena, Calif.

U. S. Geological Survey, Pasadena, Calif.

U. S. Geological Survey, Golden, Colo.

U. S. Geological Survey, Menlo Park, Calif.

SCEC/ University of Southern California

U. S. Geological Survey, Pasadena, Calif.

U. S. Geological Survey, Golden, Colo.

U. S. Geological Survey, Menlo Park, Calif.

U. S. Geological Survey, Golden, Colo.

University of Oregon, Eugene, Oreg.

U. S. Geological Survey, Menlo Park, Calif.

San Diego State University, San Diego, Calif.

SCEC/University of Oregon, Eugene, Oreg.

California Geological Survey

University of Oregon, Eugene, Oreg.

U. S. Geological Survey, Golden, Colo. 


\section{Table of Contents}

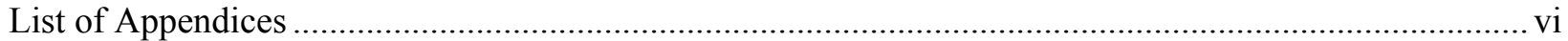

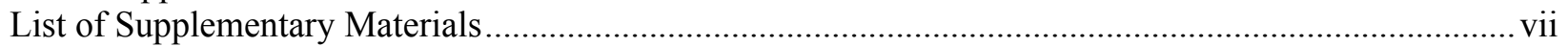

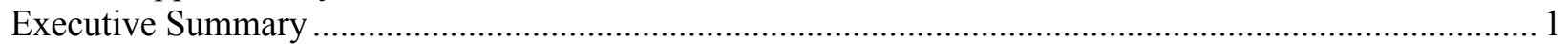

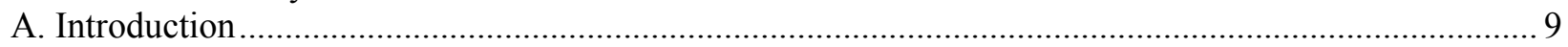

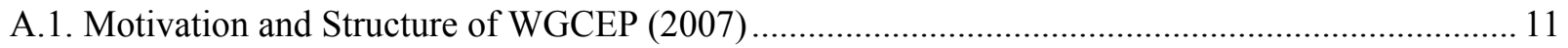

A.2. Key Differences and Updates from Previous WGCEP Models .................................................. 12

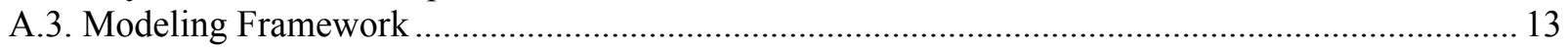

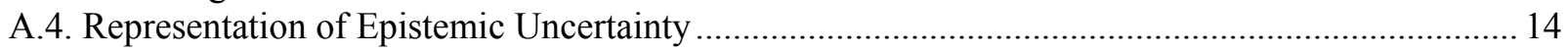

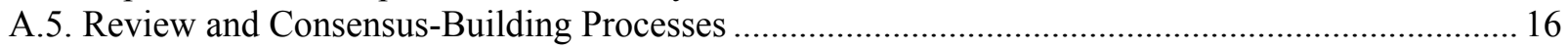

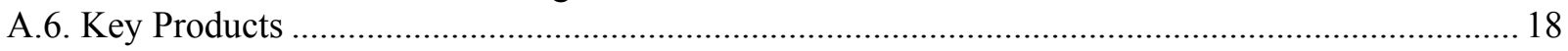

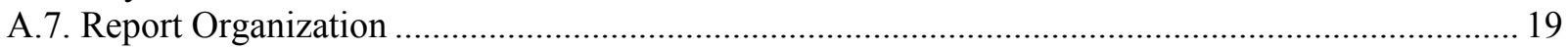

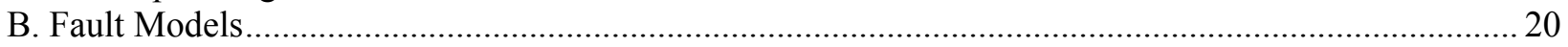

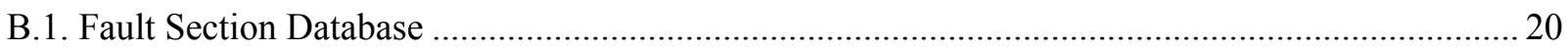

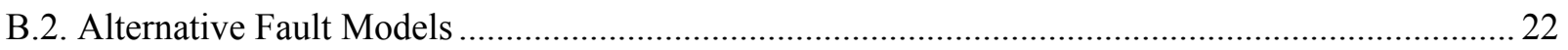

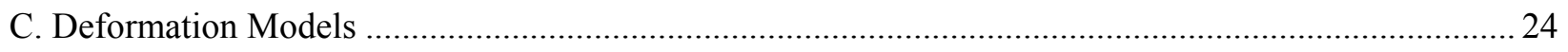

C.1. Preferred and Alternative Deformation Models ................................................................... 24

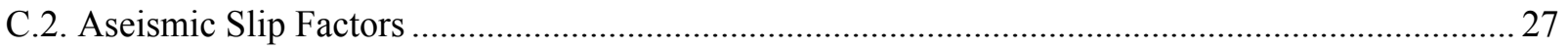

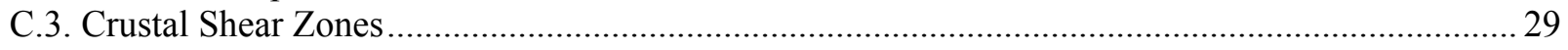

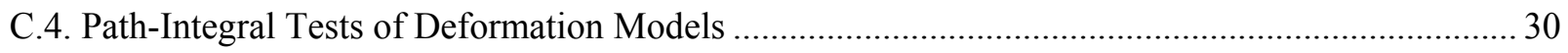

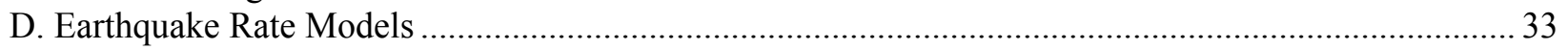

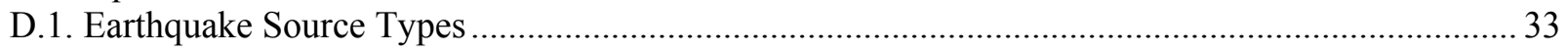

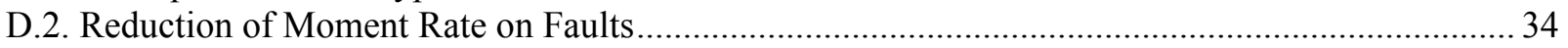

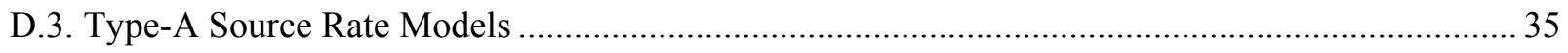

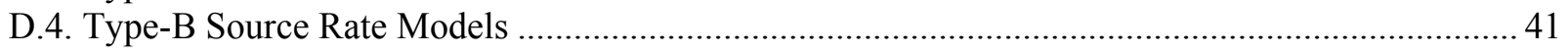

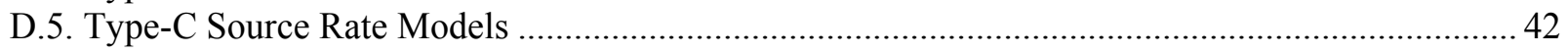

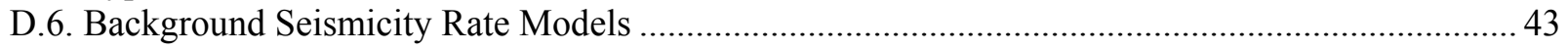

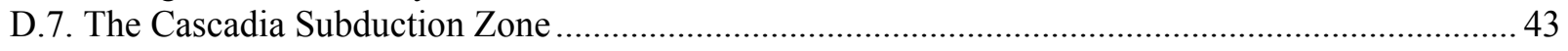

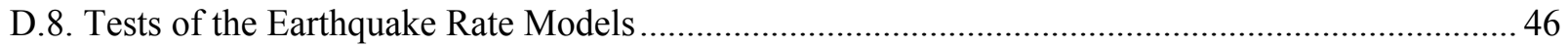

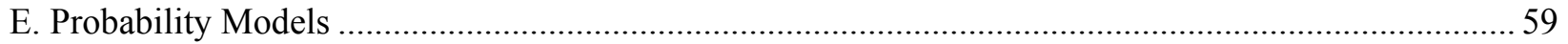

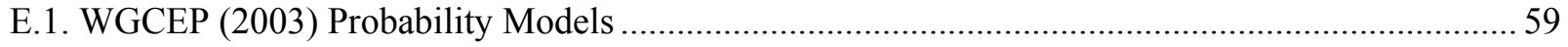

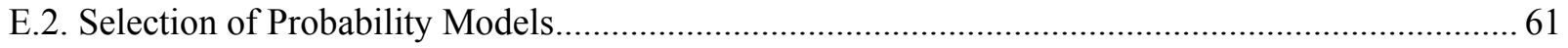

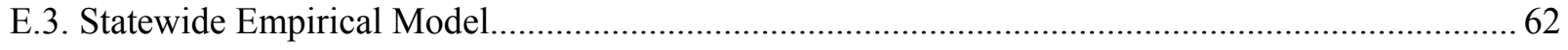

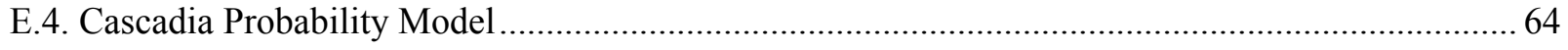

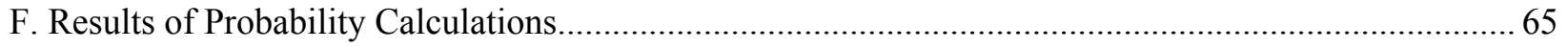

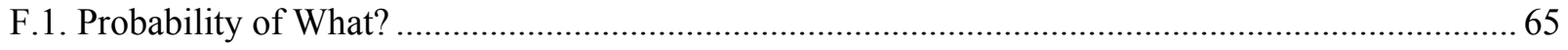

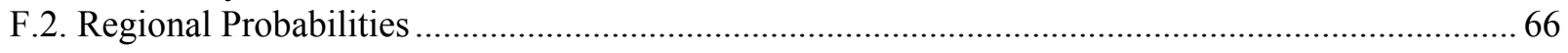

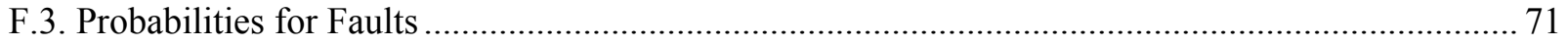

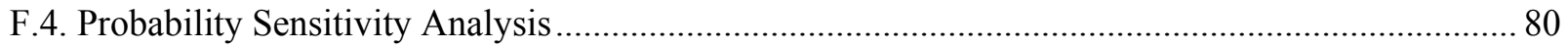

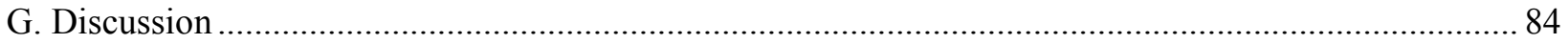

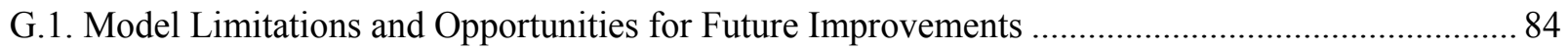

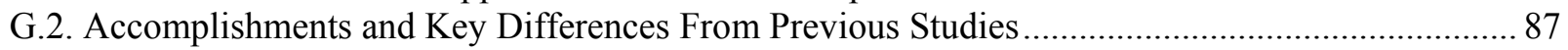

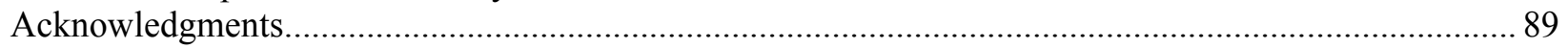

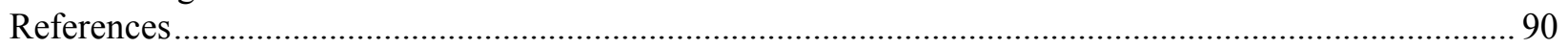

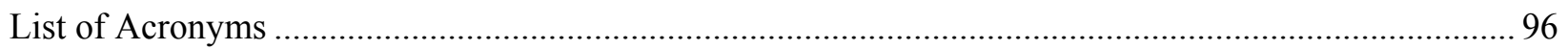




\section{List of Appendices}

A. California Fault Parameters for the National Seismic Hazard Maps and Working Group on California Earthquake Probabilities 2007, by C. J. Wills, R. J. Weldon II, and W. A. Bryant

B. Recurrence Interval and Event Age Data for Type A Faults, by T. E. Dawson, R. J. Weldon II, and G. P. Biasi

C. Monte Carlo Method for Determining Earthquake Recurrence Parameters from Short Paleoseismic Catalogs: Example Calculations for California, by T. Parsons

D. Magnitude-Area Relationships, by R.S. Stein

E. Overview of the Southern San Andreas Fault Model, by R. J. Weldon II, G. P. Biasi, C. J. Wills, and T.E. Dawson

F. Summary of Geologic Data and Developments of A-Priori Rupture Models for the Elsinore, San Jacinto, and Garlock Faults, by T. E. Dawson, T. K. Rockwell, R. J. Weldon II, and C. J. Wills

G. Development of Final A-Fault Rupture Models for WGCEP/NSHMP Earthquake Rate Model 2.3, by E. H. Field, R. J. Weldon II, V. Gupta, T. Parsons, W. J. Wills, T. E. Dawson, R. S. Stein, and M. D. Petersen

H. WGCEP Historical California Earthquake Catalog, by K. R. Felzer and T. Cao

I. Calculating California Seismicity Rates, by K. R. Felzer

J. Spatial Seismicity Rates and Maximum Magnitudes for Background, by M. D. Petersen, C. S. Mueller, A. D. Frankel, and Y. Zeng

K. A-Priori Rupture Models for Northern California Type-A Faults, by C. J. Wills, R. J. Weldon II, and E. H. Field

L. Cascadia Subduction Zone, by A. D. Frankel and M.D. Petersen

M. Empirical Estimation of Regional Time Variation in Seismicity, by K. R. Felzer

N. Conditional, Time-Dependent Probabilities for Segmented Type-A Faults in the WGCEP UCERF 2, by E. H. Field and V. Gupta

O. Paleoseismic Investigations of the Walnut Site on the San Jacinto Fault, by T. E. Fumal and K. J. Kendrick

P. Compilation of Surface Creep on California Faults and Comparison of WGCEP 2007 Deformation Model to Pacific-North America Plate Motion, by B. A. Wisely, D. A. Schmidt, and R. J. Weldon II 


\section{List of Supplementary Materials}

\section{Supplementary Excel Spreadsheet}

Sheet 1: Rupture Magnitudes \& Rates

Sheet 2: Total 30-year Rupture Probabilities

Sheet 3: Total 5-year Rupture Probabilities

Sheet 4: $\quad M \geq 6.7$ 30-year Rupture Probabilities

Sheet 5: Segment Rates \& Mean Recurrence Intervals

Sheet 6: Total 30-year Segment Probabilities

Sheet 7: Total 5-year Segment Probabilities

Sheet 8: $\quad M \geq 6.7$ 30-year Segment Probabilities

Sheet 9: $\quad M \geq 6.7$ Probabilities in WGCEP (2003: Box

Sheet 10: Total 30-year Probabilities on Faults

Sheet 11: $\quad \mathrm{M} \geq 6.7$ 30-year Probabilities on Faults

Sheet 12: B-Fault Data

Sheet 13: Region Polygons 
UCERF 2 Report 


\section{The Uniform California Earthquake Rupture Forecast, Version 2 (UCERF 2)}

\section{Working Group on California Earthquake Probabilities (WGCEP) and the USGS National Seismic Hazard Mapping Program (NSHMP)}

\section{Executive Summary}

California's 35 million people live among some of the most active earthquake faults in the United States. Public safety demands credible assessments of the earthquake hazard to maintain appropriate building codes for safe construction and earthquake insurance for loss protection. Seismic hazard analysis begins with an earthquake rupture forecast $-a$ model of probabilities that earthquakes of specified magnitudes, locations, and faulting types will occur during a specified time interval. This report describes a new earthquake rupture forecast for California developed by the 2007 Working Group on California Earthquake Probabilities (WGCEP 2007).

\section{Working Group on California Earthquake Probabilities}

WGCEP 2007 was organized in September, 2005, by the U. S. Geological Survey (USGS), the California Geological Survey (CGS), and the Southern California Earthquake Center (SCEC). It was charged with two tasks: (1) collaborate with the National Seismic Hazard Mapping Program (NSHMP) in producing a revised, timeindependent forecast for California as input to the 2007 revisions of the national seismic hazard maps, and (2) create a uniform, statewide, timedependent model that, among other purposes, could be used by the California Earthquake Authority (CEA) in setting earthquake insurance rates.

The national seismic hazard maps utilize a time-independent forecast in which the probability of each earthquake rupture is completely independent of the timing of all others. Timedependent models are based on the concept of stress renewal: the probability of a fault rupture drops immediately after a large earthquake releases tectonic stress on the fault and rises again as the stress is regenerated by continuous tectonic loading. However, observations in California and elsewhere show that the earthquake cycle associated with this elastic rebound theory can be highly irregular, owing, for example, to stress interactions among neighboring faults. We do not understand these interactions well enough to model them explicitly; therefore, variations in the earthquake cycle must be calibrated empirically using historical observations of seismicity and geologic data on the dates and sizes of prehistoric earthquakes (paleoseismology).

Time-dependent earthquake rupture forecasts, in which the probabilities of future events are conditioned on the dates of previous earthquakes, have been the focus of five previous Working Groups on California Earthquake Probabilities (WGCEP 1988, 1990, 1995 \& 2003). Each of 
these working groups has expanded on its predecessors, improving the data and forecasting methodology, and each has drawn on input from broad cross-sections of the earth science community. Building on this experience, we calculate time-dependent probabilities of large earthquakes on major faults (generally those with the highest rates of slip) where the requisite information is available: the expected mean frequency of earthquakes and the elapsed time since the last earthquake. Where such information is lacking, we use time-independent probabilities, which require only an estimate of earthquake frequency.

The WGCEP 2007 study differs from previous WGCEP efforts by:

- reporting earthquake probability for the entire state of California instead of subregions;

- using uniform methodology across all regions;

- using the same earthquake rate model as the 2007 National Seismic Hazard Map Program;

- compiling and using updated, uniform, and publicly accessible statewide data;

- developing new methods to make models more rigorously adherent to observational data, particularly fault slip rates (moment balanced);

- making analysis tools and data available through a readily accessible web-based interface.

In general, we have adopted the results from previous working groups where justified and have updated the model only when compelled to by new information or understanding, or by necessity to conform the analysis to a uniform statewide approach and with the NSHMP assessment.

\section{Review and Consensus-Building Processes}

All UCERF 2 model elements and WGCEP 2007 documents were reviewed by an internal Scientific Review Panel (SRP) comprising experts who were not WGCEP 2007 members. The SRP reported to the Management Oversight Committee (MOC), which coordinated the review and oversaw consensus-building processes. External oversight and review was provided by the National Earthquake Prediction Evaluation Council (NEPEC) and the California Earthquake Prediction Evaluation Council (CEPEC), as well as CEA's Multidisciplinary Research Team. CEPEC and NEPEC tracked model development throughout the WGCEP 2007 process and reviewed the final report.

Advice and comment from the scientific and engineering communities was sought regularly through open meetings and workshops during the several phases of UCERF development. Participants included experts from academia, private and corporate providers of hazard assessments, consulting companies, and government agencies. WGCEP progress was reported at major scientific gatherings such as annual meetings of the American Geophysical Union, the Seismological Society of America, and the Southern California Earthquake Center.

\section{Model Framework}

We have built on previous WGCEP and NSHMP efforts to quantify regional earthquake probabilities in California, using the best available science to develop a new framework for a Uniform California Earthquake Rupture Forecast (UCERF). The UCERF framework comprises a sequence of four model types: a fault model that gives the physical geometry of the larger, known faults; a deformation model that gives slip rates and 
aseismicity factors to each fault section; an earthquake rate model that gives the long-term rate of all earthquakes of magnitude five or greater $(\mathrm{M} \geq 5)$ throughout the region; and a probability model that gives a probability of occurrence for each earthquake during a specified (future) time interval. This report presents the latest versions of each of these models, including the statewide time-independent earthquake rate model incorporated into the 2007 revisions to the national seismic hazard map (ERM 2.3) and the timedependent earthquake probability model derived from ERM 2.3 (UCERF 2). The results are intended for use in forecasting the intensity of ground shaking throughout California.

The model incorporates both aleatory uncertainties (arising from natural variability) and epistemic uncertainties (resulting from lack of knowledge). The latter were included by constructing a logic tree with branches representing viable alternative hypotheses. We restricted our consideration to data and methods that have been published, or accepted for publication, in peer-reviewed scientific journals or as U.S. Geological Survey Open File Reports. If relevant published models differed significantly, we applied logic-tree weighting to represent the alternatives. Generally, two alternatives were given equal weight in the absence of any clear evidence to favor one over the other. When there was evidence to favor a given branch, the assignment of relative weights was made though a consensus-building process, which we describe for each case.

\section{Earthquake Rate Model}

The WGCEP 2007 earthquake rate model features a new fault geometry with more accurate values of dip and seismogenic depth, and new compilations of fault slip rates and paleoseismic events. The final version, ERM 2.3, includes two alternative fault models for southern California thrust-fault geometry and three alternatives representing the uncertain slip distribution between the southern San Andreas and San Jacinto faults. A significant logic-tree branching involves the choice of the magnitude-area relationship, which is used to translate from fault slip rates to earthquake rates; the global database of rupture areas and magnitude determinations has significant spread, leaving room for alternative interpretations.

Another important model branching incorporates alternative representations of the earthquake rates on major faults. We compiled an a priori earthquake rate model derived by a community consensus of paleoseismic and other geologic observations. We also calculated a moment-balanced version of the model, which modifies the earthquake rate to match the observed long-term slip-rate data; the resulting rates were constrained to fall within the ranges derived from paleoseismic observations. These two models balance a consensus of geologic and seismologic expert opinion with strict adherence to specific observational data.

We tested ERM 2.3 in three different ways: by comparing the predicted magnitude-frequency distributions of earthquakes with a unified historic and instrumental earthquake catalog for California and surrounding regions, by comparing integrating measures of deformation across the plateboundary zone with the plate rate, and by comparing the distribution of source types in the model with historical data. A major issue was overprediction of the rate of $\mathrm{M} \geq 6.5$ earthquakes, known informally as "the bulge", a problem common to previous WGCEP and NSHMP studies. ERM 2.3 predicts an annual rate for $M \geq 6.5$ earthquakes of 0.32 events/yr, which exceeds the historically observed rate of 0.24 events/yr by about a third, though it lies within the 
95\% confidence bounds on the observed rate (0.13-0.35 events/yr). In comparison, the NSHMP 2002 model for California exceeded the observed rate by a factor of two.

\section{Time-Dependent Earthquake Probability Model}

We tightly coordinated the development of the earthquake rate models for California with NSHMP, so that both the 2007 revisions of the national seismic hazard maps and UCERF 2 are based on ERM 2.3. Constructing an earthquake rupture forecast from ERM 2.3 required a probability model that specifies how events are distributed in time, and here we departed from the NSHMP 2007 conventions by considering, along with a time-independent (Poisson) forecast, timedependent forecasts that use stress-renewal assumptions to condition the event probabilities for the most active faults on the date of their last major rupture.

Our choice of UCERF 2 model branches was based on a careful review of all available probability models. A particularly influential branching is the "empirical" probability model, which includes a geographically variable estimate of California earthquake rate changes observed during the last 150 years. We lack consensus on the underlying physics that causes broad earthquake rate changes, though there is much promising research involving fault interactions. Rather than applying complex physical models to adjust probability, WGCEP 2007 relies on the simpler empirically-based correction.

An important seismic hazard for California is the Cascadia subduction zone, which extends

\section{Participation Probabilities}

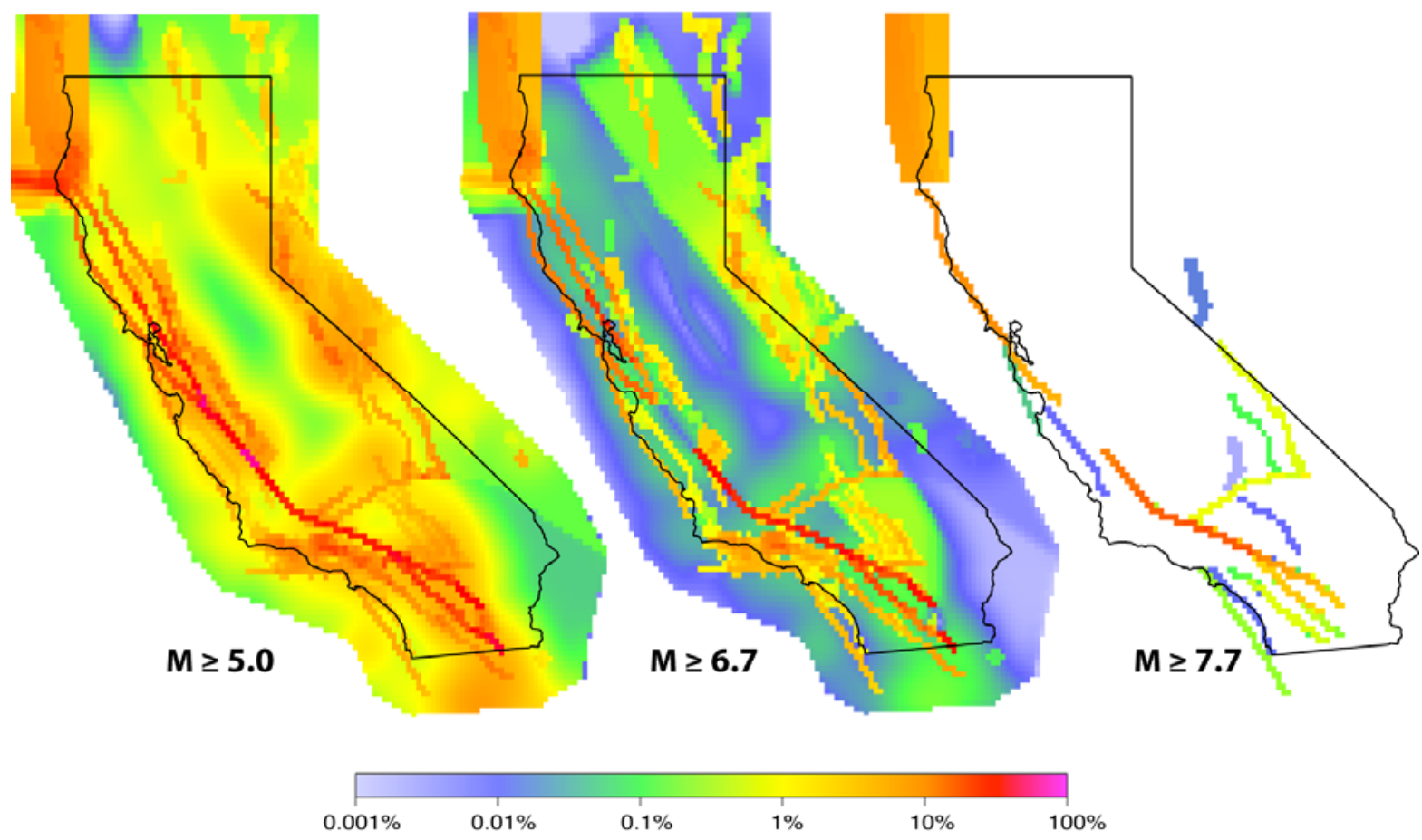

Figure A. Participation probability maps, displaying the mean UCERF 2 probabilities that an individual $0.1^{\circ} \times 0.1^{\circ}$ cell in the statewide grid will be involved in a fault rupture of any source type above the specified magnitude threshold during the next 30 years. The magnitude thresholds shown here are $\mathrm{M} \bullet 5.0$, 6.7, and 7.7. Probability color scale is logarithmic; i.e. each decrement unit represents a 10 -fold decrease in probability. 
about $1200 \mathrm{~km}$ from Vancouver Island in British Columbia to Cape Mendocino in California and is capable of generating an earthquake of M 9 or larger. Because this fault lies mostly outside the state, we treated it as a special case with its own logic tree, which included two rupture scenarios: (1) M 8.8-9.2 events that rupture the entire Cascadia subduction zone every 500 years on average, and (2) M 8.0-8.7 events whose ruptures cover the entire zone over a period of about 500 years. A time-independent model was applied to the M 8.0-8.7 scenario, and a time-dependent model to the M 8.8-9.2 scenario.

In computing event probabilities, the branches were weighted by expert opinion gathered in open workshops. The UCERF 2 model has been implemented in a modular (object-oriented), extensible framework using the OpenSHA platform, so that experiments with alternative branch weights can be easily investigated and future updates can be quickly accommodated as new data and methods emerge. The final UCERF 2 logic tree incorporated 480 branches that received nonzero weight, each of which produces a separate set of probabilities for all earthquakes in California. We take the mean and spread of these results to represent the best estimate of earthquake probability and its sensitivity to parameter uncertainty.

\section{Results of Probability Calculations}

According to UCERF 2, a $M \geq 6.7$ earthquake is virtually assured in California during the next 30 years (99.7\% probability of occurrence). Larger events are less likely: the mean 30-year UCERF 2 estimate gives a $94 \%$ chance of a $M \geq 7.0$ earthquake, a $46 \%$ chance of a $M \geq 7.5$ shock, and $4.5 \%$ chance of a $\mathrm{M} \geq 8.0$ event. The UCERF 2 range for these latter probabilities is $85-99 \%, 29$ $65 \%$, and $0-11 \%$, respectively. In addition, we estimate a $10 \%$ probability of a $\mathrm{M} \geq 8.0$ earthquake somewhere along the Cascadia subduction zone (perhaps far from California) in the next 30 years. We emphasize that the probabilities calculated for the largest magnitude events should be used with caution, because they depend critically on rupture scenarios that involve fault lengths longer than historically observed ruptures, as well as an extrapolation of scaling relationships, such as the magnitude-area relationships, beyond the limits of the empirical data.

Dividing the state into two approximately equal areas, we find the 30-year probability of a large earthquake to be higher in the southern half: a $M \geq 6.7$ earthquake has a $97 \%$ chance of occurring in southern California in 30-years, compared to a $93 \%$ probability in northern California, and the odds for a $M \geq 7.5$ event are doubled (37\% vs. $15 \%)$. In addition to state-wide and regional estimates, our report gives probabilities for individual faults and fault segments throughout the state, as well as a geographically variable background rate.

The UCERF 2 earthquake rupture forecast can be visualized by mapping the mean probability that an element of area on a statewide grid will include a fault rupture of any source type above a specified magnitude threshold during the next 30 years. Figure A presents these "participation probability" maps for three magnitude thresholds. For events with $M \geq 5.0$, the areas where the participation probabilities exceed $1 \%$ (yellow or warmer in color) include over half the state, reflecting the widespread distribution of California seismicity, much of which is represented in the model as "background." At $M \geq 6.7$, this same probability level is confined to the major faults, and at $M \geq 7.7$, it is generally restricted to the longer strike-slip strands of the San Andreas fault system. 
Table A. 30-year probability of $\mathrm{M} \bullet 6.7$ events on the Type-A faults, rounded to the nearest percent.

\begin{tabular}{|l|c|c|c|}
\hline Fault & $\begin{array}{c}\text { WGCEP (2007) Mean } \\
{[\text { Min-Max] }}\end{array}$ & $\begin{array}{c}\text { WGCEP (2003) Mean } \\
{[\mathbf{2 . 5 \%} \text { and 97.5\%] }}\end{array}$ & WGCEP (1995) Mean \\
\hline S. San Andreas & $59 \%[22-94]$ & & $53 \%$ \\
\hline $\begin{array}{l}\text { Hayward-Rodgers } \\
\text { Creek }\end{array}$ & $31 \%[12-67]$ & $27 \%[10-58]$ & \\
\hline San Jacinto & $31 \%[14-54]$ & & $61 \%$ \\
\hline N. San Andreas & $21 \%[6-39]$ & $23 \%[3-52]$ & $24 \%$ \\
\hline Elsinore & $11 \%[5-25]$ & & \\
\hline Calaveras & $7 \%[1-22]$ & $11 \%[3-27]$ & \\
\hline Garlock & $6 \%[3-12]$ & & \\
\hline
\end{tabular}

Table A summarizes the mean probabilities for $M \geq 6.7$ events on the principal strike-slip faults of California, which accommodate most of the motion between the North America and Pacific plates, and it compares our results with those of WGCEP 1995 for southern California and WGCEP 2003 for the Bay Area.

The most dangerous fault is the southern part of the San Andreas, which has a $59 \%$ probability of generating a $M \geq 6.7$ earthquake in the next 30 years. This compares with $21 \%$ for the northern San Andreas fault.

We have enough data to calculate timedependent earthquake probability on the principal strike-slip faults in Table A. These faults exist within a web of faults with lower slip rates that we know less about, which are consequently treated as time-independent sources. In southern California, the contribution to overall regional probability from these lower slip-rate faults, which include the reverse faults of the Transverse Ranges, exceeds that of the principal strike-slip faults.

\section{Reliability of Results}

The larger the area considered and the longer the time considered generally makes a probability calculation more reliable. Thus the statewide 30year probability values are more reliable estimates than those for individual faults. However, even the most reliable of our calculations are subject to considerable sensitivity to parameters. For example, across the 480 branches of the logic tree we find a minimum 30 -year probability of $29 \%$ for a $M \geq 7.5$ earthquake, and a maximum of $65 \%$. Calculations are quite sensitive to parameter choices on individual faults; while the mean calculated probability on the southern San Andreas fault is $59 \%$, we find that the value could reasonably be anywhere between $22 \%$ and $94 \%$ (see Table A).

There are known limitations with the WGCEP 2007 model, which are discussed in detail in the main report. More research time will bring improvements in key topical areas. For example, new earthquake faults will continue to be discovered. Improvements in our methods for determining maximum magnitudes associated with poorly understood faults are needed. A related major research challenge involves improving our ability to forecast more complex earthquake ruptures that include fault jumps, branching, and segment-breaking ruptures.

\section{Comparisons with Previous Studies}

The 30-year probability of a $M \geq 6.7$ earthquake striking the San Francisco Bay Area is $63 \%$ for UCERF 2, which is indistinguishable from the $62 \%$ value reported by WGCEP 2003 
(see Table A). Moreover, the extrema calculated from all of the UCERF 2 branches [0.41-0.84] approximate the $95 \%$ confidence interval of WGCEP 2003 results for the aggregate Bay Area probabilities [0.38-0.85]. This agreement indicates that we succeeded in capturing the most important epistemic uncertainties (in part because we were guided by the comprehensive uncertainty analysis of the WGCEP 2003 report).

As shown in the table, there are differences between WGCEP 2007 and WGCEP 2003 calculations for individual fault probabilities in the Bay Area. However, none exceed the uncertainty ranges reported by either working group. The differences resulted primarily from inclusion of paleoseismic observations in UCERF 2 and the restricted inventory of probability models that could be used for our statewide analysis.

The differences in the mean 30-year probabilities for $M \geq 6.7$ events between the 1995 and 2007 studies are more significant. The most important arise from new paleoseismic data and analysis, new geodetic data, and an earthquake rate model that allows a greater variety of rupture sizes on faults. One important change is to the San Jacinto fault, where the probability has been halved from $61 \%$, reported by WGCEP 1995, to 31\% [14\%-54\%] calculated by WGCEP 2007 (see table). Similarly, Elsinore fault probability is halved from $24 \%$ to $11 \%$ [5\%-25\%] because of the increased array of possible earthquake magnitudes allowed in the model.

\section{Recommendations}

The comprehensive nature of the UCERF 2 analysis has identified many opportunities for future model improvements, and we outline in the report specific recommendations for further research. Examples include the relaxation of fault segmentation and the inclusion of fault-to-fault ruptures, which may be in part responsible for the "bulge" problem; the inclusion of earthquake triggering and clustering, as manifested in aftershock sequences; and improved magnitudearea relationships. 


\section{Uniform California Earthquake Rupture Forecast 2 (UCERF 2)}

By the Working Group on California Earthquake Probabilities 2007 and Participants

\section{A. Introduction}

California's 35 million people live among some of the most active earthquake faults in the United States. Public safety demands credible assessments of the earthquake hazard to maintain appropriate building codes for safe construction and earthquake insurance for loss protection. Seismic hazard analysis begins with an earthquake rupture forecast - a model of probabilities that earthquakes of specified magnitudes, locations, and faulting types will occur during a specified time interval. This report describes Version 2 of the Uniform California Earthquake Rupture Forecast (UCERF 2), which estimates the longterm rate of earthquakes with magnitudes greater than five $(M \geq 5.0)$ and the conditional time-dependent probability of large earthquakes in California and its boundary zones. Figure 1 shows a representative earthquake rate calculation for the study region, annotated with some of the model elements and subregions used in the analysis.

Figure 1. Map of California and its boundary zone used to develop UCERF 2. Colors depict a representative calculation of the expected number of $\mathrm{M} \geq 5$

earthquakes with hypocenters in $0.1^{\circ} \times 0.1^{\circ}$ geographic cells during the next 30 years (logarithmic color scale). Also shown are three types of earthquake sources described in this report: Type-A faults (red), Type-B faults (blue), and Type-C shear zones (as dashed polygons). The Bay Area box is WGCEP (2003) study region, and the black line shows the convention used here for dividing the northern California subregion from southern California subregion. The boundary zone (colored region outside the state boundaries) is identical to the testing region for the Regional Likelihood Models (RELM) project (Field, 2007a). Not shown are faults in the boundary zone that lie entirely outside the state boundaries and the Cascadia megathrust, which extends offshore from northern California to Canada.

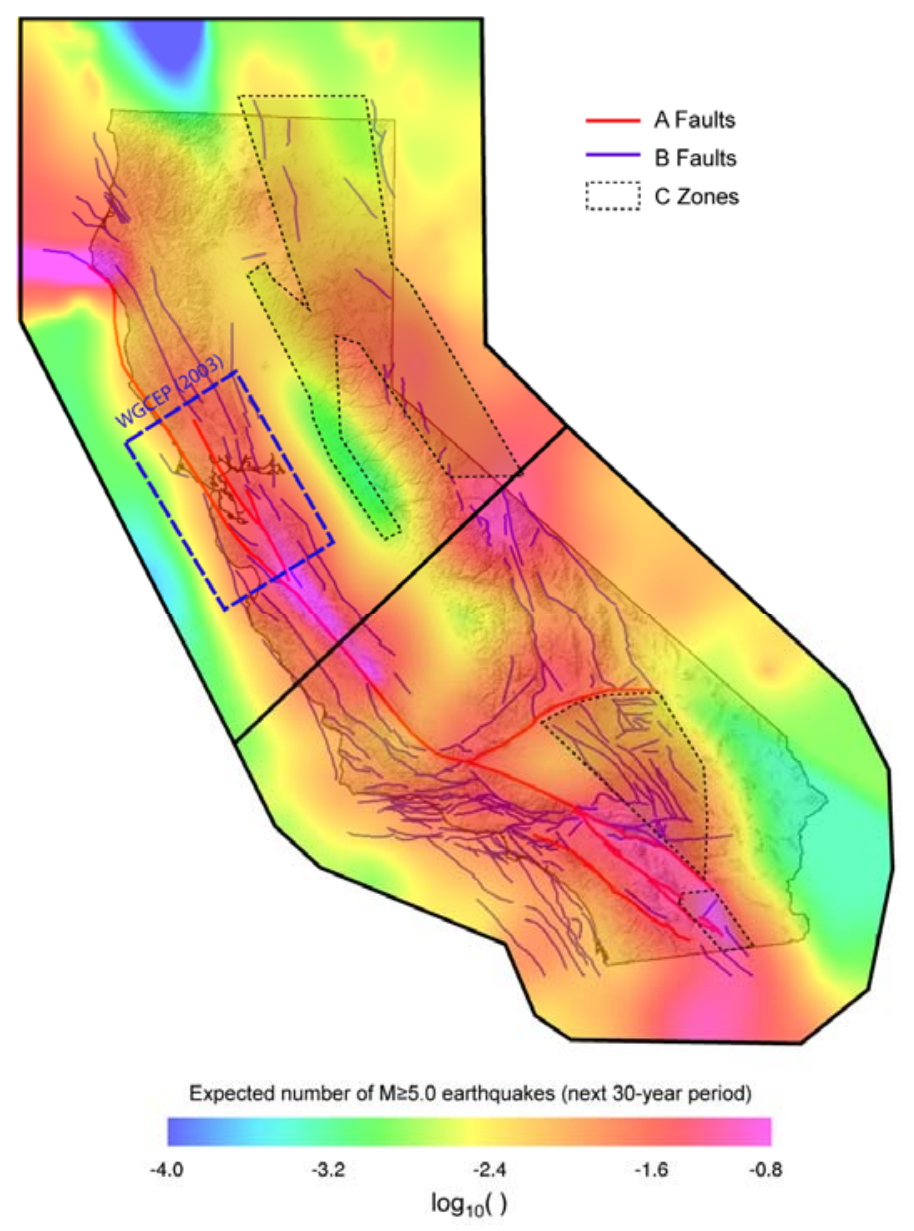


Two types of studies have traditionally developed official earthquake forecast models for California: the National Seismic Hazard Mapping Program (NSHMP) and the Working Groups on California Earthquake Probabilities (WGCEPs). Through the NSHMP, the U.S. Geological Survey (USGS) has cooperated with the California Geological Survey (CGS) and academia to map seismic hazard, which specifies the likelihood that levels of shaking will be exceeded at sites throughout the state (Algermissen and Perkins, 1982; Frankel et al. 1996, 2002; Petersen et al. 1996). The NSHMP framework is based on long-term estimates using a time-independent (Poisson) probability model for earthquake ruptures. The resulting hazard maps are used to establish building codes and promote mitigation efforts.

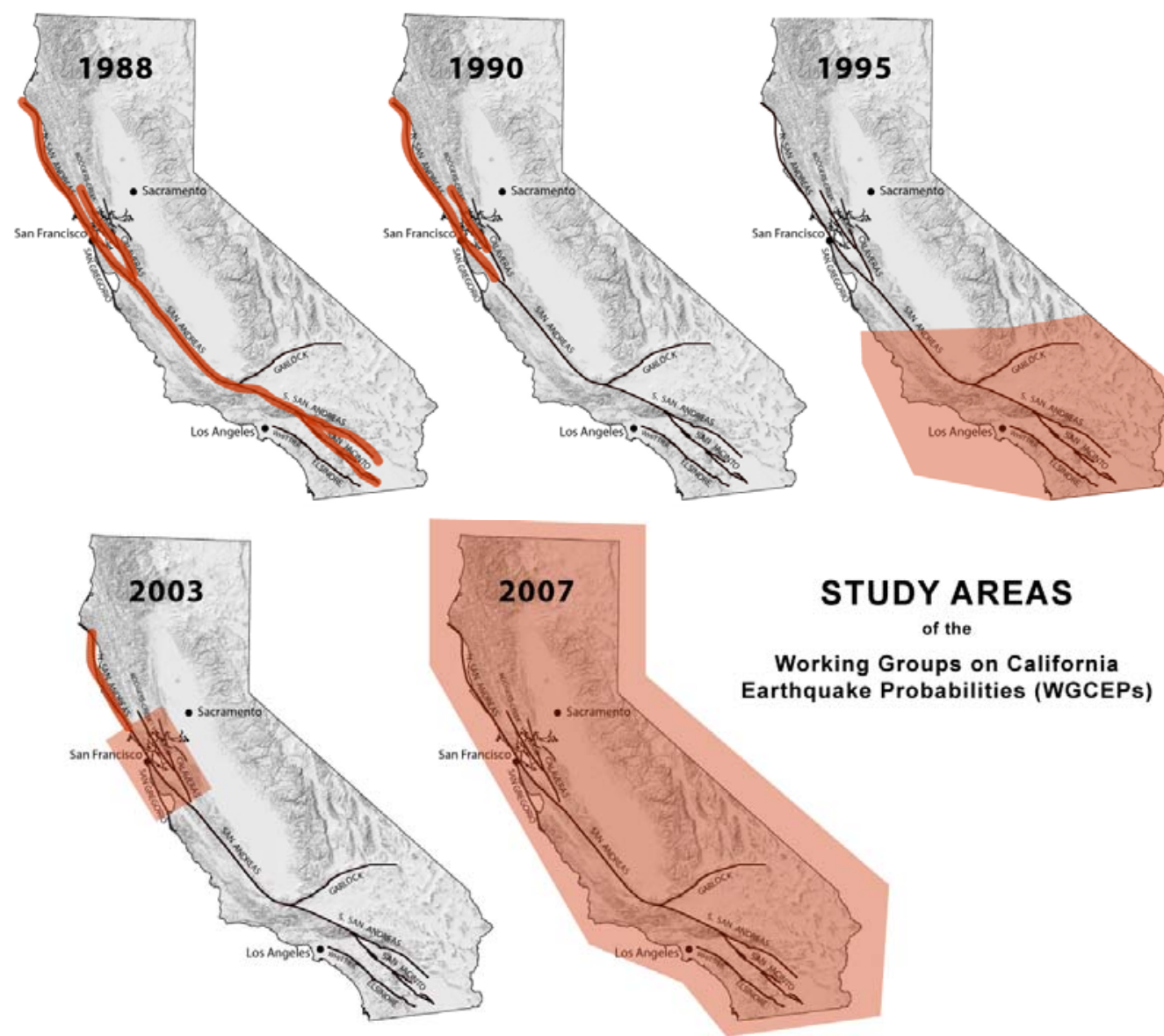

Figure 2. Previous Working Groups (WGCEP 1988, 1990, 1995 \& 2003) considered subsets of faults or subregions of California, highlighted in red on these maps (Field, 2007b). The present Working Group (WGCEP 2007) has developed a Uniform California Earthquake Rupture Forecast (UCERF) that applies a common methodology across the entire state.

Time-dependent rupture models have been the focus of five previous Working Groups on California Earthquake Probabilities (WGCEP 1988, 1990, 1995 \& 2003). In these studies, event probabilities were conditioned on the dates of previous earthquakes using stress-renewal models, in which probabilities drop immediately after a large earthquake releases tectonic stress on a fault and rise as the stress reaccumulates. Such models are motivated by the elastic rebound theory of the earthquake cycle (Reid, 
1911; NRC, 2003) and have been calibrated for variations in the cycle using historical and paleoseismic observations (e.g., WGCEP, 2003, Chapter 5). The WGCEPs specifically considered previous large earthquakes associated with California's San Andreas fault system, such as the 1906 San Francisco earthquake (M 7.8) on the northern San Andreas and the 1857 Ft. Tejon earthquake (M 7.9) on the southern San Andreas. Only a subset of California faults, or only part of the state, was considered by each past WGCEP, and the recent studies have alternated between northern and southern California subsets (Figure 2). The methodology and results of these previous Working Groups are summarized in a recent review by Field (2007b).

\section{A.1. Motivation and Structure of WGCEP (2007)}

An earthquake rupture forecast is the basis for probabilistic seismic hazard analysis (PSHA), a method for estimating the probability that ground shaking at a specified site will exceed a specified intensity threshold (Cornell, 1968; SSHAC, 1997). The end-users of PSHA include decision-makers concerned with land-use planning, the seismic safety provisions of building codes, disaster preparation and recovery, emergency response, and earthquake insurance; engineers who need estimates of maximum seismic intensities for the design of buildings, critical facilities, and lifelines; and organizations that promote public education for mitigating earthquake risk. According to the Federal Emergency Management Agency, the earthquake risk in California comprises about $75 \%$ of the national total (FEMA, 2000), so there is a continuing need to improve earthquake rupture forecasts within the state.

The present study (WGCEP, 2007) was initiated in September 2004, as a partnership among the USGS, the CGS, and the Southern California Earthquake Center (SCEC). The project was coordinated by a Management Oversight Committee (MOC), comprising leaders with the authority to commit resources from the three participating organizations. The MOC appointed a WGCEP Executive Committee and charged the new working group with two main tasks: (1) to collaborate with the NSHMP in producing a revised, time-independent forecast for California as input to the 2007 revisions of the national seismic hazard maps, and (2) to create a uniform, statewide, time-dependent model that, among other purposes, could be used by the California Earthquake Authority (CEA) in setting earthquake insurance rates. The completion date of the study was set at September 30, 2007.

The CEA is a privately financed, publicly managed organization that was created by the California state legislature in response to an earthquake-insurance availability crisis following the 1994 Northridge earthquake. It is currently the largest provider of residential earthquake insurance in the state of California. Its policies are sold only through participating insurance companies. The enabling legislation for the CEA states that, "Rates shall be based on the best available scientific information for assessing the risk of earthquake frequency, severity and loss." The California Insurance Code places strictures on the evidence required by CEA to support rate differential within the state:

"Scientific information from geologists, seismologists, or similar experts shall not be conclusive to support the establishment of different rates ... unless that information, as analyzed by experts such as the United States Geological Survey, the California Division of Mines and Geology, and experts in the scientific or academic community, 
clearly shows a higher risk of earthquake frequency, severity, or loss between those most populous rating territories to support those differences." (California Insurance Code section 10089.40, http://law.onecle.com/california/insurance/10089.40.html)

The mandate that insurance rates be based on best available science, coupled with the need for evidence to support insurance-rate differentials throughout the state, has raised some practical issues for the CEA. Because insurance policies are renewed annually (whereas building codes are generally updated every decade or so), the CEA seeks to apply time-dependent hazard models where available. The most authoritative time-dependent analysis has been WGCEP (1995) for southern California and WGCEP (2003) for northern California. The eight-year time lag between these studies has inevitably introduced differences in the amount of data and the level of model development for the two parts of the state. Moreover, large geographic areas were missing from both studies. This situation has left CEA and its contractors with the task of patching together a statewide forecast that could be used to defend regional rate differentials.

The need for a statewide, time-dependent model based on a uniform methodology expressed by CEA was the primary motivation for forming the new WGCEP. The project was supported using the internal resources of the USGS, CGS, and SCEC, and by the CEA through a contract to SCEC, managed by the MOC. The CEA participated in the reviews of WGCEP products and reports; however, no CEA personnel were involved in the development of the UCERF models, and the entire WGCEP process was monitored by two independent panels of experts, the National Earthquake Prediction Evaluation Council (NEPEC) and the California Earthquake Prediction Evaluation Council (CEPEC) (see §A.5).

\section{A.2. Key Differences and Updates from Previous WGCEP Models}

The primary products of WGCEP (2007) are a time-independent earthquake rate model (ERM 2.3) and time-dependent probability model (UCERF 2) derived from ERM 2.3. For the first time within the Working Group process, a model set has been constructed using consistent statewide databases and probability calculations (Figures $1 \& 2$ ). The California boundary zone, shown as the polygon surrounding the state boundaries in Figure 1, was chosen to be identical to the testing region for the Regional Earthquake Likelihood Models (RELM) project. The RELM project, described by Field (2007a) and Schorlemmer et al. (2007), involves the comparative, prospective evaluation of a number of experimental California earthquake rupture forecasts based on well-defined statistical measures of forecasting success. Use of the RELM grid will thus facilitate the prospective testing of the UCERF 2 against the experimental forecasts of the RELM project, as well as against future seismicity.

The entire development of ERM 2.3 has been coordinated with the National Seismic Hazard Mapping Project. Consequently, the earthquake rate model that underlies the time-dependent UCERF 2 is identical to the California model used for the 2007 revisions to the national seismic hazard map (NSHMP, 2007). Owing to this coordination, which set the project timetable and completion date, the hazard calculations applied to California by CEA can now be aligned with the standard NSHMP calculations available for the rest of the nation. 
Uniformity in the underlying data sets is prerequisite to applying uniform methods across the state of California. We thus compiled new fault geometry and fault slip-rate databases that include more accurate values of dip and seismogenic depth, and we developed earthquake rate models using a newly assembled database of paleoseismic sites. To test the earthquake rate model, we unified the historic and instrumental earthquake catalogs for California and surrounding regions and carefully assessed the catalog uncertainties. All data are available at http://www.wgcep.org/.

We also calculated moment-balanced earthquake rate solutions using a more rigorous method than past studies. Moment-balancing means that the earthquakes that occur along each fault over a long time will produce a cumulative slip that is consistent with the observed long-term slip rate for the fault. Our approach, discussed in the Earthquake Rate Model section, permits consideration and relative weighting of geologically-determined fault slip rates, paleoseismically-determined earthquake recurrence intervals, and other geologic insights to build a long-term earthquake rate model.

For this study, we have developed publicly available tools that allow anyone to analyze the model and experiment with different parameter choices. The tools can now be downloaded from http:/www.wgcep.org/. The new model has been implemented in a modular (object-oriented), extensible framework, so that future updates can be easily accommodated as new data and methods emerge. The comprehensive nature of our analysis has identified many opportunities for future model improvements. Specific recommendations for further research are outlined in the discussion at the end of this report (§G.2).

\section{A.3. Modeling Framework}

The general WGCEP goal is to model the probability of all possible damaging earthquake ruptures in a study region for some specified time span. In general, an earthquake rupture forecast (ERF) is any model that achieves this purpose. The specific objective for WGCEP (2007) was to construct a uniform California earthquake rupture forecast (UCERF). Because there are many credible ways to build a UCERF, the modeling framework must accommodate alternative models, which are continually evolving. We therefore implemented an extensible framework, built on concepts developed by WGCEP (2003), that can handle existing alternatives as well as future versions. The four basic UCERF model components are described in Figure 3.

\section{Components of the Uniform California Earthquake Rupture Forecast 2}

\begin{tabular}{|c|c|c|c|}
\hline $\begin{array}{l}\text { Fault } \\
\text { Models } \\
\text { Specifies the spatial geometry } \\
\text { of larger, more active faults. }\end{array}$ & $\begin{array}{l}\text { Deformation } \\
\text { Models } \\
\text { Provides fault slip rates used to } \\
\text { calculate seismic moment } \\
\text { release. }\end{array}$ & $\begin{array}{l}\text { Earthquake-Rate } \\
\text { Models } \\
\text { Gives the long-term rate of all } \\
\text { possible damaging earth- } \\
\text { quakes throughout a region. }\end{array}$ & $\begin{array}{l}\text { Probability } \\
\text { Models } \\
\text { Gives the probability that each } \\
\text { earthquake in the given Earth- } \\
\text { quake Rate Model will occur } \\
\text { during a specified time span. }\end{array}$ \\
\hline
\end{tabular}

Figure 3. The four basic components of the UCERF 2 model. 
Simply put, the fault model gives the physical geometry of the larger, known faults; the deformation model gives slip rates and aseismicity factors to each fault section; the earthquake rate model gives the long-term rate of all earthquakes throughout the region above a specified threshold (chosen here and by the NSHMP to be $\mathrm{M} \geq 5$ ); and the probability model gives a probability for each event over a specified time span. As described in $\S \mathrm{D}$, the earthquake rate model is generally composed of three types of sources (Figure 1):

- ruptures on known active faults (Type-A and Type-B sources),

- earthquakes in zones of distributed shear (Type-C sources), and

- earthquakes distributed to account for unknown faults (background sources).

A probabilistic rupture forecast must make simplifying assumptions about the earthquake process. For example, the potentially infinite number of possible earthquake ruptures must be reduced to a practically manageable finite set. In so doing, we have generally followed previous working groups in terms of imposing fault segmentation (see $\S \mathrm{D}$ ). The advantages, limitations, and implications of such assumptions are discussed in subsequent sections.

To prototype and test the WGCEP (2007) modeling capabilities, we constructed an initial timedependent model, UCERF 1 (Petersen et al., 2007a). The earthquake rate model for UCERF 1 is almost the same as the NSHMP (2002) California model; the only substantial difference was a new option for the southern San Andreas fault. The UCERF 1 probability model applies WGCEP (2003) earthquake probabilities to faults in the San Francisco Bay Area, and a somewhat less sophisticated set of stressrenewal models for the larger faults in southern California. This prototyping exercise helped us to identify several modeling inconsistencies and thereby improve the uniformity of the UCERF 2 model.

The documentation given here presents all elements used in UCERF 2. Earthquake rate model (ERM 2.3) constitutes the time-independent forecast of UCERF 2 (because it completely specifies the Poisson conditional probability). Thus, the time-independent version of UCERF 2 is the same as the model used in the NSHMP 2007 hazard maps.

\section{A.4. Representation of Epistemic Uncertainty}

Probabilistic statements about the timing, location, and magnitude of future large earthquakes contain two basic types of uncertainty, and both must be quantified in the probabilistic model. "Epistemic" uncertainty comes from lack of knowledge (our inability to identify the correct model), whereas "aleatory" uncertainty arises from the influence of random chance within the context of a particular model (SSHAC, 1997). Epistemic uncertainties are usually included in seismic hazard analyses by constructing logic trees, where each branch represents a viable alternative model or hypothesis, only one of which can be correct. In computing event probabilities, the branches are weighted by collective expert opinion on the probability that each may be correct. We have followed this approach in developing the UCERF framework.

The modularity of the UCERF framework makes it straightforward to include alternative branches, and Field et al. (2005) have shown how the calculations can easily be carried beyond earthquake probabilities to "end-to-end" hazard analysis. However, the ideal of including every viable scientific 
hypothesis as an alternative logic-tree branch is not realistic for several reasons. The epistemic uncertainties represented by alternative branches may be correlated, which can complicate the assignment of plausible branch weights (Page and Carlson, 2006). Many of the possible alternatives actually contribute very little to the final uncertainties, so the effort put into implementing more logic tree branches was weighed against the inherent limitations of the model. For example, some of the alternatives that we think are most important have not been included in UCERF 2 because there is not yet a scientific consensus on how to implement them as quantified models; two important examples discussed in $\S$ G.2 are fault-to-fault ruptures and earthquake clustering effects. Finally, the primary use of the model is in terms of mean hazard and loss estimates, rather than an explicit use of every branch of the logic tree. We have balanced all of these considerations in constructing the UCERF 2 logic tree. Our choices were guided by the comprehensive logic tree built by WGCEP (2003), which we used to help identify the most important sources of epistemic uncertainty.

\section{Components of the Uniform California Earthquake Rupture Forecast 2}

(abbreviated logic tree of 480 branches)

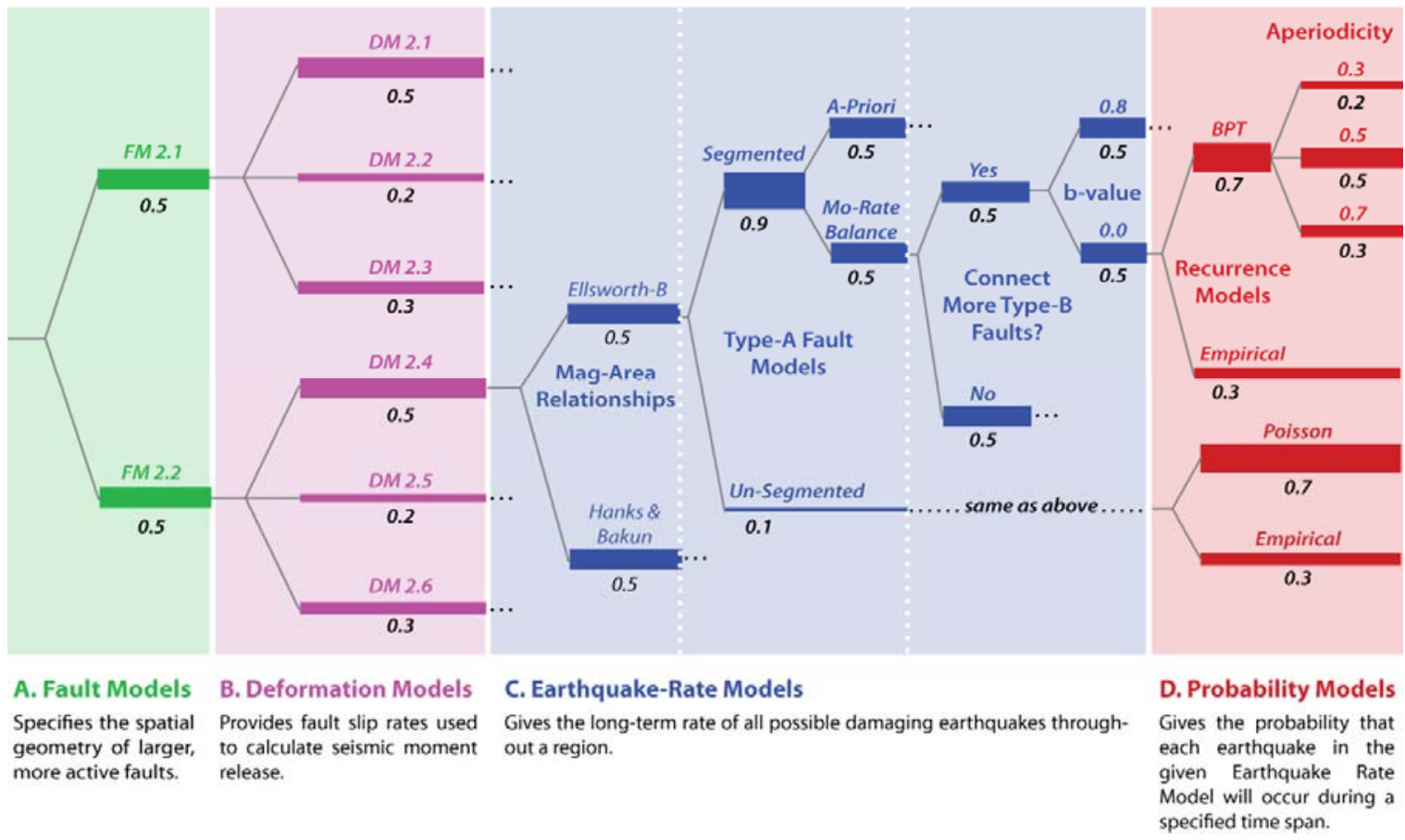

Figure 4. Branches of the UCERF logic tree that received non-zero weights (black numbers) in the final model calculations. The branches are organized by the basic model components of Figure 3: fault models (green), deformation models (purple), earthquake rate models (blue), and probability models (red). The branches and weighting decisions are described in the sections for each component.

The final UCERF 2 logic tree incorporated 480 branches that received nonzero weight. Figure 4 organizes these branches in terms of the four basic model components described in Figure 3. A number of other branches were also investigated in the course of our analysis, but they were given zero weights in the final model for reasons described in later sections. They remain in the UCERF framework as 
alternative branches that can be assigned non-zero weights in any future explorations of epistemic uncertainties.

\section{A.5. Review and Consensus-Building Processes}

UCERF 2 was constructed by members of the Executive Committee and other key WGCEP scientists. All model elements and WGCEP documents were reviewed by an internal Scientific Review Panel (SRP) comprising experts who were not WGCEP members (see personnel listings at the beginning of this report). The SRP reported to the Management Oversight Committee (MOC), which coordinated the review and oversaw the consensus-building processes. External oversight and review was provided by the National Earthquake Prediction Evaluation Council (NEPEC) and the California Earthquake Prediction Evaluation Council (CEPEC), as well as CEA's Multidisciplinary Research Team. CEPEC and NEPEC tracked model development throughout the WGCEP (2007) process and reviewed the final report.

We achieved the CEA goal of incorporating the "best available science" by restricting our consideration to data and methods that have been published, or accepted for publication, in peer-reviewed scientific journals or as U.S. Geological Survey Open File Reports. If relevant published models differed significantly, we applied logic-tree weighting to represent the alternatives. Generally, two alternatives were given equal weight in the absence of any clear evidence to favor one over the other. When there was evidence to favor a given branch, the assignment of relative weights was made through a consensus building process, which we describe for each case.

Newly developed datasets and methods used in this report have been documented as appendices to this report (Table 1). Each appendix was reviewed by the SRP and often by additional experts selected by the SRP; each has been published as an independent element of the U.S. Geological Survey Open File Report 2007-1437 and, in some cases, as a peer-reviewed journal paper (see http://www.wgcep.org/ for a listing of publication status).

Advice and comment for the scientific and engineering communities was sought regularly through open meetings and workshops during the several phases of UCERF development. Participants included experts from academia, private and corporate providers of hazard assessments, consulting companies, and government agencies. A list of the major consensus-building activities is shown in Table 2. WGCEP progress was reported at major scientific gatherings such as annual meetings of the American Geophysical Union, the Seismological Society of America, and the Southern California Earthquake Center.

A draft of this final report was submitted for review on September 30, 2007. We received reviews from the SRP, NEPEC, CEPEC, and CEA's Multidisciplinary Research Team by November 16, 2007, and we addressed all review comments before submitting a revised report on December 31, 2007. Our response to the reviews is documented in the Supplementary Materials. The revised report underwent additional review and revision prior to its finalization in mid-February, 2008. 
Table 1. Appendices to the final WGCEP (2007) report. *

\begin{tabular}{|c|c|c|}
\hline Appendix & Title & Authors \\
\hline A & $\begin{array}{l}\text { California Fault Parameters for the National Seismic Hazard } \\
\text { Maps and Working Group on California Earthquake Probabilities } \\
2007\end{array}$ & $\begin{array}{l}\text { Wills, CJ, RJ Weldon II, and } \\
\text { WA Bryant }\end{array}$ \\
\hline $\mathrm{B}$ & Recurrence Interval and Event Age Data for Type A Faults & $\begin{array}{l}\text { Dawson, TE, RJ Weldon II, and } \\
\text { GP Biasi }\end{array}$ \\
\hline $\mathrm{C}$ & $\begin{array}{l}\text { Monte Carlo Method for Determining Earthquake Recurrence } \\
\text { Parameters from Short Paleoseismic Catalogs: Example } \\
\text { Calculations for California }\end{array}$ & Parsons, $\mathrm{T}$ \\
\hline $\mathrm{D}$ & Magnitude-Area Relationships & Stein, RS \\
\hline $\mathrm{E}$ & Overview of the Southern San Andreas Fault Model & $\begin{array}{l}\text { Weldon II, RJ, GP Biasi, CJ } \\
\text { Wills, and TE Dawson }\end{array}$ \\
\hline $\mathrm{F}$ & $\begin{array}{l}\text { Summary of Geologic Data and Development of A-Priori } \\
\text { Rupture Models for the Elsinore, San Jacinto, and Garlock Faults }\end{array}$ & $\begin{array}{l}\text { Dawson, TE, TK Rockwell, RJ } \\
\text { Weldon II, and CJ Wills }\end{array}$ \\
\hline G & $\begin{array}{l}\text { Development of Final A-Fault Rupture Models for } \\
\text { WGCEP/NSHMP Earthquake Rate Model } 2.3\end{array}$ & $\begin{array}{l}\text { Field, EH, RJ Weldon II, V } \\
\text { Gupta, T Parsons, CJ Wills, TE } \\
\text { Dawson, RS Stein, and MD } \\
\text { Petersen }\end{array}$ \\
\hline $\mathrm{H}$ & WGCEP Historical California Earthquake Catalog & Felzer, KR and T Cao \\
\hline I & Calculating California Seismicity Rates & Felzer, KR \\
\hline $\mathrm{J}$ & $\begin{array}{l}\text { Spatial Seismicity Rates and Maximum Magnitudes for } \\
\text { Background }\end{array}$ & $\begin{array}{l}\text { Petersen, MD, CS Mueller, AD } \\
\text { Frankel, and Y Zeng }\end{array}$ \\
\hline $\mathrm{K}$ & A-Priori Rupture Models for Northern California Type-A Faults & $\begin{array}{l}\text { Wills, CJ, RJ Weldon II, and EH } \\
\text { Field }\end{array}$ \\
\hline $\mathrm{L}$ & Cascadia Subduction Zone & Frankel, $\mathrm{AD}$, and MD Petersen \\
\hline M & Empirical Estimation of Regional Time Variation in Seismicity & Felzer, KR \\
\hline $\mathrm{N}$ & $\begin{array}{l}\text { Conditional, Time-Dependent Probabilities for Segmented Type- } \\
\text { A Faults in the WGCEP UCERF } 2\end{array}$ & Field, EH, and V Gupta \\
\hline $\mathrm{O}$ & $\begin{array}{l}\text { Paleoseismic investigations of the Walnut Site on the San Jacinto } \\
\text { Fault }\end{array}$ & Fumal, TE and KJ Kendrick \\
\hline $\mathrm{P}$ & $\begin{array}{l}\text { Compilation of Surface Creep on California Faults and } \\
\text { Comparison of WGCEP } 2007 \text { Deformation Model to Pacific- } \\
\text { North America Plate Motion }\end{array}$ & $\begin{array}{l}\text { Wisely, BA, DA Schmidt, and } \\
\text { RJ Weldon II }\end{array}$ \\
\hline
\end{tabular}

* All appendices can be cited as independent elements of this open file report; e.g. Wills C. J., R. J. Weldon II, and W. A. Bryant (2007). California Fault Parameters for the National Seismic Hazard Maps and Working Group on California Earthquake Probabilities 2007, U.S. Geological Survey Open File Report 2007-1437-A. The appendices are available at http://www.wgcep.org/. 
Table 2. WGCEP (2007) consensus-building activities.

\begin{tabular}{|c|c|c|}
\hline \multicolumn{2}{|c|}{ Date } & Meeting Description \\
\hline \multirow{12}{*}{ 용 } & Dec 31 & Revised Report Submitted \\
\hline & Nov 15 & Reviews Received from SRP, CEPEC, NEPEC, and CEA \\
\hline & Sep 30 & Draft Final Report Submitted for Review \\
\hline & Sep 24 & Conference Call with SRP, CEPEC, and NEPEC \\
\hline & Sep 9-12 & SCEC Annual Meeting \\
\hline & Aug 24 & Review CEA Deliverables \\
\hline & Aug 20-22 & SRP/NEPEC/CEPEC Review UCERF 2 \\
\hline & Jul 17 & Presentation of WGCEP Activities to Menlo Park, USGS \\
\hline & Apr 25-26 & Meeting to Finalize A-Fault Models \\
\hline & Mar 22-23 & WGCEP Meeting in Menlo Park, USGS \\
\hline & Mar 6-8 & $\begin{array}{l}\text { Time-Dependent Earthquake Probabilities: What Represents } \\
\text { Best Available Science? }\end{array}$ \\
\hline & Jan 17 & Review of Earthquake Rate Model 2.1 \\
\hline \multirow{9}{*}{ ঠ } & Nov 13 & $\begin{array}{l}\text { Southern California Slip Rates and Earthquake Frequency } \\
\text { Models }\end{array}$ \\
\hline & Nov 13 & Southern \\
\hline & Nov 8 & $\begin{array}{l}\text { Northern California Slip Rates and Earthquake Frequency } \\
\text { Models }\end{array}$ \\
\hline & Nov 1 & Magnitude-Area Relationships Review \\
\hline & Oct $4-5$ & Review of Proposed NSHMP 2007 Model \\
\hline & Aug 9-10 & Review of Earthquake Rate Model 2 \\
\hline & May 31-Jun 1 & $\begin{array}{l}\text { Intermountain West Update of USGS National Seismic Hazard } \\
\text { Maps }\end{array}$ \\
\hline & Mar 28-29 & Pacific NW Update of USGS National Seismic Hazard Maps \\
\hline & Mar 15-17 & $\begin{array}{l}\text { Segmentation/Cascade Models \& Fault-to-Fault Rupture } \\
\text { Jumps }\end{array}$ \\
\hline \multirow{10}{*}{$\stackrel{n}{\check{c}}$} & Nov $17-18$ & Project Review \\
\hline & Nov 11 & Earthquake Simulators \\
\hline & Sep 10 & Evaluate Southern California Fault Data \\
\hline & Jul 26 & Evaluate Northern California Fault Data \\
\hline & Jul 18 & Viable Time-Dependent Probabilities for UCERF1 \\
\hline & Jul 12 & California Reference Geologic Fault Parameter Database \\
\hline & Jun 3 & Deformation Modeling \\
\hline & May 27 & Project Progress and Planning \\
\hline & Feb 17 & Review S. SAF Paleoseismic Analysis by Weldon et al. \\
\hline & Jan 10 & Project Planning \\
\hline
\end{tabular}

\section{A.6. Key Products}

This report summarizes all elements of the WGCEP (2007) study. In particular, we describe the following key products:

- Fault data (Appendix A)

- A historic earthquake catalog (Appendix H) and its analysis (Appendices I, J \& M)

- A compilation of paleoseismic data (Appendix B) and corresponding recurrence interval estimates at key fault locations (Appendix C)

- An evaluation of magnitude-area relationships (Appendix D) 
- An evaluation of fault creep (Appendix P)

- Development of "a-priori" rupture models for Type-A faults based on the analysis of paleoseismic data and geologic insights (Appendices E, F, and K)

- The methodology and tools used to modify the "a-priori" Type-A fault rupture models, via generalized inversion, to be consistent with various constraints (Appendix G)

- A complete model for the Cascadia subduction zone (Appendix L)

- An evaluation and implementation of various time-dependent earthquake-probability models (Appendix N)

- Open-source software for model implementation and graphical-user-interface-based evaluation tools (http://www.WGCEP.org/resources/tools)

- A version of the UCERF 2 model in which all logic-tree branches have been collapsed to a single, average branch by treating all epistemic uncertainties as aleatory, providing a simple representation of the mean hazard (as requested by CEA for their loss estimation).

\section{A.7. Report Organization}

This report is organized by sections that correspond to the four basic model components arrayed in Figure 3. The next section describes the fault section database and the alternative fault models constructed to capture the main epistemic uncertainty. It is followed by a discussion of fault slip rates and alternative deformation models, including tests applied to validate the models. These components provide the basis for the California earthquake rate model (ERM 2.3), which is described in detail. We then discuss tests applied to the rate model and their implications. The rate model leads to the UCERF 2 probability calculations; we discuss the probability models used and present the results in magnitude-probability diagrams. We compare our results with past WGCEP efforts, and close with a discussion of model limitations and recommendations for future improvements.

The Supplementary Material includes (1) an Excel Spreadsheet containing some useful input and output values used in UCERF 2, and (2) a summary of reviewer comments and responses. All appendices to this report can be downloaded at http://www.wgcep.org/. 


\section{B. Fault Models}

Most large earthquake sources in the UCERF 2 are associated with identified faults; therefore, assembling up-to-date California fault models was a major task. We began by developing an updated database for fault sections. As applied in this report, fault sectioning is for descriptive purposes only. In particular, a fault section does not necessarily correspond to fault segment, which usually implies a geometrical control on earthquake rupture lengths. A fault model is a table of fault sections that collectively constitute a complete, viable representation of the known active faults in California. We considered a number of alternative fault models, which have been winnowed to two in the UCERF 2 logic tree (Figure 4).

The Cascadia subduction zone, which extends to the north far beyond the state boundary, was treated as a special case, with its own logic tree; the model for this megathrust is fully described in Appendix L (Frankel and Petersen, 2007) and summarized in §D.7.

\section{B.1. Fault Section Database}

In the WGCEP 2007 fault section database, each section is associated with a set of geometrical and kinematic parameters: (1) section name, (2) fault trace, (3) average dip, (4) average upper seismogenic depth, (5) average lower seismogenic depth, (6) average long-term slip rate, (7) average aseismic slip factor, and (8) average rake. We define a new section only where one or more of these parameters is significantly different from its neighboring section along a fault. For most of these parameters, our definitions follow standard conventions. The "average aseismic slip factor" is defined as the fraction of moment released by creep between the average upper and lower seismogenic depths (which is one minus the "R" factor defined by WGCEP (2003)); we will discuss the assignments of this parameter in the section on fault deformation models. Each parameter has a formal uncertainty; the database supports a variety of uncertainty measures, from Gaussian parameters to arbitrary probability density functions.

The fault section database was initialized with the CGS/USGS fault model developed for NSHMP (2002) and WGCEP (2003), which we then updated with new information (Table 3). In the current database, each fault segment defined by WGCEP (2003) is described as a fault section. We have made several revisions to fault locations and slip rates in northern California outside of the region considered by the 2003 Working Group. The location, dip, and slip rates of several faults along the west side of the southern Sacramento Valley have been updated, based on the work of O'Connell and Unruh (2000), and the West Tahoe fault has been added, based on the work of Kent et al. (2005).

For many faults in southern California, the fault traces, dips, and depth were revised using the new SCEC Community Fault Model (CFM) (Plesch and Shaw, 2003; Plesch et al., 2007). A special version of the CFM, in which the triangular surfaces of the original CFM were converted to rectangular patches, was developed for this purpose (http://structure.harvard.edu/cfm-r_project/cfmr.html). The lower seismogenic depths in CFM are from the maximum depth of relocated background seismicity, following Nazareth and Hauksson (2004). The southern San Andreas was repartitioned into ten sections: the Parkfield, Cholame, Carrizo, Big Bend, Mojave north, Mojave south, San Bernardino north, San Bernardino south, San Gorgonio-Garnet Hill, and Coachella (Figure 5). 


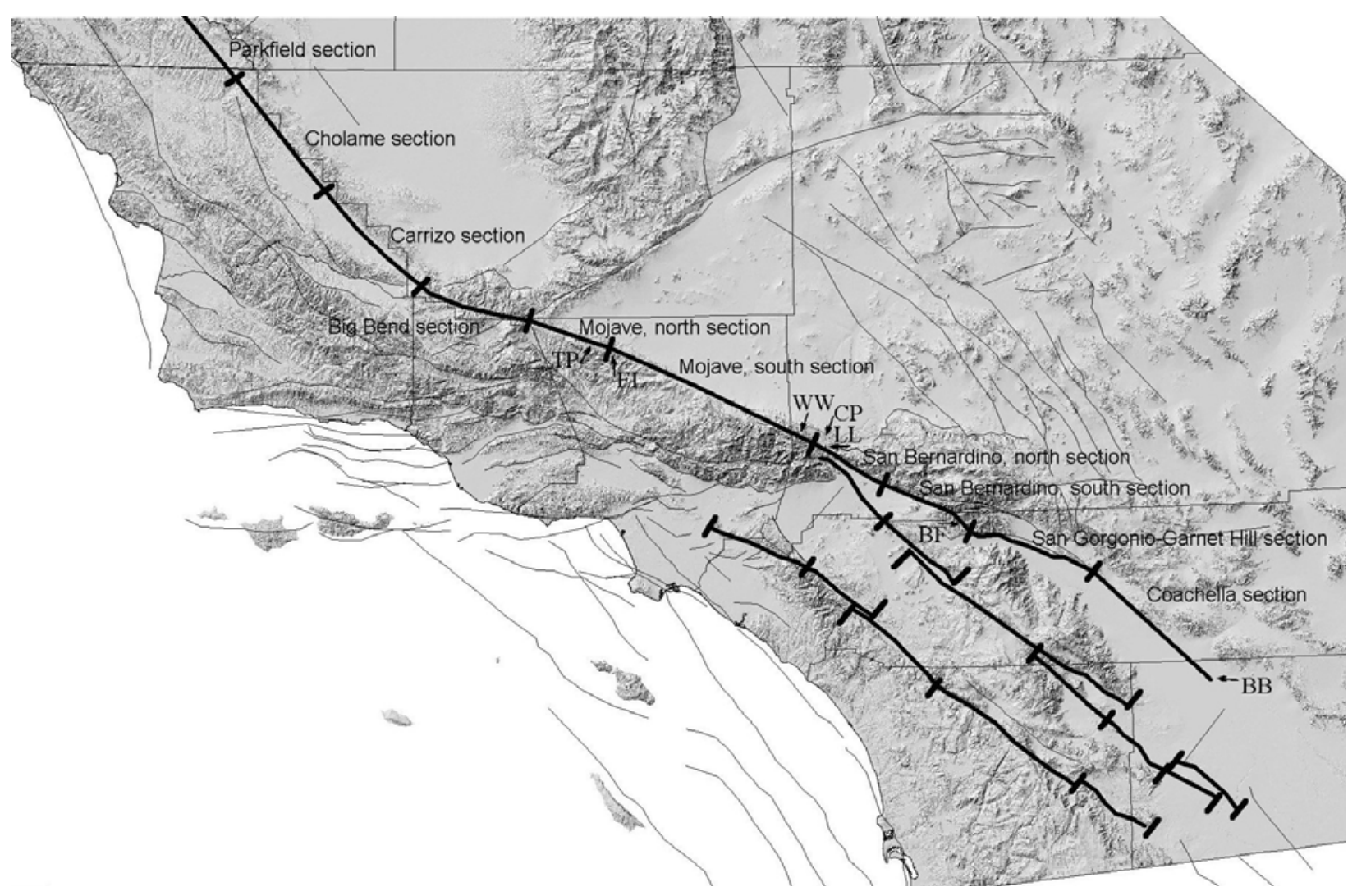

Figure 5. Sections of the southern San Andreas, San Jacinto, and Elsinore faults, showing new section names for the southern San Andreas. Annotated localities are Plieto thrust fault (PT), Three Points (TP), Elizabeth Lake (EL), Wrightwood (WW), Cajon Pass (CP), Lost Lake (LL), Burro Flats (BF), and Bombay Beach (BB).

Updates to the San Jacinto and Elsinore faults were less extensive than on the southern San Andreas fault. Both faults exhibit sub-parallel en echelon strands bounding an internal pull-apart basin. On the San Jacinto fault, the San Jacinto Valley and Anza sections are parallel to each other for about $24 \mathrm{~km}$ on either side of a pull-apart basin. The NSHMP (2002) fault model had a segment boundary approximately in the center of the basin. We also extended the San Bernardino section of the San Jacinto fault to the northwest limit of the active scarps along the San Jacinto fault zone in the San Gabriel Mountains. This location lies at the southern end of the 1857 rupture on the subparallel San Andreas, and we believe it best represents the slip transfer between these two faults.

We made similar minor adjustments to the Elsinore fault zone, splitting off small sections where there are two parallel strands on either side of a step-over. We have also re-drawn the fault from south of Corona through the Temecula area to follow the most active strand of the fault system.

Additional input on the fault section database was solicited through workshops in Northern California on July 26, 2005 and November 8, 2006 and in Southern California on September 11, 2005 and November 13, 2006. The resulting fault section database is described in Appendix A (Wills et al., 2007a). 
The fault sections and some of their parameters can be displayed using SCEC visualization tools at http://www.wgcep.org/ or the Coulomb visualization tools at http://www.coulombstress.org.

Table 3. Primary revisions to the NSHMP (2002) fault model.

\begin{tabular}{|ll|}
\hline Fault & Changes/Updates \\
\hline Southwest Sacramento Valley & Locations, geometry: O’Connell and Unruh (2000) \\
West Tahoe fault & Added: Kent et al. (2005) \\
Southern San Andreas fault & Resectioned: Wills et al. (2007a) \\
San Jacinto fault & Lengthened, minor relocation, added step overs; Wills et \\
& al. (2007a) \\
Elsinore fault & Minor relocation, added step overs: Wills et al. (2007a) \\
Lower Pitas Point-Montalvo thrust & Alternative 1: SCEC CFM \\
North Channel and Upper Pitas Point faults & Alternative 2: SCEC CFM \\
Southwest Sacramento Valley & Locations, geometry: O’Connell and Unruh (2000) \\
\hline
\end{tabular}

\section{B.2. Alternative Fault Models}

Owing to the breadth and depth of geological investigations over many years, there is substantial consensus on California fault geometry. The greatest epistemic uncertainties concern how faults geometrically interact at depth, which can lead to mutually exclusive, alternative fault sections. Alternative models were developed in the SCEC Community Fault Model for several regions in southern California, as described originally by Plesch and Shaw (2003) and Plesch et al. (2007) and in Appendix A of this report (Wills et al., 2007a).

The most complex set of alternative fault sections are found in the Santa Barbara Channel area and western Transverse Ranges (Figure 6). The main difference between these alternatives is in the northdipping thrust faults: Alternative 1 has the low-angle $\left(16^{\circ} \mathrm{dip}\right)$ north-dipping Lower Pitas Point-Montalvo thrust fault, whereas Alternative 2 has a relatively steep $\left(26^{\circ}\right.$ and $\left.42^{\circ}\right)$ North Channel and Upper Pitas Point faults and the south dipping Oak Ridge offshore fault. For these faults, the overall convergence on the north-dipping faults in the NSHMP (2002) model (the North Channel Slope and Oak Ridge-offshore) was applied either to the low-angle fault or split equally between the high-angle thrust faults. These two alternative fault models represent the first branch in the logic tree; each model received equal weighting (Figure 4a).

The alternative fault models affect the seismic hazard in the Santa Barbara region, because the low angle Lower Pitas Point fault dips beneath Santa Barbara, while the alternative Oak Ridge offshore fault dips to the south away from shore. In previous models for the NSHMP, blind thrust faults were weighted $50 \%$, representing the uncertainly that the long term slip rates represent current seismic hazard. Based on the extensive new research in developing the CFM, blind thrust faults are weighted equally with other faults in the current model, which increases the hazard in areas overlying blind thrust faults. 


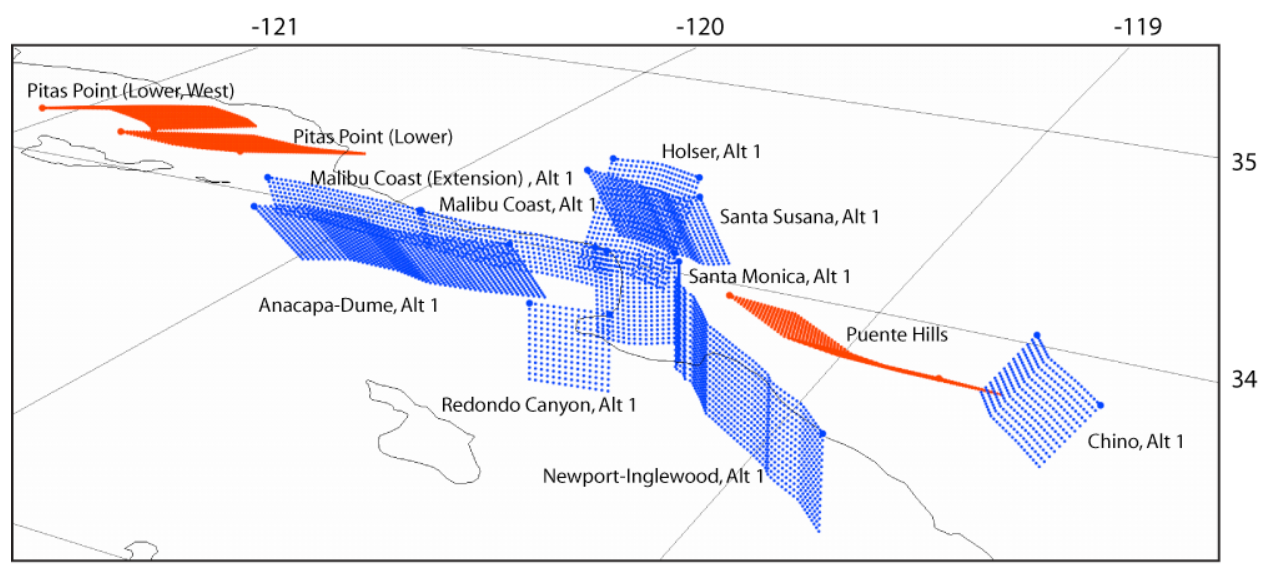

Fault Sections Unique to Fault Model 2.1

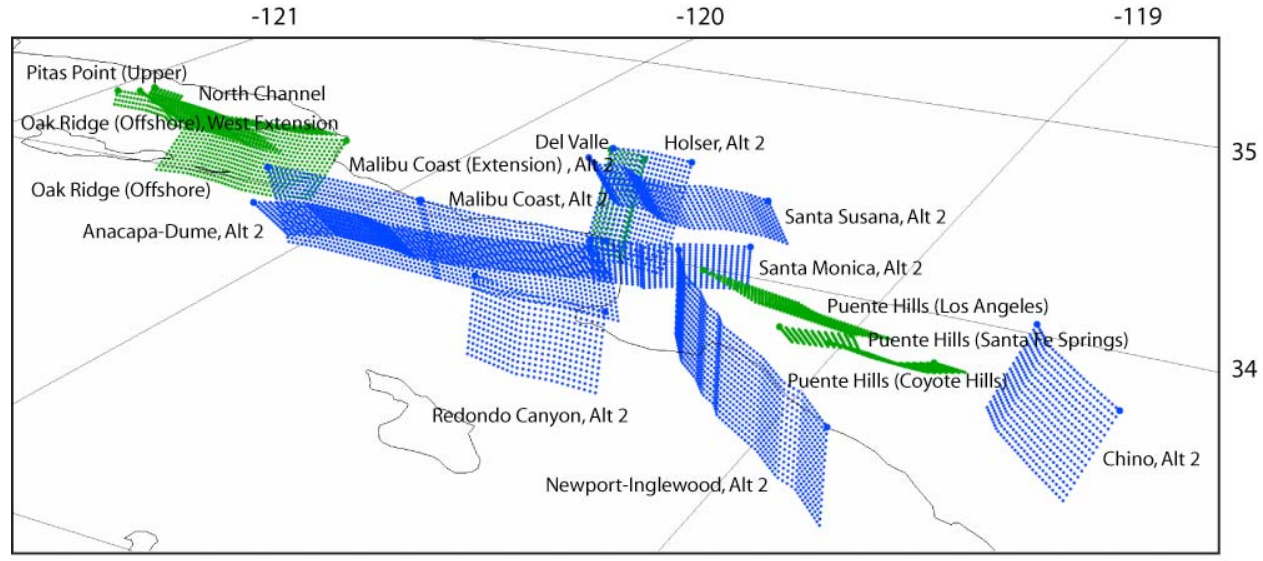

Fault Sections Unique to Fault Model 2.2

Figure 6. Three-dimensional perspective views of the two alternative fault models for the Santa Barbara Channel area and western Transverse Ranges used in UCERF 2. The differing fault geometries are shown in red (upper panel) and green (lower panel). 


\section{Deformation Models}

In the WGCEP (2007) framework, a deformation model assigns a slip rate and an aseismic slip factor, plus their uncertainties, to each fault section in a fault model. We have developed a preferred UCERF 2 deformation model and alternatives that are consistent with the geological slip-rate studies, as well as with geodetic data and the overall Pacific-North America plate rate. The alternative deformation models pertain to the tradeoff between slip on the San Jacinto fault and the southernmost San Andreas fault. Except in this region, all deformation model parameters were drawn from the fault section database. The parameters for the Type-A faults are given in Table 4.

The deformation models were derived primarily from geologically-estimated fault slip rates. Following the NSHMP and previous WGCEPs, we used expert opinion to select average long-term slip rates for individual fault sections from the wide range of published rates. In some cases, geodeticallyconstrained slip rates were considered. Geodetic data were also used to constrain the strain rates for the crustal shear zones that contained the Type-C earthquake sources (discussed in $\S \mathrm{D} .5$ ). The special case of the Cascadia subduction zone is treated in $§ \mathrm{D} .7$.

Our main effort was to develop a preferred deformation model and alternatives that were consistent with the geological slip rate studies as well as with geodetic rates and the plate rate. Our guiding principle in this modeling was that the rates on the faults across the plate boundary had to approximately sum to the plate rate and that slip along fault zones had to be constant between fault intersections or splays. The most significant change from the model used in the NSHMP (2002) is that we developed a more consistent model for right-lateral shear in eastern California. In the NSHMP model, total shear across a broad zone east of the Sierra Nevada was about 8 to $10 \mathrm{~mm} / \mathrm{yr}$ at the latitude of Reno, about $8 \mathrm{~mm} / \mathrm{yr}$ to the south across Death Valley, but only about $3 \mathrm{~mm} / \mathrm{yr}$ across the Mojave Desert. Geodetic deformation across the Mojave suggests high rates of shear (Savage et al., 1990; Meade and Hagar, 2005). Recent geologic studies by Oskin et. al. (2007) show that slip rates on several faults in the Mojave may have been previously underestimated. Higher shear in the Eastern California shear zone has important implications: any shear in the Eastern California shear zone is removed from the San Andreas fault system at the north end of the Coachella Valley. Slip on the San Andreas fault itself and earthquake potential along the San Andreas system is reduced by the amount of shear in the Eastern California shear zone.

The uncertainties in the slip rates of closely spaced, parallel faults can be anti-correlated. For example, if the southern San Andreas fault were to slip at a rate greater than its estimated value, then the San Jacinto fault would have to slip at a rate less than its estimated value. Alternative deformation models have been developed to minimize these slip-rate uncertainty correlations.

\section{C.1. Preferred and Alternative Deformation Models}

Although several alternative deformation models were developed, we found that only the trade-off between the slip rates on the San Jacinto and San Andreas faults was significant enough to warrant the inclusion of multiple deformation models in the UCERF 2 logic tree. A number of recent studies suggest that the slip rate on the San Jacinto fault zone is equal to or only slightly less than that on the adjacent San Andreas, in contrast to previous models where the slip rate on the San Jacinto was about half that of the 
San Andreas. These include geodetic models (Fay and Humphreys, 2005; Fialko, 2006; Bennett et al. 2004; Meade and Hagar, 2005), as well as geologic studies calculating short-term and long-term slip rates for the San Jacinto fault (Kendrick et al. 2002; Dorsey, 2003; Janecke et al. 2005) and San Andreas fault (Yule and Sieh, 2003; van der Woerd, 2006).

There are no new data on the slip rate on the northern sections of the San Jacinto fault, but all the alternative models include increasing slip rates southward on the San Jacinto from its junction with the San Andreas near Cajon Pass. These slip rates are constrained by slip rate studies along the San Andreas, the San Jacinto to the south, and the requirement that the sum of the slip rates on the two faults equal the slip rate on the San Andreas north of their junction. Because the long term slip rate on the San Bernardino, north section of the San Andreas is only a few millimeters per year lower than the Mojave section, the modeled slip rate on the San Bernardino Valley section of the San Jacinto fault is only 6 $\mathrm{mm} / \mathrm{yr}$ in Deformation Model 2.1. This is less than the slip rate in previous models and only one third of the slip rate on the sections of the San Jacinto to the south, implying that significant slip transfers from the San Andreas to the San Jacinto across the San Bernardino Valley or farther south.

Three sets of deformation models have been derived to reflect uncertainties in slip-rate partitioning between these two faults (Figure 7). There are two deformation models in each set, corresponding to the two alternative fault models. In the preferred set (Deformation Models $2.1 \& 2.4$ ), the slip rates are approximately equal on the San Jacinto and San Andreas faults. In one alternative set, the slip rate is higher on the San Andreas and lower on the San Jacinto fault (Deformation Models $2.2 \& 2.5$ ); in the other, the slip rate is lower on the San Andreas and higher on the San Jacinto fault (Deformation Models $2.3 \&$ 2.6). Slip rates for all other faults are the same in all deformation models, with the values coming from the fault section database.

The rates in the preferred deformation models $(2.1 \& 2.4)$ are close to the rates used by NSHMP (2002). In the NSHMP (2002) model, the San Jacinto fault did not have a consistent long-term slip rate along its length; the $12 \mathrm{~mm} / \mathrm{yr}$ slip rate assigned to the Anza section remained constant to the south end of the fault zone, including where the parallel Coyote Creek fault slips at $4 \mathrm{~mm} / \mathrm{yr}$. In our revised model, we split the Anza section at the north end of the Coyote Creek fault, creating a new Clark section of the San Jacinto fault. In all of the deformation models, slip on the Anza section, to the north, is the sum of the sub-parallel Coyote Creek and Clark sections to the south. Past the south end of the Clark fault, there does not appear to be a through-going fault at the surface.

Epistemic uncertainty is treated with the three logic-tree branches that have the alternative slip rates on the San Jacinto and San Andreas faults for each of the two alternative fault models (Figure 4b). In the WGCEP (2007) workshops, the consensus reached from recent research holds that the slip rate on the Coachella section of the San Andreas fault and the San Jacinto fault are approximately equal. Therefore, Deformation Models $2.1 \& 2.4$ were given 50\% weight in the UCERF 2 model. A $30 \%$ weight was assigned to the minority view that the San Andreas carries most of the slip ( $2.3 \& 2.6$ ). Deformation models in which the San Jacinto fault carries more slip (2.2 \& 2.5) received less support, so they were given a combined weight of $20 \%$. 
(a) Deformation Model $2.1 \& 2.4$

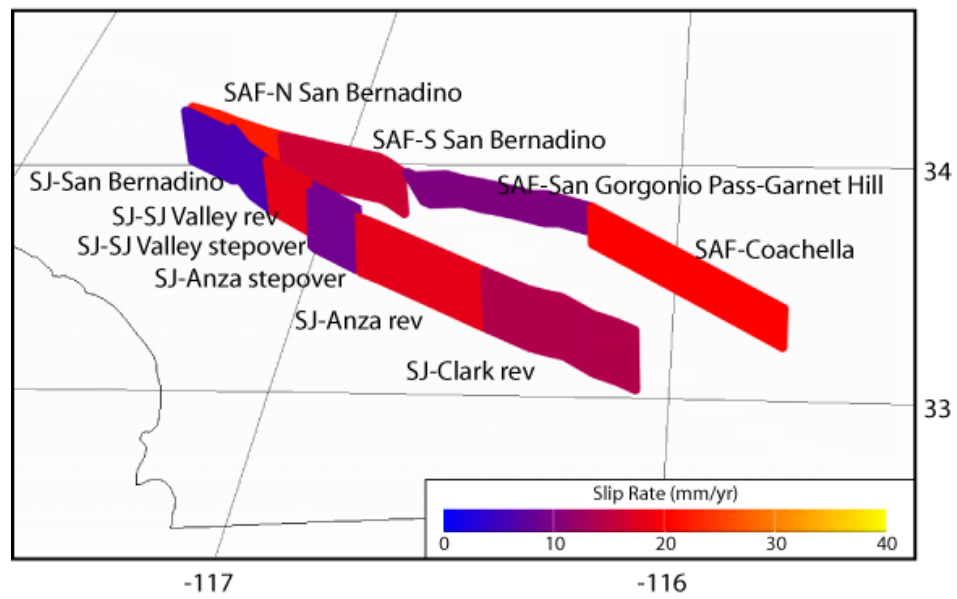

(b) Deformation Model $2.2 \& 2.5$

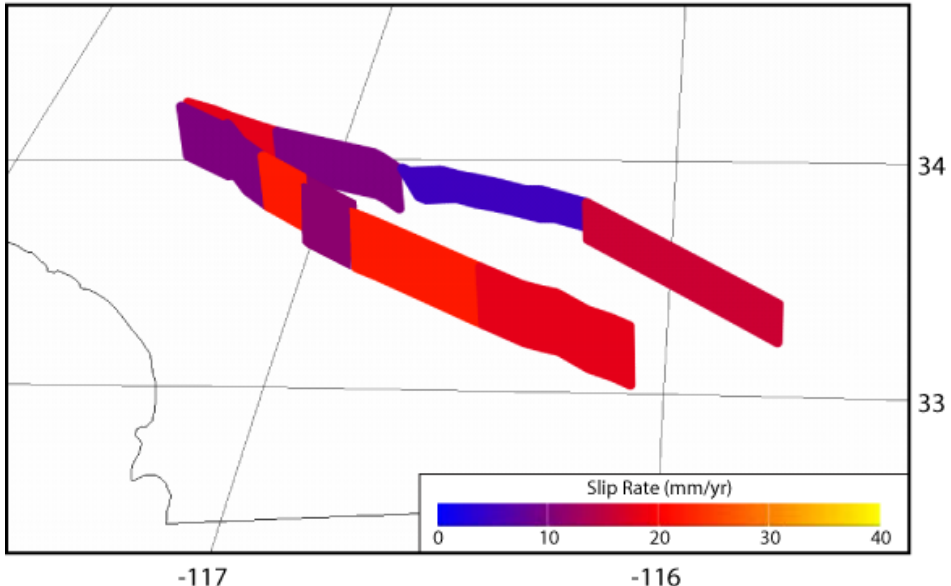

(c) Deformation Model $2.3 \& 2.6$

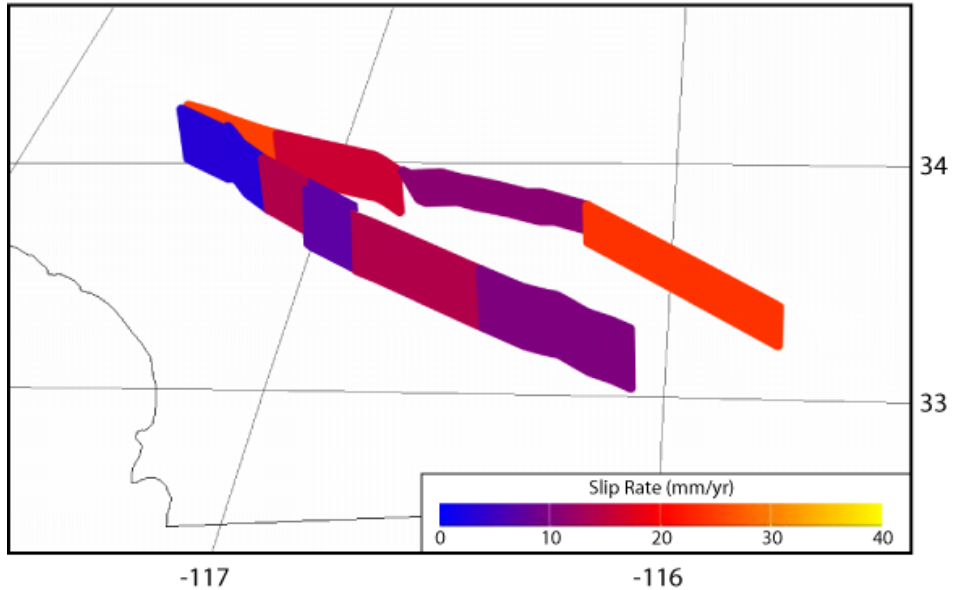

Figure 7. Alternative deformation models used in the UCERF 2 logic tree, which represent the trade-off of slip rate between the San Jacinto (SJ) and San Andreas (SAF) faults. The UCERF 2 preferred models are 2.1 and 2.4 . 


\section{C.2. Aseismic Slip Factors}

The average aseismic slip factor is a parameter assigned to fault sections in the database, and these were used in the deformation models without modification. To determine the factors, we conducted an extensive literature search to identify and characterize all of the faults with known surface creep in California. The results are presented in a series of tables and maps in Appendix P (Wisely et al., 2007). Creep includes continuous or episodic fault slip, often associated with nearby earthquakes; where known, such earthquake associations are documented. With very few exceptions, the rates presented are measured at the ground surface, and so it is unknown how deep creep extends. We assume that the more rapid the creep, the deeper creep extends. Therefore, in applying aseismic slip factors, we have reduced the surface area of the fault on which the slip occurs, rather than reducing the slip rate (consistent with WGCEP (2003)).

In northern California, most of the non-zero values come directly from WGCEP (2003), where we use the weighted average of their logic-tree branch values. Exceptions include two high-creep sections outside the WGCEP (2003) study area: the Maacama and Bartlett Springs fault zones north of San Francisco Bay were each assigned aseismic slip factors of 0.4 and 0.5 , respectively, corresponding to the aseismic slip factors of the Hayward and Concord-Green Valley faults, which align with the Maacama and Bartlett Springs faults to the south.

In southern California, aseismic slip factors of 0.1 were assigned to the San Andreas (Coachella section), Imperial, Garlock (west), San Jacinto (Borrego), and Superstition Hills faults for consistency with all other faults that creep (Wisely et al., 2007, Appendix P). The minimum value of 0.1 was based on the calculations of Sieh \& Williams (1990) for the Coachella section of the San Andreas fault, suggesting that the fault slipped to at least $10 \%$ of its locked depth, and the similar setting of the other faults within the Imperial Valley. The San Andreas Parkfield section was assigned an aseismic-slip value of 0.79 to

produce $M \cong 6.0$ earthquakes (the historical average) when applying our magnitude-fault area relationships. We will return to the impact of these assignments in the section on earthquake rate models. 
Table 4. Segment data for the Type-A faults. *

\begin{tabular}{|c|c|c|c|c|c|c|c|c|}
\hline Name & $\begin{array}{l}\text { DDW } \\
(\mathbf{k m})\end{array}$ & $\begin{array}{c}\text { Length } \\
\text { (km) }\end{array}$ & $\begin{array}{l}\text { Aseis } \\
\text { Factor }\end{array}$ & $\begin{array}{l}\text { Area } \\
\left(\mathrm{km}^{2}\right)\end{array}$ & $\begin{array}{c}\text { Slip Rate, } v \\
\text { (mm/yr) }\end{array}$ & $\begin{array}{c}\sigma_{V} \\
(\mathrm{~mm} / \mathrm{yr})\end{array}$ & $\begin{array}{l}\text { Last } \\
\text { Event } \\
\text { (Year) }\end{array}$ & Sections in Segment \\
\hline \multicolumn{9}{|c|}{ Elsinore } \\
\hline $\mathrm{W}$ & 14.6 & 46.2 & 0 & 674.8 & 2.5 & 0.5 & 207 & Whittier, alt 2 \\
\hline GI & 13.2 & 37.0 & 0 & 488.6 & 4.2 & 0.8 & 1910 & $\begin{array}{l}\text { Glen Ivy, rev + Glen } \\
\text { Ivy, stepover }\end{array}$ \\
\hline $\mathrm{T}$ & 14.2 & 51.8 & 0 & 734.9 & 4.4 & 0.9 & 1732 & $\begin{array}{l}\text { Temecula, rev }+ \\
\text { Temecula, stepover }\end{array}$ \\
\hline $\mathrm{J}$ & 18.9 & 75.4 & 0 & 1426.1 & 5.0 & 1.0 & 807 & Julian \\
\hline $\mathrm{CM}$ & 13.3 & 38.8 & 0 & 517.3 & 4.0 & 1.0 & 1892 & Coyote Mountain \\
\hline Total & & 249.2 & & 3841.7 & & & & \\
\hline \multicolumn{9}{|c|}{ Garlock } \\
\hline GE & 11.5 & 45.2 & 0 & 519.3 & 3.0 & 1.0 & 1000 & Garlock (East) \\
\hline $\mathrm{GC}$ & 11.5 & 111.0 & 0 & 1276.1 & 7.0 & 1.0 & 1540 & Garlock (Central) \\
\hline GW & 14.7 & 97.6 & 0.1 & 1290.9 & 6.0 & 1.5 & 1695 & Garlock (West) \\
\hline Total & & 253.7 & & 3086.3 & & & & \\
\hline \multicolumn{9}{|c|}{ San Jacinto } \\
\hline SBV & 16.1 & 45.1 & 0 & 725.7 & $6.0(10.0,3.0)$ & $2.0(4.0,1.0)$ & 1769 & San Bernardino \\
\hline SJV & 16.1 & 42.7 & 0 & 686.7 & $12.9(15.8,10.0)$ & $2.5(2.5,2,5)$ & 1918 & $\begin{array}{l}\text { SJ Valley, rev + SJ } \\
\text { Valley, stepover }\end{array}$ \\
\hline A & 16.8 & 71.1 & 0 & 1193.9 & $14.8(18.1,11.5)$ & $2.8(2.8,2.8)$ & 1795 & $\begin{array}{l}\text { Anza, stepover }+ \\
\text { Anza, rev }\end{array}$ \\
\hline $\mathrm{C}$ & 16.8 & 46.8 & 0 & 786.1 & $14.0(18.0,10.0)$ & $3.0(3.0,2.0)$ & 1795 & Clark, rev \\
\hline $\mathrm{CC}$ & 15.9 & 42.9 & 0 & 681.5 & 4.0 & 3.0 & 1892 & Coyote Creek \\
\hline B & 13.1 & 34.2 & 0.1 & 403.6 & 4.0 & 3.0 & 1968 & Borrego \\
\hline SM & 12.4 & 26.3 & 0 & 325.8 & 5.0 & 1.5 & 1540 & Superstition Mtn \\
\hline Total & & 309.0 & & 4803.5 & & & & \\
\hline \multicolumn{9}{|c|}{ S. San Andreas } \\
\hline PK & 10.2 & 36.4 & 0.79 & 78.0 & 34.0 & 2.5 & 2004 & Parkfield \\
\hline $\mathrm{CH}$ & 12.0 & 62.5 & 0 & 750.2 & 34.0 & 2.5 & 1857 & Cholame, rev \\
\hline $\mathrm{CC}$ & 15.1 & 59.0 & 0 & 891.2 & 34.0 & 1.5 & 1857 & Carrizo, rev \\
\hline $\mathrm{BB}$ & 15.1 & 49.7 & 0 & 751.0 & 34.0 & 1.5 & 1857 & Big Bend \\
\hline NM & 15.1 & 36.9 & 0 & 556.5 & 27.0 & 3.5 & 1857 & Mojave $\mathrm{N}$ \\
\hline SM & 13.1 & 97.6 & 0 & 1279.0 & 29.0 & 3.5 & 1857 & Mojave S \\
\hline NSB & 12.8 & 35.3 & 0 & 451.9 & $22.0(18.0,25.0)$ & $3.0(2.5,5.0)$ & 1812 & San Bernardino N \\
\hline SSB & 12.8 & 43.4 & 0 & 555.5 & $16.0(10.0,16.0)$ & $3.0(3.0,4.0)$ & 1812 & San Bernardino S \\
\hline BG & 15.1 & 55.9 & 0 & 843.0 & $10.0(5.0,11.0)$ & $3.0(1.0,3.0)$ & 1680 & $\begin{array}{l}\text { San Gorgonio Pass- } \\
\text { Garnet Hill }\end{array}$ \\
\hline $\mathrm{CO}$ & 11.1 & 69.4 & 0.1 & 693.4 & $20.0(16.0,24.0)$ & $3.0(3.0,3.0)$ & 1680 & Coachella, rev \\
\hline Total & & 546.1 & & 6849.7 & & & & \\
\hline \multicolumn{9}{|c|}{ N. San Andreas } \\
\hline SAO & 11.0 & 136.1 & 0.02 & 1469.9 & 24.0 & 1.5 & 1906 & Offshore \\
\hline SAN & 11.0 & 189.4 & 0.02 & 2044.4 & 24.0 & 1.5 & 1906 & North Coast \\
\hline SAP & 13.0 & 84.5 & 0.02 & 1078.4 & 17.0 & 2.0 & 1906 & Peninsula \\
\hline SAS & 15.0 & 62.1 & 0.1 & 838.5 & 17.0 & 2.0 & 1906 & Santa Cruz Mtn \\
\hline Total & & 472.1 & & 5431.1 & & & & \\
\hline \multicolumn{9}{|c|}{ Hayward-Rodgers Creek } \\
\hline $\mathrm{RC}$ & 12.0 & 62.4 & 0.02 & 734.5 & 9.0 & 1.0 & 1758 & Rodgers Creek \\
\hline $\mathrm{HN}$ & 12.0 & 34.8 & 0.4 & 250.7 & 9.0 & 1.0 & 1715 & Hayward (No) \\
\hline HS & 12.0 & 52.5 & 0.4 & 377.7 & 9.0 & 1.0 & 1868 & Hayward (So) \\
\hline Total & & 149.6 & & 1362.8 & & & & \\
\hline \multicolumn{9}{|c|}{ Calaveras } \\
\hline $\mathrm{CN}$ & 13.0 & 45.2 & 0.2 & 470.2 & 6.0 & 1.0 & 1775 & Calaveras (No) \\
\hline $\mathrm{CC}$ & 11.0 & 58.9 & 0.76 & 155.5 & 15.0 & 1.5 & 1982 & Calaveras (Central) \\
\hline $\mathrm{CS}$ & 11.0 & 19.3 & 0.8 & 42.5 & 15.0 & 1.5 & 1899 & Calaveras (So) \\
\hline Total & & 123.4 & & 668.2 & & & & \\
\hline
\end{tabular}


* A segment is defined as one or more contiguous fault sections from the Fault Section Database (those composed of more than one have a "+" between the names in the "Sections in Segment" column). "DDW" stands for down-dip width and "Aseis Factor" is the effective area reduction due to aseismicity between the lower and upper seismogenic depths (those for N. San Andreas, Hayward-Rodgers Creek, and Calaveras represent a weight average of those listed in WGCEP (2003; Table 3.8)). Area is the product of DDW, Length, and one minus the Aseis Factor. The slip rate and its standard deviation $\left.{ }^{(} \mathrm{v}\right)$ come from Deformation Model 2.1, and values that follow in parentheses are from Deformation Models 2.2 and 2.3, respectively (listed only if they differ from 2.1). All aforementioned values come from Wills et al. (2007a, Appendix A), and those for segments composed of more than one section represent weight averages (weighted by area).

\section{C.3. Crustal Shear Zones}

Some areas of California experience significant shear, but they contain few mapped faults, have inadequate slip rate data, or exhibit rates of geodetically measured shear much higher than expected from the fault slip-rate data. NSHMP $(1996,2002)$ included Type-C earthquake sources from four shear zones in northeastern California: the Foothills Fault System, Mohawk-Honey Lake, Northeast California, and Western Nevada shear zones (Figure $8 \&$ Table 5). We retain these zones with the minor modifications described in Wills et al. (2007a, Appendix A).

We found that three shear zones were needed in southern California to improve the kinematic consistency of the deformation model. We named them the Eastern California, San Gorgonio Knot, and Imperial Valley shear zones; they are described in Wills et al. (2007a, Appendix A), listed in Table 5, and plotted in Figure 8. Although the Imperial Valley shear zone is needed for kinematic consistency, much of the shear in this zone is thought to be released as microseismicity, aseismic creep, triggered slip, and afterslip.

Table 5. Parameters for Type-C zone sources.*

\begin{tabular}{|c|c|c|c|c|c|c|c|}
\hline Parameter $^{\dagger}$ & $\begin{array}{c}\text { Foothills } \\
\text { Fault } \\
\text { System }\end{array}$ & $\begin{array}{c}\text { Mohawk- } \\
\text { Honey } \\
\text { Lake }\end{array}$ & $\begin{array}{c}\text { NE } \\
\text { California }\end{array}$ & $\begin{array}{l}\text { Western } \\
\text { Nevada }\end{array}$ & $\begin{array}{c}\text { Eastern } \\
\text { CA Shear } \\
\text { Zone } \\
\end{array}$ & $\begin{array}{c}\text { Imperial } \\
\text { Valley }\end{array}$ & $\begin{array}{c}\text { San } \\
\text { Gorgonio } \\
\text { Knot } \\
\end{array}$ \\
\hline Slip rate $(\mathrm{mm} / \mathrm{yr})$ & 0.1 & 4.0 & 4.0 & 8.0 & 4.0 & \multirow{4}{*}{ Aseismic } & 4.0 \\
\hline Depth $(\mathrm{km})$ & 12 & 15 & 15 & 15 & 15 & & 18 \\
\hline Strike (deg) & 325 & 315 & 335 & 315 & 313 & & 293 \\
\hline Length (km) & 360 & 88 & 230 & 245 & 219 & & 102 \\
\hline
\end{tabular}

* Earthquake sources in all zones have a Gutenberg-Richter minimum magnitude of 6.5, maximum magnitude of 7.6, and a b-value of 0.8 .

${ }^{\dagger}$ Slip rate is the total slip rate across the zone; depth is the seismogenic thickness; strike set the strike for all ruptures; length is the length of the shear zone. Polygon coordinates are available in the Supplementary Spreadsheet (Sheet 13). 


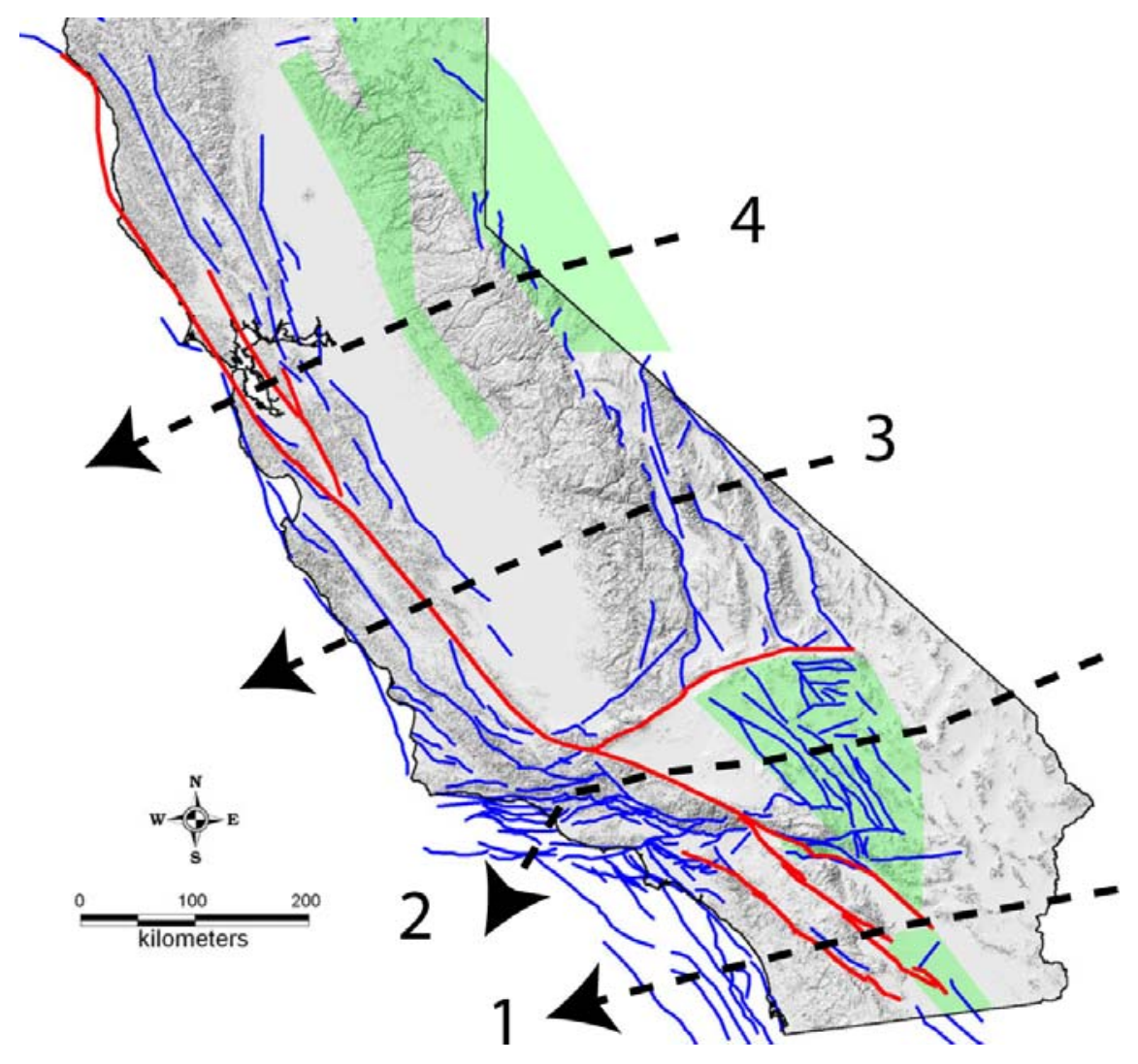

Figure 8. Approximate location of path integrals used to test our deformation model (see Appendix P for table of exact input values). (1) Peninsular Ranges path, (2) Transverse Ranges path, (3) Central California path, and (4) Northern California path. Deformation east of the modeled area is included from Humphreys and Weldon (1994). Red lines are A-Faults, blue are B-Faults, and green polygons are C-zones, which are modeled as vertical faults with simple shear appropriately oriented.

\section{C.4. Path-Integral Tests of Deformation Models}

To test our deformation model, four path integrals were constructed across California. Path integrals are a widely used approach to test the kinematic consistency of a tectonic model and can be thought of as walking a path across a deforming zone and adding up the incremental deformation as each structure is stepped over. In this case the results of the path integrals are compared to the motion between the Pacific and North American plates as determined by NUVEL-1A (DeMets et al., 1994), the generally accepted global plate model. We used the method of Humphreys and Weldon (1994) to accumulate uncertainty along the path and used several of their input values where the UCERF 2 deformation model does not contain required data, including uncertainties in the rake and orientation of the faults, deformation between stable North America and the eastern edge of the UCERF 2 region (taken to be the eastern edge of California for this analysis), and block rotations. All of the data used in the analysis (and additional discussion) can be found in Appendix P; we only present results for Deformation Model 2.1, because the results do not vary significantly between the different deformation models, which mainly trade motion between the sub-parallel San Andreas and San Jacinto faults. The paths were chosen, from south to north, to cross the plate boundary (1) south of the Transverse Ranges, (2) through the Transverse Ranges, 
(3) through Central California, and (4) through the Bay Area in Northern California (Figure 8). Paths 1-3 repeat those of Humphreys and Weldon (1994) and yield similar results. Deformation along all paths sum to values that overlap in uncertainty with the Pacific-North America plate rate (Figure 9).

While this is a good check on the deformation model, it is not a completely independent test; in the WGCEP (2007) modeling, as in previous Working Groups, the preferred slip rates on major faults have been chosen from uncertain data to approximately add up to the plate rate. A second caveat is that the path integrals are sensitive to the chosen path. As can be seen in Figure 8, it is easy to slightly change the path to avoid or add discontinuous structures or to cross structures where their geometry, slip rate, dip or rake vary. Thus, the uncertainties reflected in Figure 9, which do not take into account possible different paths, should be considered minima. We have constructed multiple, slightly different paths along the routes shown in Figure 8 and found that the results can vary by up to $10 \%$, with the exception of the Transverse Ranges path where the results can vary up to $20 \%$, owing to the large number of short thrust faults that can be included or avoided with small path changes and poorly understood block rotations. Finally, path integral paths that cross rotating blocks must correctly account for rotations that are not included in our deformation model. In our calculations, we have used the rotations determined by Humphreys and Weldon (1994), but it is unlikely, particularly in southern California, that all of the rotations are known and well characterized. This may be the reason for the systematic westerly bias observed for all three southern paths and the underestimate in rate for the most complex Transverse Ranges path, which certainly crosses rotating blocks.

At least two of the paths (Northern California and Peninsular Ranges) accumulate deformation that may exceed the plate rate. This is a bit surprising given that the path integrals only sum deformation on discrete faults, C-zones and block rotations, and do not include distributed deformation, so we might expect our results to slightly underestimate the plate rate. It is difficult to estimate how much distributed deformation there is in California, but if we assume that the "background seismicity" in our model represents distributed deformation, it could be 5 to $10 \%$ of the total deformation in the region. If this deformation were added to our total, our results could exceed the plate total by approximately this amount. The answer to this possible discrepancy may be that the path integrals are generally chosen to cross the faults where the slip rates are best known and the faults are simple, straight, and generally parallel to the plate boundary. By choosing the "best" paths and slip rates, we may be biasing the result towards higher slip rates that may not be representative of the faults as a whole. This is a particular concern for discontinuous zones where the slip rate determinations often comes from the middle of a fault, where the slip rate is the highest and the actual slip rate likely tapers to each end of individual strands.

It is also possible that the current plate rate is slightly higher than the widely accepted NUVEL-1A rate (48 $\pm 3 \mathrm{~mm} / \mathrm{yr}$, averaged over the region considered, DeMets et al., 1994). NUVEL-1A includes input that averages over the past $\sim 3 \mathrm{Ma}$, including the orientation of magnetic anomalies to define plate motions, whereas recent GPS and VLBI studies suggest the decadal rate may be $5-10 \%$ higher (e.g., Wdowinski et al., 2007). Because our model uses the geometry of faults that cannot change rapidly and geologic estimates of slip rate, we believe comparison with NUVEL-1A is most appropriate. While these issues suggest that the total uncertainty could be larger than represented in Figure 9, the similarity of our 
path integrals in both direction and magnitude strongly suggests that our deformation model is kinematically consistent with the plate motion that drives the deformation. Related testing of the earthquake rate models using strain tensor analysis is discussed in $§ \mathrm{D} .8$.
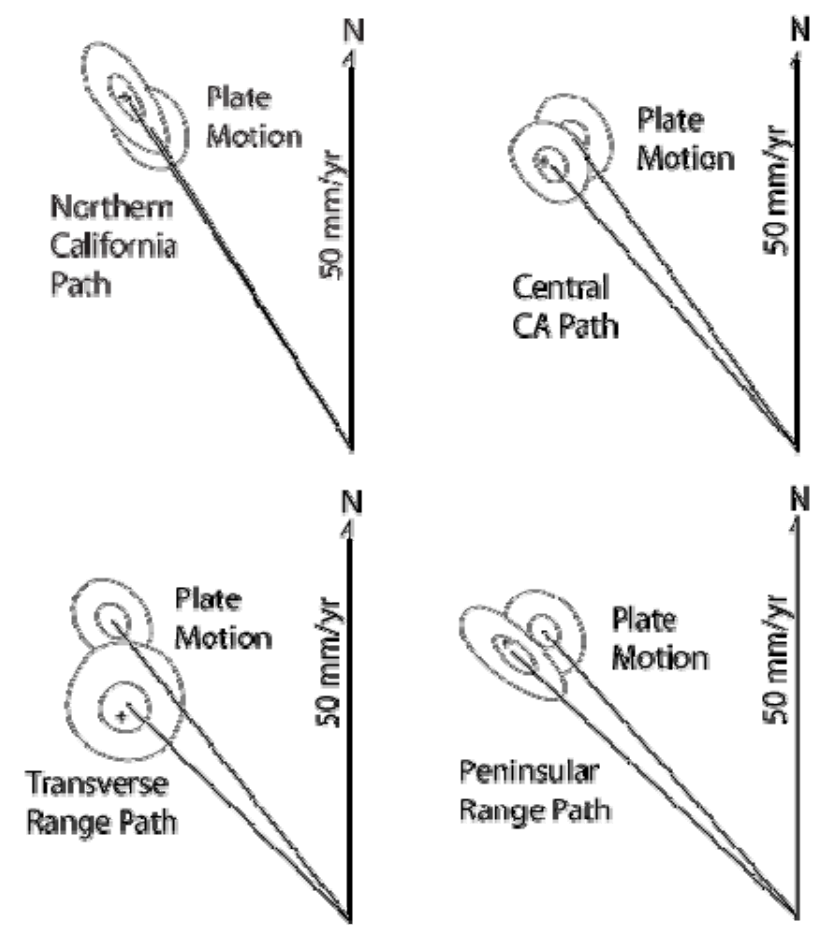

Figure 9. Vector sum of path integrals compared to the expected Pacific North America plate motion NUVEL-1A (DeMets et al., 1994). The tips of the vectors are the best estimates from Monte Carlo sampling of the uncertainties associated with all inputs, and the uncertainty contours are 30 and $90 \%$ (following Humphreys and Weldon, 1994). The pluses (+) are the sum of the individual fault slip vectors and block rotations; they are distinct from the best estimates because the individual fault uncertainties are asymmetric. Note that the plate motion varies slightly from path to path, rotating to a more northerly direction at higher latitudes. 


\section{Earthquake Rate Models}

California earthquake hazard is fundamentally tied to the expected rate of damaging earthquakes. In this section, the long-term earthquake rate models developed cooperatively by WGCEP (2007) and NSHMP (2007) are presented. The data and model analysis require conversion of seismic moment release $M_{0}$ to earthquake magnitude $\mathrm{M}$ (for comparisons between observed and model earthquakes) and to fault area $A$ and average fault slip $D$ (for comparisons with geologic and geodetic slip rates). For the former, we used the Hanks and Kanamori (1979) magnitude-moment equation: $\log M=1.5 M_{0}+9.05$. For the latter, we assumed the moment definition $M_{0}=\mu A D$ with $\mu=30 \mathrm{GPa}$.

The earthquake rate model is a combination of the following seismic sources: (1) earthquake rates on Type-A faults, (2) earthquake rates on Type-B faults, (3) earthquake rates from crustal shear zones (Type$\mathrm{C}$ sources), and (4) a grid of background earthquake rate values not associated with $\mathrm{A}, \mathrm{B}$, or $\mathrm{C}$ sources.

(a) Type-A Faults

(b) Type-B Faults

(c) Connected B Faults \& C-Zones

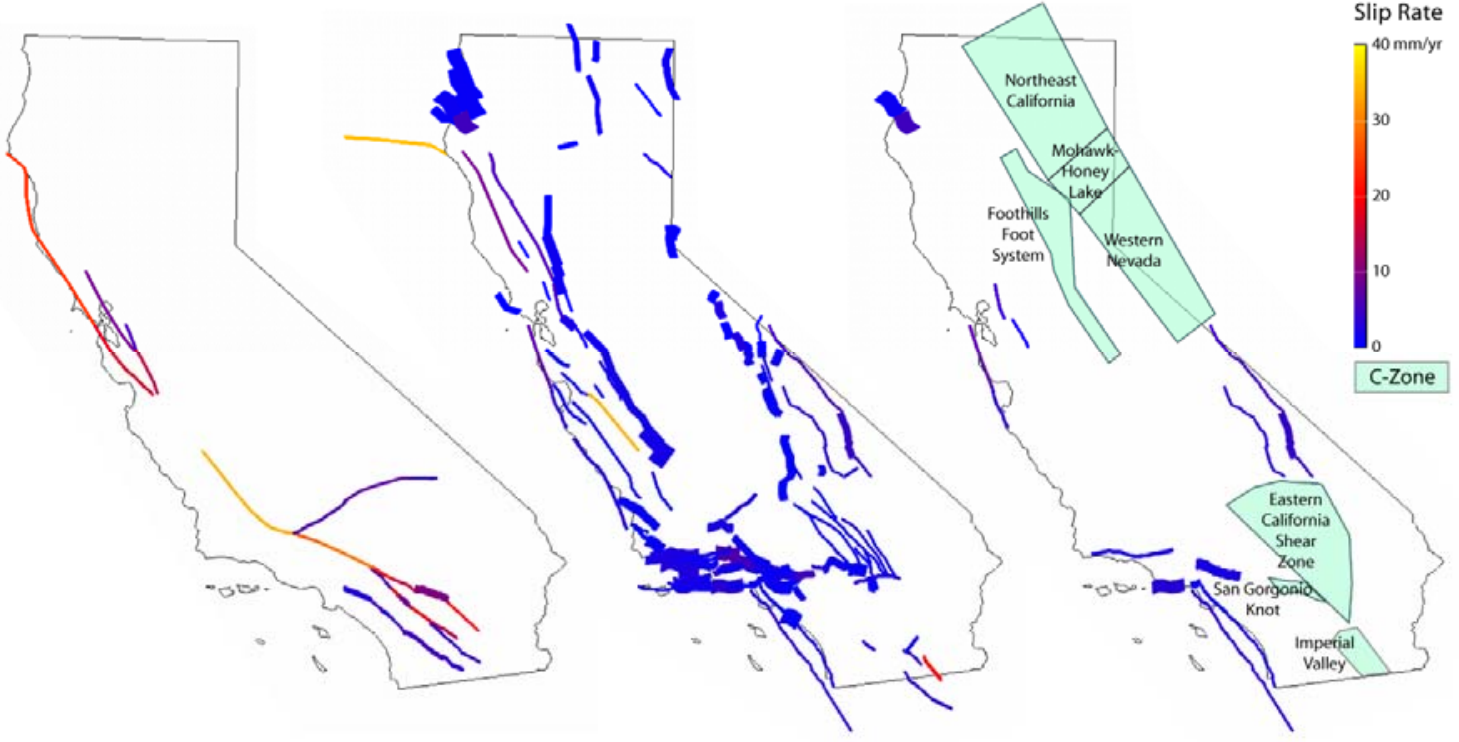

Figure 10. Distribution of California faults by earthquake source type. (a) Type-A faults have known slip rates and paleoseismic estimates of recurrence interval. (b) Type-B faults have observed slip rates. (c) Type-C zones are regions of crustal shear. Also shown are connected B faults designate sets of Type-B faults close enough that they may rupture together in large earthquakes. Not shown are Type-B faults in the boundary zone that lie entirely outside the state boundaries.

\section{D.1. Earthquake Source Types}

Seismic sources in California were originally designated as Type A, B, or C by WGCEP (1995), based on the level of knowledge. This designation was also utilized in the 1996 and 2002 National Seismic Hazard Maps (Frankel et al., 1996 and 2002), and we adopt it here. Type-A sources occur on faults that have enough information on the location, timing, and (in some cases) the slip in previous earthquakes that permanent rupture boundaries (segment endpoints) can be hypothesized and a stressrenewal recurrence model can be applied. There are six Type-A faults in the UCERF 2 model: (1) San 
Andreas, (2) San Jacinto, (3) Elsinore, (4) Garlock, (5) Calaveras, and (6) Hayward-Rodgers Creek. The fault traces of these sources are presented in Figure 10a.

The Type-B sources occur on faults that have slip-rate estimates, but where the data on the distribution and timing of previous events are inadequate to model them with stress-renewal probabilities. "Connected B faults" designate sets of Type-B faults close enough that they may rupture together in large earthquakes. Type-B faults in the California boundary zone that lie entirely outside the state boundaries were modeled in a slightly different way for those within California, as described below. WGCEP (2003) did not use the Type-A versus Type-B distinction. For statewide consistency we have classified their San Gregorio, Concord-Green Valley, Greenville, and Mt Diablo faults as Type-B.

Type-C sources lie within crustal shear zones where significant strain is accommodated, but where knowledge is insufficient to apportion slip onto specific faults. Background seismicity accounts for all other possible earthquake sources, and is determined from historic and instrumental earthquake catalogs. Sources for the shear zones and background events are modeled as gridded seismicity in latitude and longitude bins and an earthquake magnitude-frequency distribution is assigned to each cell.

\section{D.2. Reduction of Moment Rate on Faults}

In addition to the average aseismic slip factor (described in §C.2), the WGCEP (2007) considered two additional variables that could act to reduce the moment rate, or seismic slip rate, on all faults in the deformation model: the seismic coupling coefficient, and the percentage of moment accommodated by small events and aftershocks. Although aseismic slip factors in our deformation model are defined as a reduction of rupture area between the upper and lower seismogenic depths, another manifestation of creep could be a uniform reduction of seismic slip rate over the entire fault surface. We accommodate this alternative type of aseismic behavior using a coupling coefficient that specifies the amount of slip rate between the upper and lower seismogenic depths that is released aseismically; i.e., unity corresponds to full coupling. A coupling coefficient less than unity could account for afterslip, creep, or distributed shear. Although branches involving this parameter were constructed, we set their weights to zero in UCERF 2 based on a strong preference of NSHMP participants that we not change the model without strong supporting evidence. As with all other zero-weight branches, these alternative models nevertheless remain available for further explorations of epistemic uncertainties.

The second moment reduction variable that we considered accounts for the moment reduction due to smaller earthquakes and aftershocks. Type-A, B, and $\mathrm{C}$ sources were generally restricted to $\mathrm{M} \geq 6.5$ events, with smaller events modeled as part of the background seismicity, and the constraints on them from historical earthquake rates were developed accordingly. Furthermore, the Type-A, B, and C source models excluded foreshocks and aftershocks from the forecast (as specified by NSHMP). We therefore reduced the slip rates used in these models by the amount that is typically accommodated by foreshocks, aftershocks, and smaller events.

WGCEP (2003) cited moment-reduction values of $0.06 \pm 0.02$ and $0.03 \pm 0.02$ for smaller events and aftershocks, respectively, although they did not include the latter in their final analysis. Nevertheless, these ratios are supported by the fraction-of-aftershocks analysis given in Appendix I by Felzer (2007a), who looked at several ways of estimating this parameter within the Gardner and Knopoff (1974) 
definition of aftershocks and foreshocks used by the NSHMP. Given a lack of certainty on the appropriate values for these parameters, coupled with a reluctance to make changes to the NSHMP (2002) model without strong evidence, a total moment-rate reduction of 0.1 was assigned to all faults, which is close to the value of 0.09 obtained by combining the preferred values of WGCEP (2003).

\section{D.3. Type-A Source Rate Models}

A fault-rupture model gives the long-term rate of all possible earthquakes. The primary challenge in developing such a model is to satisfy all available constraints: slip rate data, paleoseismic event-rate constraints at particular locations, event-date correlations between sites, magnitude-area relationships, how slip varies along the length of each rupture, and any other geologic insight into what features might influence the distribution of ruptures. As depicted in Figure 4c, we have developed two sets of segmented models ("a-priori" versus "moment balanced") and one set of unsegmented models for each of our TypeA faults. In the segmented models, a fault segment is defined as one or more fault sections (from a given deformation model) that are assumed to rupture together and entirely during an earthquake; an earthquake rupture might involve one or more neighboring segments but never involves only part of a segment.

The approach we have adopted represents both a generalization and extension of that developed by WGCEP (2003). In that previous study, a "source characterization" group was assembled that developed models representing the relative rate of single versus multi-segment ruptures for each fault (as well as a "floating" earthquake defined over a relatively narrow magnitude range). Between three and five models were constructed by the source characterization groups for each fault, each of which was given a relative weight of being the correct model for their logic tree. Because these models were not generally moment balanced, meaning they did not satisfy fault slip rates, each was converted to a model that was both moment balanced and as close as possible, in a least squares sense, to their originally specified relative rates.

We take an analogous approach in that we first use geologic expertise to develop "a-priori" models, and then use a mathematical inversion to adjust them by whatever minimal amount is need to make them consistent with slip-rate data (moment balanced) and perhaps other constraints as described below. An important difference is that our a-priori models specify absolute rates of events, whereas the WGCEP (2003) initial models specified relative rates. In general, our a-priori models are constructed by satisfying paleoseismically inferred rates of events on each segment, which means they constitute a viable model even before any moment balancing is applied. Another difference is that our unsegmented model, described below, allows a broader range of magnitudes than applied by WGCEP (2003) in their "floating" earthquake model.

A-Priori Models. These are consensus models developed in consultation with experts. Three different apriori models were constructed for each fault:

- Geologic Insight Model: best estimate based on as much information as possible.

- Minimum Rate Model: minimizes the total rate of ruptures (and therefore maximizes event magnitudes) while honoring the data. 
- Maximum Rate Model: maximizes the total rate of ruptures (and therefore minimizes event magnitudes) while honoring the data.

The Geologic Insight Model is the preferred estimate, whereas the Minimum- and Maximum-Rate Models are intended to be viable end-members that bracket the range of hazard. Because our primary goal is to capture mean hazard and loss, the consensus was to include only the Geologic Insight a-priori model in our final logic tree. Nevertheless, the results for the other two models are available to those interested in exploring the epistemic uncertainties represented by these alternatives (Field et al., 2007, Appendix G).

Given the recent and extensive model development conducted WGCEP (2003), we generally used their final, average rupture rates as our a-priori models for the Northern San Andreas, Hayward-Rodgers Creek, and Calaveras faults. Following data-review and consensus-building workshops in Menlo Park on July 26, 2005 and November 8, 2006, some slight modifications were made to the models as described in Appendix K. One of the more significant changes was to increase the rate of events on the northern Calaveras in order to bring the model into consistency with the event-rate data of Kelson et al. (1996).

A-priori models for the Elsinore, San Jacinto, and Garlock faults were developed using a significant quantity of new paleoseismic information that was not available to WGCEP (1995). In general, these models were developed by apportioning the total, paleoseismically constrained rate of event on each segment onto the various rupture possibilities, while considering other geologic constraints such as stepover distance between segments. Details are provided in Appendix F (Dawson, 2007b). These models were developed during a series of meeting among WGCEP participants and presented to the broader community at a Nov 13, 2007, workshop in southern California.

For the southern San Andreas fault, a greater abundance of data allowed a more systematic analysis of rupture possibilities than usually constructed by expert opinion. We applied an objective method of Weldon et al. (2007, Appendix E) to combine all of the observations of size, timing, and distribution of past earthquakes into a comprehensive set of earthquake scenarios that each represent a feasible history of earthquakes for the past $\sim 1400$ years. Event scenarios were ranked according to their overall consistency with the data and then the frequencies of all ruptures permitted by the UCERF 2 segmentation model were calculated. Details on southern San Andreas fault event rates are given in Appendix E (Weldon et al., 2007). This model was also presented to the broader community at the workshop on Nov 13, 2007.

Moment-Balanced Models. The problem with the a-priori models is that, depending on what one assumes about the total average slip as well as the slip distribution along the fault in a given rupture, the models may not be moment balanced. This section outlines how we developed the alternative, moment-balanced models from our a-priori models; the full details are provided in Appendix G (Field et al., 2007).

The segment slip rates implied by a fault-rupture model depend on assumptions regarding the amount of slip on each segment produced by each rupture. Our methodology supports the four options listed in Table 6. In this table, $D_{s r}$ is the average amount of slip on the $s^{\text {th }}$ segment in the $r^{\text {th }}$ rupture. It is important to note that these models represent the behavior averaged over many earthquakes, as there will most certainly be variation within any single event. 
Table 6. Earthquake slip-distribution models

\begin{tabular}{|lc|}
\hline Name & Relation \\
\hline Characteristic Slip & $D_{s r}=D_{s}$ \\
WGCEP (2003) & $D_{s r} \propto v_{s}$ \\
Uniform/Boxcar Slip & $D_{s r}=D_{r}$ \\
Tapered Ends & {$[\sin (x)]^{1 / 2}$} \\
\hline
\end{tabular}

The first option is the Characteristic Slip model, which was employed by the WGCEP (1995) and assumes that the amount of slip on a segment is independent of whether it is a single or multi-segment rupture. This assumption makes developing moment-balance models nearly trivial (the final model is exactly as specified in the a-priori model, where the characteristic slip on each segment is simply the segment slip rate divided by the total rate of events on that segment). Unfortunately, as demonstrated in Appendix G (Field et al., 2007), this model leads to magnitude-area implications that are not consistent with the magnitude-area regressions in Appendix D (Stein, 2007).

The second option is the slip distribution implicitly assumed by the WGCEP (2003) methodology, where the amount of slip on a segment in a given rupture is proportional to the slip rate of that segment. As discussed in Appendix G (Field et al., 2007), this model has some implications that we found undesirable. For example, if paleoseismic data imply that any given segment only participates in full-fault ruptures, then all other segments can only participate in full-fault ruptures; i.e. all ruptures are full-fault ruptures. Furthermore, if a segment at the end of a fault only ruptures by itself, then its adjacent neighbor can only rupture by itself as well. We had originally planned to use this slip model, but abandoned it when we encountered these limitations.

The Uniform/Boxcar Slip model, the third option in Table 6, assumes the amount of slip for a given rupture is the same on all segments. The Tapered Ends model, the fourth option, assumes that segments near the end of the rupture have less slip that those near the middle. This model fits the average slip distributions determined from historical earthquakes, as discussed in Appendix E (Weldon et al., 2007) and reproduced in Figure 11. Given this clear observational support for the Tapered Ends model, we gave it exclusive weight in the final logic tree. Results for the other slip-distribution assumptions can be found in Appendix G (Field et al., 2007). 


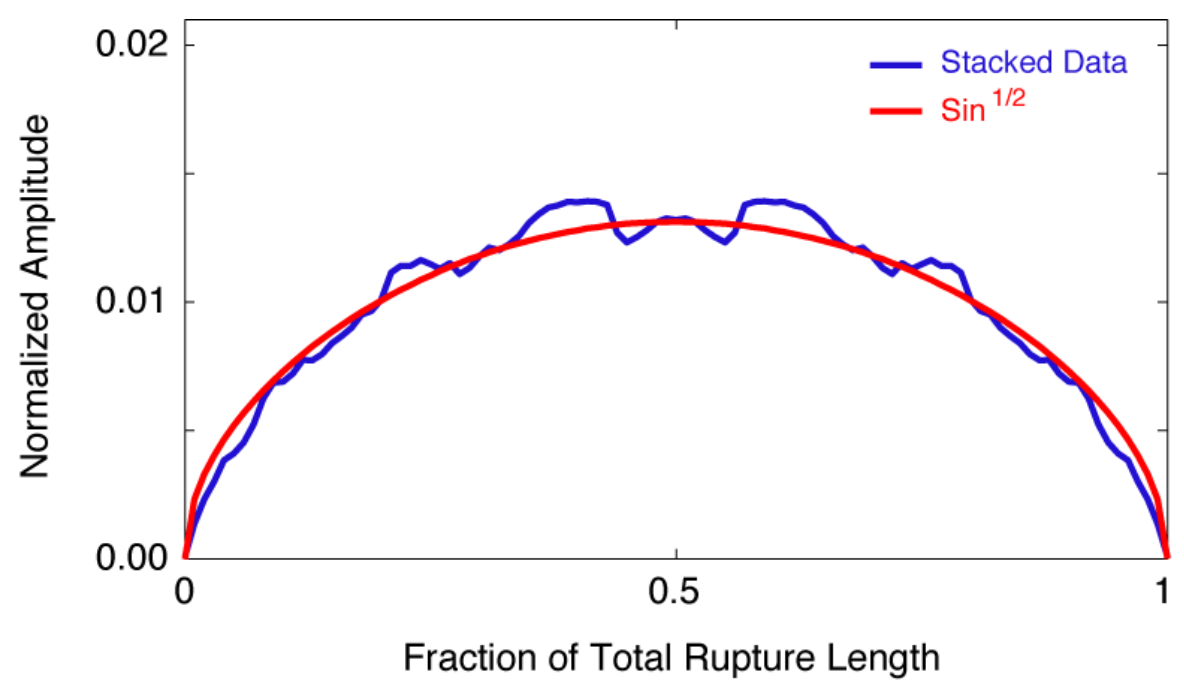

Figure 11. Mean rupture profile based on a stack of 13 mapped surface ruptures. The stack was obtained by normalizing the observed profiles to unit length and averaging them with their reflections about the midpoint. The details of this analysis are presented in Appendix E (Weldon et al., 2007).

As in WGCEP (2003), the magnitude (and consequently the average slip) for each rupture is determined from a magnitude-area relationship, unless a characteristic slip has been chosen. We considered the magnitude-area relationships given in Table 7. The weights for the magnitude-area relations were developed by consensus process that included an open meeting of scientists, a solicitation of outside opinions from additional scientists, and presentation of our approach to the Scientific Review Panel; see Appendix D (Stein, 2007).

Table 7. Magnitude-area relations considered by WGCEP 2007, where A is fault area in km-sq.

\begin{tabular}{|l|l|}
\hline Name & Relation \\
\hline Ellsworth-A (WGCEP, 2003, Eqn. 4.5a) & $\mathrm{M}=\log A+4.1$ \\
\hline Ellsworth-B (WGCEP, 2003, Eqn. 4.5) & $\mathrm{M}=\log A+4.2$ \\
\hline Hanks \& Bakun (2007) & $\mathrm{M}=\log A+3.98$ if $A<537 \mathrm{~km}^{2}$ \\
$\mathrm{M}=1.333 \log A+3.07$ if $A \geq 537 \mathrm{~km}^{2}$
\end{tabular}

According to this consensus, which was unanimous among the WGCEP (2007) Executive Committee, the Ellsworth-B (WGCEP, 2003, eqn. 4.5b) and Hanks \& Bakun (2007) functions were each given 50\% weight in the UCERF 2 logic tree (Figure 4c), and the weights for the other model branches were set to zero. In contrast, WGCEP (2003) gave nonzero weights to Ellsworth-A and Wells \& Coppersmith (1994) with weights of 0.25 , and 0.15 , respectively. Our choice is equivalent to what NSHMP (2002) applied to all sources other than those in the WGCEP (2003), and thus provides statewide uniformity. We note that the manner in which the rupture area is defined and measured in the Somerville (2006) study is not consistent with our definition of upper and lower seismogenic depth (Stein, 2007, 
Appendix D), so to use this model, we would also have to modify our seismogenic thicknesses. Appendix $\mathrm{G}$ (Field et al., 2007) gives results for all models.

Different implied segment slip rates will emerge from the a-priori models depending on the choice of earthquake slip distribution and magnitude area relation. To obtain moment-balanced models, we therefore carried out the inversion described in Appendix G (Field et al., 2007), where we solved for the model that is as close as possible to the a-priori model, in a least-squares sense, but that also fits the sliprate data.

The inversion procedure allowed us to include paleoseismic event-rate constraints in the inversion, though we found that doing so exerted a strong influence on the results. The event-rate estimates inferred from paleoseismology have inherently large uncertainties; for example, the results can depend on what one assumes about the underlying distribution of recurrence intervals, as discussed in Appendix $\mathrm{C}$ (Parsons, 2007a). In addition, the paleoseismic data were used to construct the a-priori models in the first place, raising the issue of double-counting. We therefore excluded the event-rate data in the final inversions and used them only as a check on the moment-balanced models.

As discussed in Appendix G (Field et al., 2007), and exemplified in Figure 12, most of the a-priori models do not fit the slip-rate data very well, which underscores the need for moment balancing. Conversely, some moment-balanced models violate the event-rate data. In the UCERF 2 logic tree, we have therefore given equal weight to the moment-balanced models and the unaltered Geologic Insight models (Figure 4c). Following WGCEP (2003), each single and multi-segment rupture was given a Gaussian magnitude-frequency distribution with a standard deviation of 0.12 and a truncation at \pm 2 standard deviations. NSHMP (2002) used a lower truncation level of 1.25 sigma for their non-WGCEP (2003) sources, but this change does not influence the results significantly.

In summary, UCERF 2 has four logic tree branches for the segmented models representing equally weighted combinations of the Ellsworth-B (WGCEP, 2003, Eqn. 4.5b) and Hanks \& Bakun (2007) magnitude-area relationships, and equally weighted a-priori versus moment-balanced earthquake rate models (Figure 4c). The consequent magnitudes and rates for each rupture are listed in Supplementary Spreadsheet (Sheet 1), and total magnitude-frequency distributions for each fault and comparisons with previous models are given in Appendix G (Field et al., 2007). 

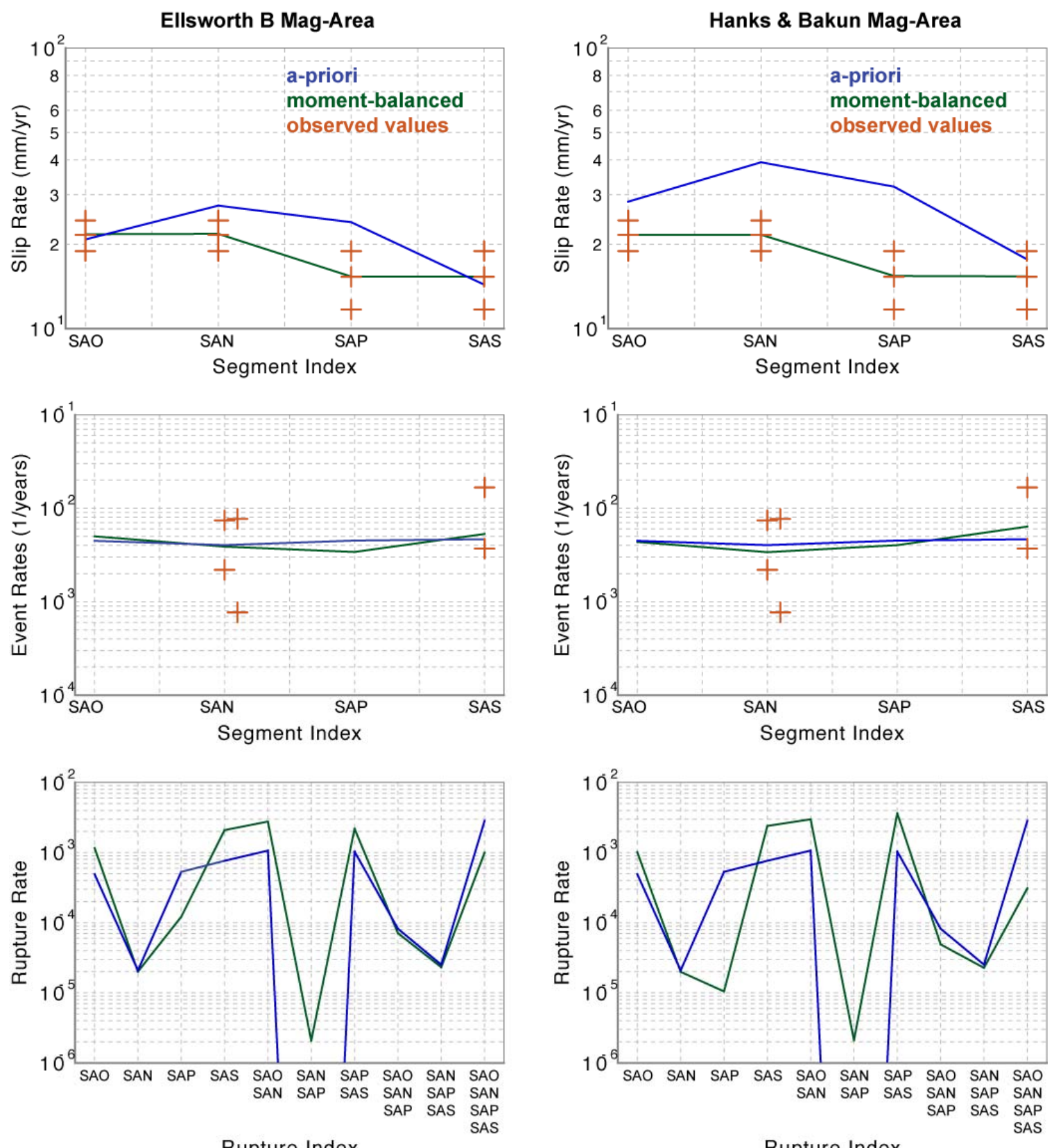

Northern San Andreas Fault

Figure 12. The top row of this figure (from Field et al, 2007, Appendix G) shows how the four segmented models for the northern San Andreas fault fit the slip-rate data (shown as red crosses with 95\% confidence bounds). The a-priori models are plotted as blue lines, and those for the moment-balanced model are plotted as green lines. The moment-balanced models match the slip-rate data exactly, as expected. The results for the Ellsworth-B magnitude-area relationship are shown on the left side, and those for Hanks and Bakun are on the right. The second row is an equivalent comparison for segment event rates, where the data come from Table 8 of Appendix C (Parsons, 2007a) and only the 95\% bounds are shown given the uncertainties associated with defining a "best estimate". The segments are identified by their abbreviations. The third row plots the rate of each rupture type, identified by the segments involved in the rupture, for the a-priori model (blue lines) and the moment-balanced models (green lines). See Appendix G (Field et al., 2007) for further details. 
Unsegmented Models. As an alternative to the segmented models described above, we have also implemented an unsegmented option for each Type-A fault. The purpose was to recognize the possibility that some earthquakes may not honor segment boundaries. Each unsegmented fault was given an incremental magnitude-frequency distribution with a constant rate (zero b-value) between M 6.5 and an upper magnitude, computed from total fault area using the prescribed magnitude-area relationship. This $b$ value was chosen because it approximated that of the segmented models described above, and also because a b-value of 0.8 (the other option considered) significantly exacerbated the over-prediction of earthquake rates near M 6.5 (discussed in $§ \mathrm{D} .8$ ). The rate of events was calculated by matching the total fault moment rate. Finally, we assumed that ruptures for a given magnitude, which may not extend along the entire length of the fault, have a uniform probability of occurring anywhere along the fault. Thus, there are only two logic-tree branches for unsegmented faults: one for each magnitude-area relationship (Figure 4c).

Our unsegmented model differs from the "floating earthquake" model applied by WGCEP (2003). Specifically, the latter study applied a single magnitude to their floating earthquakes (e.g., M 6.9 for the northern San Andreas Fault) with an aleatory uncertainty of up to $\pm 0.24 \mathrm{M}$ units. Our unsegmented model includes a broader range of magnitudes because we thought it important to acknowledge that larger earthquakes on the northern San Andreas, for example, might not honor our segment boundaries. Unfortunately it is difficult to fit all slip-rate and event-rate data with this unsegmented model, as documented in Appendix G (Field et al., 2007). We have therefore given this branch a weight of 10\% compared to the segmented model (Figure 4c).

Because our unsegmented model constitutes a different branch of the logic tree, it represents an epistemic uncertainty in our framework. This is in contrast to the floating earthquakes of WGCEP (2003), which were regarded as an aleatory uncertainty. We spent considerable time discussing this distinction. Most working group participants felt that neither the segmented nor unsegmented models are absolutely correct, but rather that the blend we have chosen is probably best for defining mean hazard and loss (for which the distinction between aleatory and epistemic is not important).

\section{D.4. Type-B Source Rate Models}

All fault sections from a deformation model that are not part of a Type-A fault are treated as Type-B fault sources. Following NSHMP (2002), 67\% of the moment rate on Type-B sources is put into fullfault, "characteristic" ruptures using a Gaussian magnitude-frequency distribution, where the mean is computed using the chosen magnitude-area relationship, as discussed above, the standard deviation is 0.12 magnitude units, and the distribution is truncated at \pm 2 standard deviations. The other $33 \%$ of the moment rate is put into a truncated, incremental Gutenberg-Richter magnitude-frequency distribution, with a minimum magnitude of M 6.5 and a maximum magnitude determined by the chosen magnitudearea relationship. Our final logic tree has two options for the Gutenberg-Richter b-value: 0.8 and 0.0, with $50 \%$ weight assigned to each; the former is the value used by NSHMP (2002) and the latter was introduced in order to reduce an over-prediction of M 6.5 to 7.0 events, discussed in $\S \mathrm{D} .8$.

If the maximum magnitude on a given Type-B fault is less than or equal to $\mathrm{M} 6.5$, all of the moment rate is put into the characteristic distribution. The rate of events at each magnitude is determined by 
matching the total moment rate. It should be noted that while we have specified the characteristic-versusGutenberg-Richter contributions to be an aleatory uncertainty, some within the working group would prefer to treat this as an epistemic uncertainty; however, this distinction is not important in terms of mean hazard and loss estimates.

The creeping section of the San Andreas Fault is handled differently than described above in order to more accurately match historical seismicity; see Appendix J (Petersen et al., 2007b) for details. Another exception is that the magnitudes for the Type-B faults lying entirely outside the California border, but within the boundary zone of Figure 1, were calculated using the Wells and Coppersmith magnitude-length relationship $(1994$, slip type $=$ all) in order to be consistent with how the NSHMP (2007) models the other fault sources in neighboring states.

Following NSHMP (2002), the vast majority of fault sections are treated as distinct Type-B sources. The exceptions are the San Gregorio, Greenville and Concord-Green Valley faults, where the sections for each of these are combined for their respective sources. A list of all type-B sources is given along with various parameters in Sheet 12 of the Supplementary Spreadsheet. We have also implemented an option to combine more Type-B faults into single, larger sources (Figure 10). The faults influenced by this option are identified in Sheet 12 of the Supplementary Spreadsheet. These Type-B sources are combined because their orientation, proximity, structural style, and slip rate are similar enough that they are believed capable of rupturing together, as described in Appendix A (Wills et al., 2007a). No information is available that allows us to give asymmetric weight as to whether or not these Type-B faults do indeed connect, so 50\% weighting was applied in the UCERF 2 logic tree (Figure 4c). The hazard contributions from some of the more notable Type-B sources are discussed in the section on probabilities $(\S \mathrm{F})$.

\section{D.5. Type-C Source Rate Models}

Six Type-C sources are included in our earthquake rate model to account for seismicity in distributed shear zones. These are plotted on the map in Figure 10c, listed in Table 5, and described above and in Appendix A (Wills et al., 2007a) in the context of the deformation models. Following the NSHMP (2002), ruptures in each of these zones were modeled as vertical strike-slip events with a strike parallel to the regional structural trend. A moment rate was calculated from the slip rate measured across the zone, the average length of the zone in the direction of shearing, and its seismogenic thicknesses. Events were assumed to conform to a Gutenberg-Richter distribution that matches the total inferred moment rate, with a minimum magnitude of 6.5 and a maximum magnitude of 7.6 to allow for earthquakes similar to the 1872 Owens Valley earthquake in eastern California. All parameters needed to implement these Type-C sources are given in Table 5.

Appendix J (Petersen et al., 2007b) describes the four northern California shear zones in more detail. They correspond to the Type-C used by NSHMP (2002), although we modified their area and increased their maximum earthquake magnitude. The orientation of shear and moment rates applied to these zones are based on geodetic strain rate data. Appendix J (Petersen et al., 2007b) also compares the strain from geodesy, historic seismicity, and geology, which show significant differences.

Of the three new shear zones added to southern California, that for Imperial Valley was deemed aseismic by expert opinion and therefore has no associated source of ruptures. For all 5 remaining Type-C 
sources, we assigned a 50\% weight because we do not know how much of the moment rate will be released in large earthquakes and how much will occur aseismically or in smaller earthquakes.

\section{D.6. Background Seismicity Rate Models}

Type-A and B sources account for earthquakes larger than $\mathrm{M} \sim 6.5$ that occur on one of our modeled faults, and Type-C sources account for M 6.5-7.6 earthquakes that occur in the identified shear zones. Smaller earthquakes near these sources, as well as all earthquakes elsewhere in California, are modeled as background seismicity. A truncated Gutenberg-Richter magnitude-frequency distribution was assigned to each $0.1^{\circ} \times 0.1^{\circ}$ bin throughout the state. The a-value for each bin was obtained by spatially smoothing historical seismicity after removing $\mathrm{M}>6.5$ earthquakes associated with Type-A, B, or $\mathrm{C}$ sources (Petersen et al., 2007b, Appendix J). This model used a revised catalog assembled by Felzer \& Cao (2007, Appendix H) and accounted for a spatially variable magnitude of completeness, the asymmetric effect on moment sums of magnitude rounding, and magnitude uncertainties in the historical catalog, as described in Appendix I (Felzer, 2007a). The b-value for each bin was assumed to be 0.8 in accordance with the average value observed after declustering the catalog using the Gardner and Knopoff (1974) algorithm. The exception was in the vicinity of the San Andreas fault creeping section, where the observed b-value of 0.9 was applied (Frankel et al., 2002). Maximum magnitudes were set to M 7.0 except in the vicinity of Type-A, B, or C sources, where maximum magnitudes were capped near the lowest magnitude for that source. Maximum magnitudes were also increased to 7.3 in the Gorda plate near the Mendocino triple junction. The details can be found in Appendix J (Petersen et al., 2007b).

An important change with respect to NSHMP (2002) was a reduction of background-seismicity rates for $M>6.5$. Because earlier versions of our model produced a rate of $M$ 6.5-7.0 shocks that significantly exceeded observed seismicity rates (discussed in $\S \mathrm{D} .8$ ), a correction made was to reduce the rate of all $M>6.5$ earthquake in the background by a factor of three (Petersen et al., 2007b, Appendix J). This reduction avoids potential double counting of large events and is consistent with assessments of the seismicity model, which indicated that approximately $2 / 3$ of $M>6.5$ earthquakes in and near California occurred on faults included in the UCERF 2 model and that $\sim 1 / 3$ occurred as background seismicity off the modeled faults (see Table 10).

\section{D.7. The Cascadia Subduction Zone}

The Cascadia subduction zone extends about $1200 \mathrm{~km}$ from Vancouver Island in British Columbia to Cape Mendocino in California (Figure 13). Adjacent to northern California, the Gorda plate is subducted eastward beneath North America at a rate of about $40 \mathrm{~mm} / \mathrm{yr}$ (Nishimura et al., 1984). The last great Cascadia rupture is thought to have occurred in January, 1700, based on analysis of tsunami records in Japan, trees along the Pacific coast, study of onshore tsunami deposits, and other geophysical data (Satake et al., 2003). A complete description of the Cascadia zone interface is included in Appendix L (Frankel and Petersen, 2007), where magnitudes, recurrence rates, and weights are provided. Shallow and deep earthquakes associated with the subduction process are modeled separately using gridded background seismicity between M 5 and 7.3 (Petersen et al., 2007b, Appendix J). 
We include the same Cascadia subduction zone geometry and weighting scheme as used by the NSHMP (2002) model. Thermal models of Flück et al. (1997) and global analogs of shallow-dipping subduction zones were used to develop alternative rupture models. These models include ruptures that extend (1) through various depth ranges thought to be related to the elastic and transitional properties of the crust and (2) down to a depth of about $30 \mathrm{~km}$ similar to other large subduction earthquakes (Figure 13).

Great earthquakes were assumed to occur along the Cascadia subduction zone on average once every 500 years, based on paleoseismic studies of coastal subsidence and tsunami deposits (e.g., Atwater \& Hemphill-Haley, 1997). We considered two rupture scenarios for these events: (1) $M=9.0 \pm 0.2$ events that rupture the entire Cascadia subduction zone every 500 years on average, and (2) $\mathrm{M}=8.0-8.7$ events whose rupture zones fill up the entire zone over a period of about 500 years. Each earthquake of the first scenario was assumed to rupture the entire seismogenic area. The rupture zones for the second scenario were floated along the strike of the Cascadia subduction zone.

For the WGCEP and the NSHMP models, we assign a probability of 0.67 to the $M=8.8-9.2$ scenario and a probability of 0.33 for the $\mathrm{M}=8.0-8.7$ floating-rupture scenario. In the NSHMP (2002) maps, $\mathrm{M}=$ 9.0 and $\mathrm{M}=8.3$ scenarios were given equal probabilities. (To be clear, "probability of a scenario" indicates that the effective rate of the scenario in the hazard calculation is the probability of that scenario multiplied by the recurrence rate calculated as if it were the only scenario.) The higher probability of the $\mathrm{M}=8.8-9.2$ rupture scenario in the 2007 update of the NSHMP (2002) maps reflects the consensus of scientists and others at the March 28-29, 2006, Pacific Northwest NSHMP workshop. Figure 14 shows the cumulative magnitude-frequency distribution of the Cascadia zone, where the annual rates are calculated using the assumed scenario probabilities and the recurrence rates and weights given in Appendix L (Frankel and Petersen, 2007). 


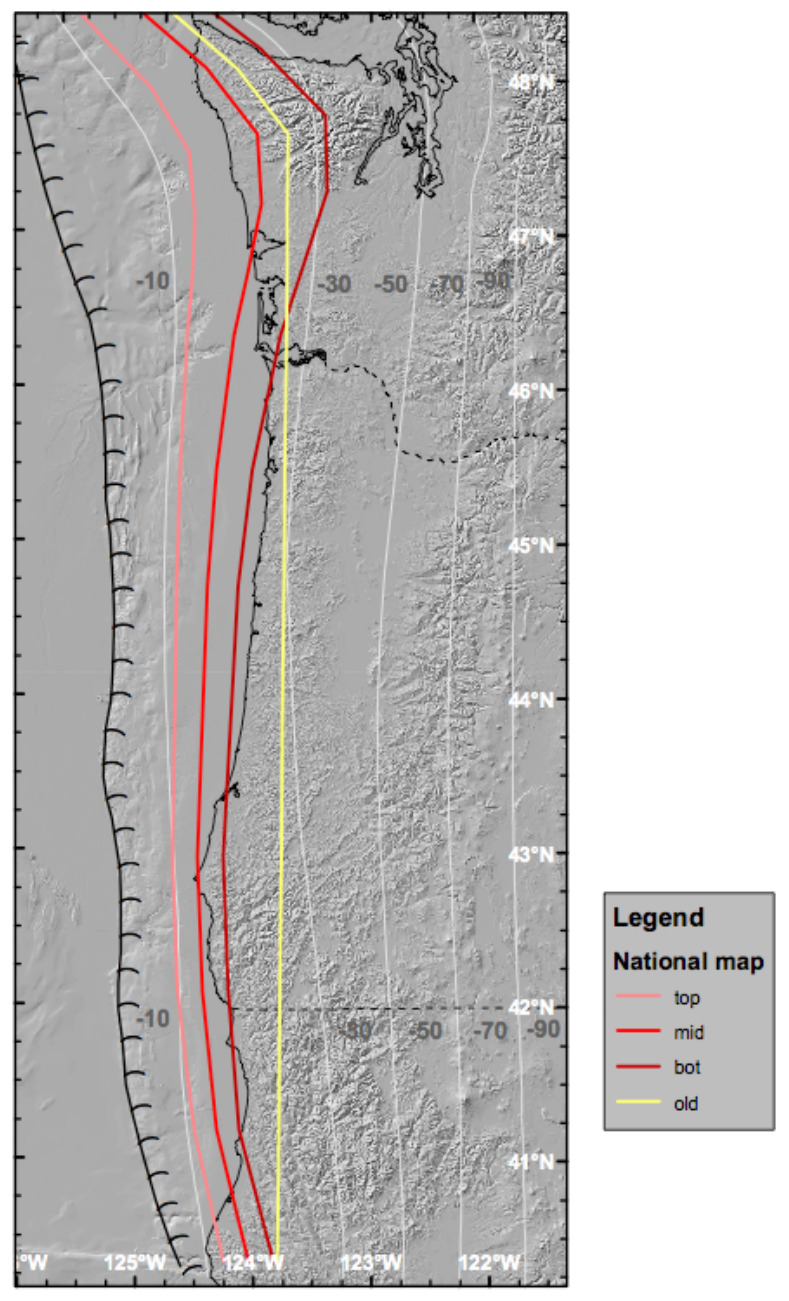

Figure 13. Map of the Cascadia megathrust, showing (as colored lines) the eastern edge of earthquake rupture zones for the various models used in this study. The reddish lines indicate, from west to east, the base of the elastic zone, the midpoint of the transition zone, and the base of the transition zones. The yellow line marks the base of the model that assumes ruptures extend down to about $30 \mathrm{~km}$ depth. The light gray lines indicate the subduction interface from McCrory et al. (2004). 


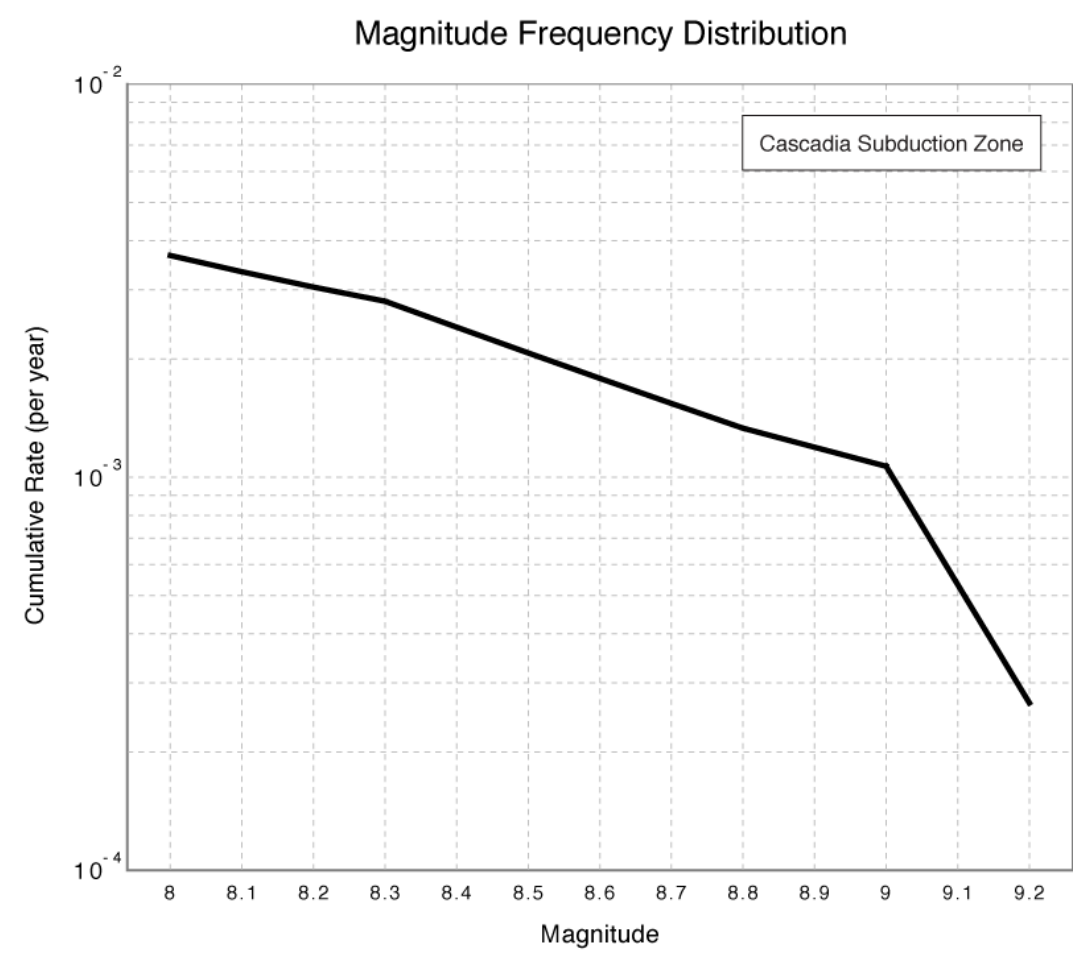

Figure 14. The cumulative magnitude-frequency distribution for large earthquakes on the Cascadia megathrust, derived from the weighted annual rate of earthquakes as a function of magnitude.

\section{D.8. Tests of the Earthquake Rate Models}

We tested the final earthquake rate model, ERM 2.3, in three different ways: by comparing the predicted magnitude-frequency distributions with historical data, by calculating integrated strain tensors across the plate-boundary zone, and by comparing the distribution of source types $(\mathrm{A}, \mathrm{B}, \mathrm{C})$ with historical data.

Magnitude-Frequency Tests. We have evaluated the predicted magnitude frequency distributions for the various earthquake sources in the model, as well as for their composite, against the historical catalog described in Appendix I (Felzer, 2007a). The observed magnitude-frequency distribution, declustered and corrected for potential biases, is plotted as the red line in Figures 15-18. The observed annual rate of $M \geq 5$ earthquakes is 4.17 events/yr with a $95 \%$ confidence bound of 2.22-5.84 events/yr, and the rate of $M \geq 6.5$ shocks is 0.24 events/yr with a $95 \%$ confidence bound of $0.13-0.35$ events/yr. Shown in black in Figure 15 is the mean magnitude-frequency distribution for the UCERF 2 earthquake rate model (ERM 2.3) with the logic-tree branches and weights given in Figure 4 (and excluding Cascadia). For $\mathrm{M} \geq 6.5$, our model predicts an annual rate of 0.319 events/yr; this exceeds the historically observed rate by $33 \%$, though it lies within the $95 \%$ confidence bounds on the observed rate.

Figure 15 also displays the contributions from the various earthquake sources; the numerical values for these cumulative distributions are listed in Table 8. The corresponding incremental magnitudefrequency distributions are shown in Figure 16. Figure 17 superposes the cumulative magnitudefrequency distributions for all of the UCERF 2 logic-tree branches, along with the 2.5, 50, and 97.5 event- 
frequency percentiles of the branches, as measured by the branch weights. Here we should re-emphasize that the branch distribution in Figure 17 does not represent all epistemic uncertainties, just those spanned by the UCERF 2 logic tree.

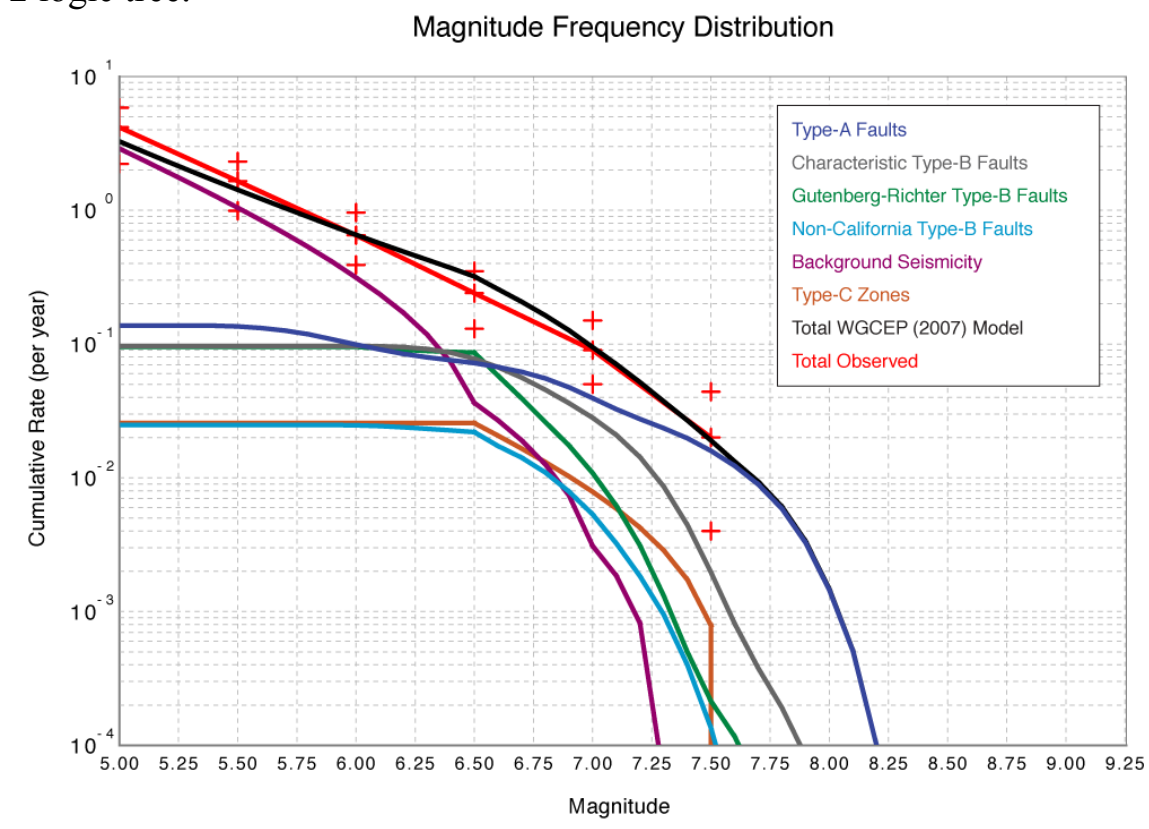

Figure 15. The total, cumulative magnitude-frequency distribution implied by ERM 2.3 (black), as well as the contributions from the various types of sources in the model. The cumulative rates inferred from the historical earthquake catalog are shown in red; the outer red crosses represent the $95 \%$ confidence bounds of Felzer (2007a), which are taken from Table 21 of Appendix I (Felzer, 2007a). Cascadia is not included.

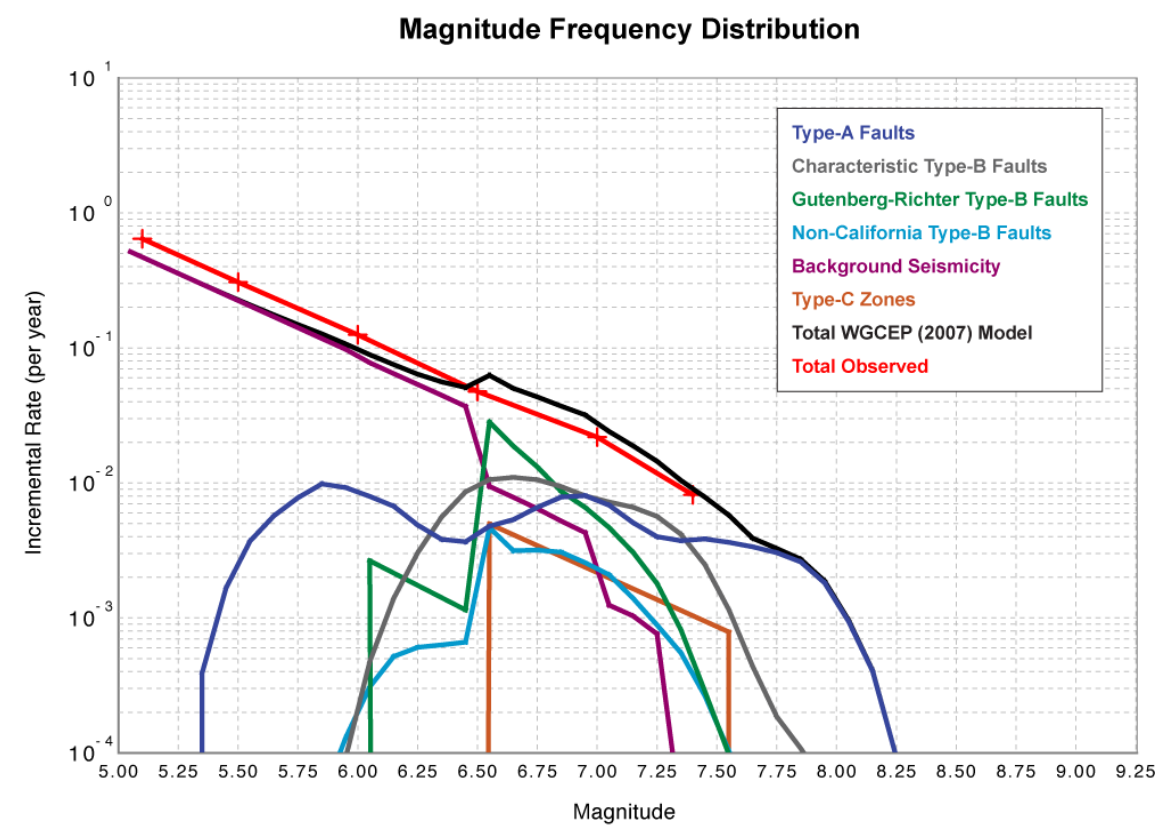

Figure 16. Same as Figure 15, but for the incremental magnitude-frequency distributions; bin widths are 0.1 magnitude units. 
Table 8. Average cumulative magnitude-frequency distributions for ERM 2.3 (excluding Cascadia)*

\begin{tabular}{|c|c|c|c|c|c|c|c|}
\hline M & A-Faults & B-Char & B-GR & B (Non-CA) & Background & C-Zones & Total \\
\hline 5.0 & 0.137393 & 0.096783 & 0.095289 & 0.024843 & 2.887115 & 0.025629 & 3.267050 \\
\hline 5.1 & 0.137393 & 0.096783 & 0.095289 & 0.024843 & 2.371144 & 0.025629 & 2.751080 \\
\hline 5.2 & 0.137393 & 0.096783 & 0.095289 & 0.024843 & 1.942398 & 0.025629 & 2.322334 \\
\hline 5.3 & 0.137393 & 0.096783 & 0.095289 & 0.024843 & 1.586122 & 0.025629 & 1.966058 \\
\hline 5.4 & 0.137000 & 0.096783 & 0.095289 & 0.024843 & 1.290062 & 0.025629 & 1.669605 \\
\hline 5.5 & 0.135329 & 0.096783 & 0.095289 & 0.024843 & 1.044034 & 0.025629 & 1.421906 \\
\hline 5.6 & 0.131620 & 0.096783 & 0.095289 & 0.024843 & 0.839580 & 0.025629 & 1.213742 \\
\hline 5.7 & 0.125905 & 0.096783 & 0.095289 & 0.024843 & 0.669671 & 0.025629 & 1.038119 \\
\hline 5.8 & 0.118140 & 0.096783 & 0.095289 & 0.024836 & 0.528468 & 0.025629 & 0.889143 \\
\hline 5.9 & 0.108306 & 0.096783 & 0.095289 & 0.024806 & 0.411205 & 0.025629 & 0.762017 \\
\hline 6.0 & 0.099075 & 0.096689 & 0.095289 & 0.024676 & 0.313750 & 0.025629 & 0.655108 \\
\hline 6.1 & 0.091128 & 0.096215 & 0.092637 & 0.024367 & 0.236020 & 0.025629 & 0.565997 \\
\hline 6.2 & 0.084406 & 0.094820 & 0.090487 & 0.023849 & 0.171500 & 0.025629 & 0.490690 \\
\hline 6.3 & 0.079526 & 0.091787 & 0.088743 & 0.023243 & 0.117837 & 0.025629 & 0.426765 \\
\hline 6.4 & 0.075704 & 0.086208 & 0.087329 & 0.022612 & 0.073202 & 0.025629 & 0.370683 \\
\hline 6.5 & 0.072035 & 0.077626 & 0.086182 & 0.021950 & 0.036300 & 0.025629 & 0.319722 \\
\hline 6.6 & 0.067253 & 0.067049 & 0.057968 & 0.017291 & 0.026866 & 0.020662 & 0.257089 \\
\hline 6.7 & 0.061899 & 0.056058 & 0.039229 & 0.014141 & 0.019043 & 0.016531 & 0.206902 \\
\hline 6.8 & 0.055307 & 0.045497 & 0.026083 & 0.010959 & 0.012595 & 0.013096 & 0.163538 \\
\hline 6.9 & 0.047449 & 0.036113 & 0.017433 & 0.007889 & 0.007378 & 0.010238 & 0.126499 \\
\hline 7.0 & 0.039402 & 0.028093 & 0.010846 & 0.005324 & 0.003097 & 0.007861 & 0.094623 \\
\hline 7.1 & 0.032565 & 0.020868 & 0.006178 & 0.003236 & 0.001852 & 0.005884 & 0.070583 \\
\hline 7.2 & 0.027487 & 0.014265 & 0.003116 & 0.001838 & 0.000818 & 0.004239 & 0.051763 \\
\hline 7.3 & 0.023488 & 0.008612 & 0.001316 & 0.000951 & 0.000056 & 0.002871 & 0.037293 \\
\hline 7.4 & 0.019753 & 0.004448 & 0.000500 & 0.000400 & 0.000025 & 0.001733 & 0.026860 \\
\hline 7.5 & 0.015907 & 0.001964 & 0.000214 & 0.000135 & 0.000000 & 0.000787 & 0.019008 \\
\hline 7.6 & 0.012277 & 0.000814 & 0.000116 & 0.000031 & 0.000000 & 0.000000 & 0.013239 \\
\hline 7.7 & 0.008914 & 0.000377 & 0.000050 & 0.000005 & 0.000000 & 0.000000 & 0.009346 \\
\hline 7.8 & 0.005870 & 0.000191 & 0.000014 & 0.000000 & 0.000000 & 0.000000 & 0.006075 \\
\hline 7.9 & 0.003268 & 0.000083 & 0.000000 & 0.000000 & 0.000000 & 0.000000 & 0.003351 \\
\hline 8.0 & 0.001449 & 0.000024 & 0.000000 & 0.000000 & 0.000000 & 0.000000 & 0.001474 \\
\hline 8.1 & 0.000506 & 0.000004 & 0.000000 & 0.000000 & 0.000000 & 0.000000 & 0.000509 \\
\hline 8.2 & 0.000100 & 0.000000 & 0.000000 & 0.000000 & 0.000000 & 0.000000 & 0.000100 \\
\hline 8.3 & 0.000007 & 0.000000 & 0.000000 & 0.000000 & 0.000000 & 0.000000 & 0.000007 \\
\hline 8.4 & 0.000001 & 0.000000 & 0.000000 & 0.000000 & 0.000000 & 0.000000 & 0.000001 \\
\hline 8.5 & 0.000000 & 0.000000 & 0.000000 & 0.000000 & 0.000000 & 0.000000 & 0.000000 \\
\hline 8.6 & 0.000000 & 0.000000 & 0.000000 & 0.000000 & 0.000000 & 0.000000 & 0.000000 \\
\hline 8.7 & 0.000000 & 0.000000 & 0.000000 & 0.000000 & 0.000000 & 0.000000 & 0.000000 \\
\hline 8.8 & 0.000000 & 0.000000 & 0.000000 & 0.000000 & 0.000000 & 0.000000 & 0.000000 \\
\hline 8.9 & 0.000000 & 0.000000 & 0.000000 & 0.000000 & 0.000000 & 0.000000 & 0.000000 \\
\hline
\end{tabular}

* Excludes earthquakes in the Cascadia subduction zone 


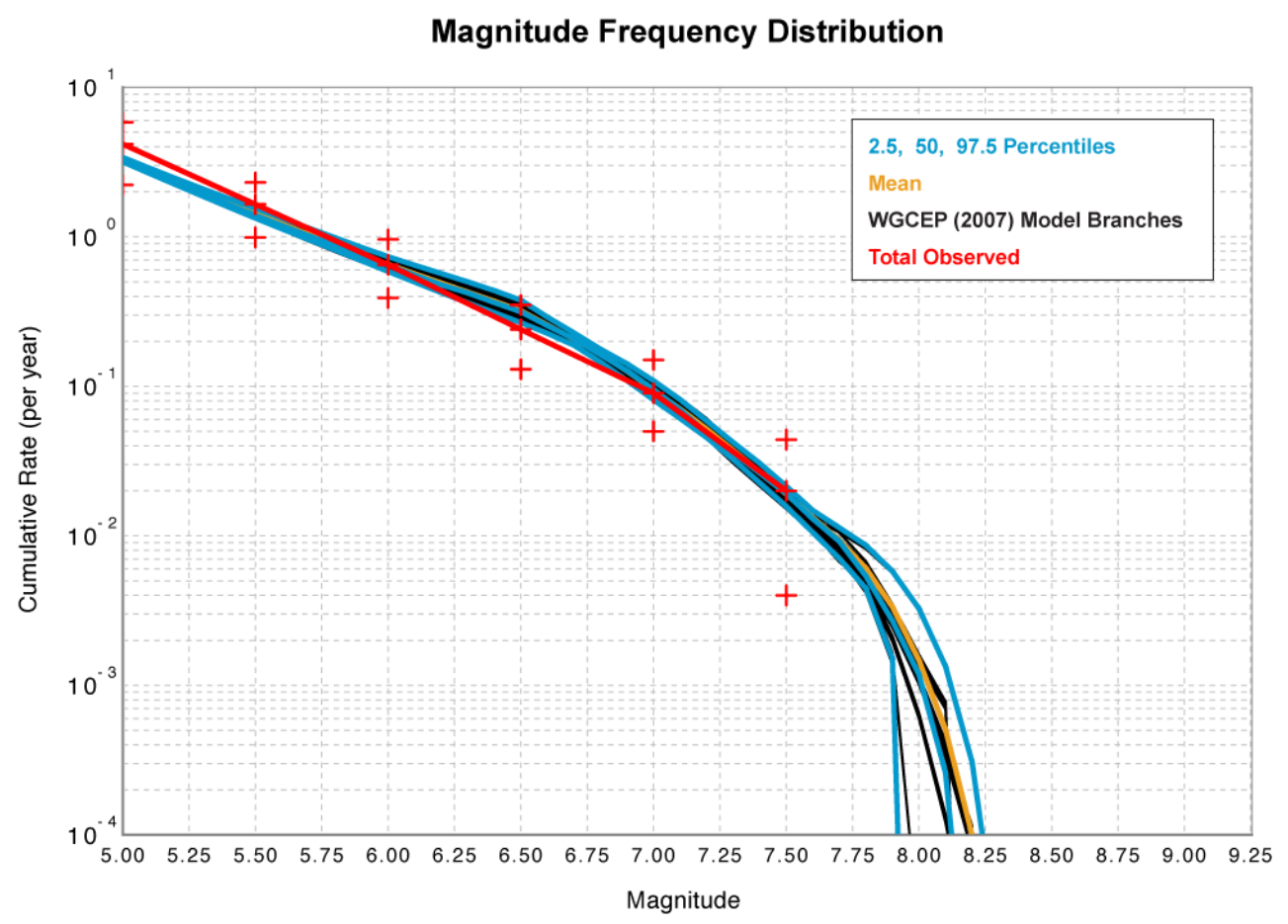

Figure 17. The cumulative magnitude-frequency distribution for each branch of the UCERF 2 logic tree (black), plus the 2.5, 50, and 97.5 percentiles (blue). The mean is also shown (orange) but is generally hidden behind the 50th percentile (median). Note that the range of values here does not represent all epistemic uncertainties, just those spanned by the UCERF 2 logic tree. Cascadia is not included.

The over-prediction of the $\mathrm{M} \geq 6.5$ rate, known informally as "the bulge", has been a common (though sometimes unrecognized) problem in previous WGCEP and NSHMP studies. For example, and as shown in Figure 18, the NSHMP (2002) model overpredicts the $M \geq 6.5$ rate by about a factor of two, compared with a factor of 1.33 for ERM 2.3. A similar bulge existed in the WGCEP (1995) model for southern California, which was extensively discussed, and apparently resolved, in the literature (Jackson, 1996; Schwartz, 1996; Hough, 1996; Stirling \& Wesnousky, 1997; Stein \& Hanks, 1998; Field et al., 1999).

The mean rate of $\mathrm{M} \geq 5$ events (3.27 per year) predicted by ERM 2.3 is less that that observed mean (4.17 events/yr), though above the lower 95\% confidence bound for the data (2.22 events/yr). In the current framework for modeling background seismicity (Petersen et al., 2007b, Appendix J), the rate of M $\geq 5$ events trades off with the bulge rate, so this discrepancy represents a compromise with the bulge discrepancy. A related discrepancy in Figure 15 concerns the slope of the magnitude-frequency curve for $5<\mathrm{M}<6.5$, where UCERF 2 has a b-value of about 0.67 , lower than the $95 \%$ confidence bound of 0.73 for the observed b-value (Felzer, 2007a, Appendix I). 


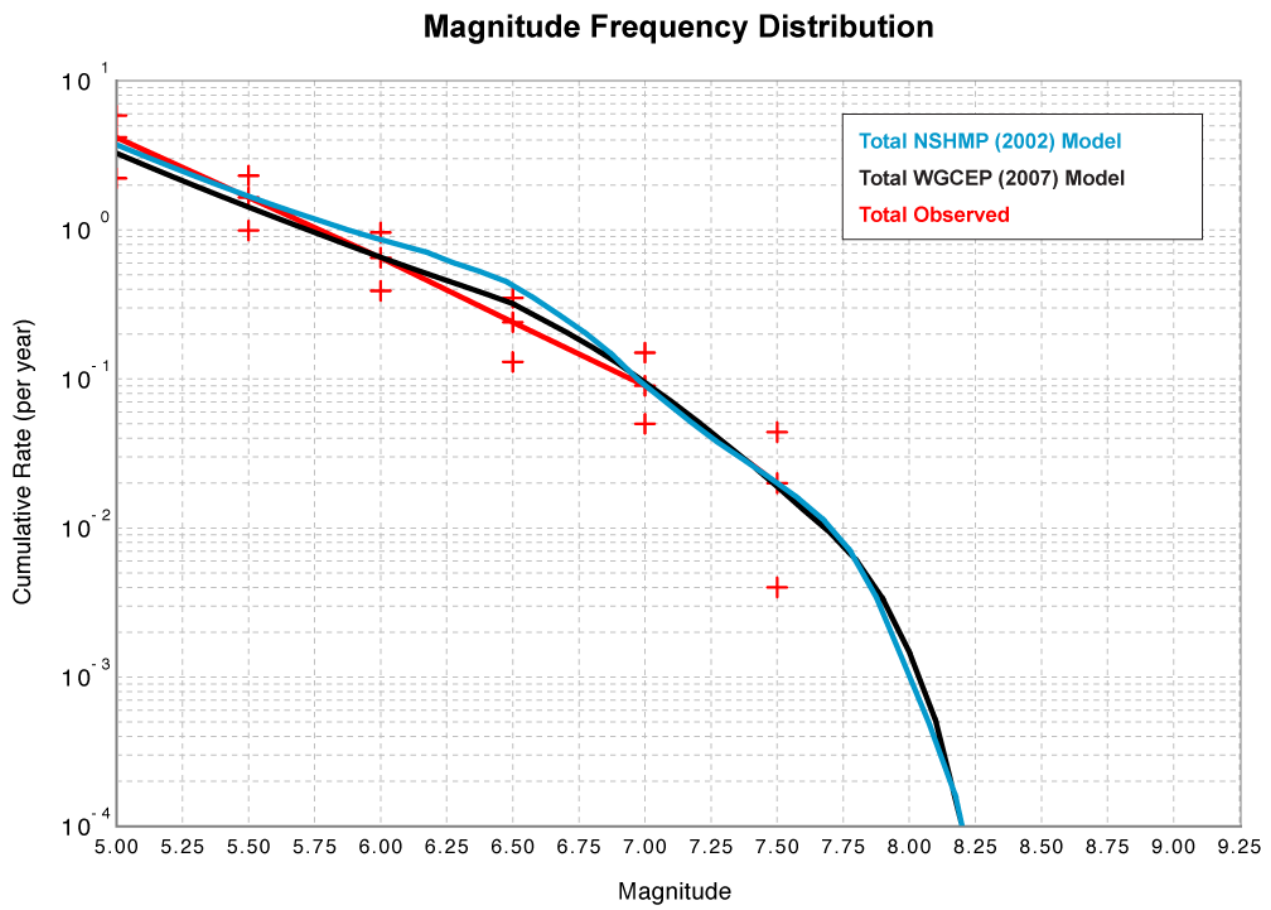

Figure 18. Comparison of cumulative, magnitude-frequency distribution of Earthquake Rate Model 2.3 with that of the NSHMP (2002) model (blue). The observed rates are plotted in red as in Figure 15. Cascadia is not included.

The rate of $M \geq 6.5$ events is mapped in Figure 19 by plotting the expected number of hypocenters per $0.1^{\circ} \times 0.1^{\circ}$ cell for a 5 -year period (again, excluding Cascadia). We can also calculate this rate by extrapolating the $M \geq 5$ rate to $M \geq 6.5$ using a b-value of 0.8 ; the ratio of these two rates is mapped in Figure 19b. The red colors on this map show where the ERM 2.3 rate is greater than the extrapolated rate are thus identify the model elements that contribute to the bulge. These include nearly all Type-A and Type-B faults, as well as all Type-C zones except the Sierra Frontal shear zone.

Within the UCERF 2 model framework, the potentially important issues related to the bulge are: (a) the segmentation of faults and assumed characteristic magnitude-frequency distribution, (b) the exclusion of fault-to-fault ruptures that link up Type-B and Type-A faults, (c) uncertain geologic fault slip rates and shear rigidity assumptions, (d) uncertainties on upper and lower seismogenic depth or other aseismic effects, and (e) uncertainties on magnitude-area relationships.

The overestimate of $6.0>\mathrm{M}>7.0$ earthquakes is likely to be a consequence of the characteristic magnitude-frequency distribution applied to our Type-A and Type-B faults. By characteristic, we mean that the rate of events near the largest magnitudes is high compared to the extrapolation of a GutenbergRichter from the observed rate at lower magnitudes (Schwartz and Coppersmith, 1984). Since the vast majority of fault sources have maximum magnitudes near 7.0, at least as currently defined, then the total sum over all faults will inevitably have relatively high rates at these magnitudes. Therefore, the background seismicity must have an anti-bulge in order to match a Gutenberg-Richter for the entire region. For this reason, the background seismicity rate was reduced by a factor of 3 for $M \geq 6.5$ events (see §D.6), which explains why the ratio for the background seismicity in Figure 19b is less than unity 
(blue). This modification appreciably reduced the bulge between the NSHMP (2002) and the current model (Figure 18).

Alternatively, the assumed characteristic magnitude-frequency distribution for faults may be incorrect. For example, most of forecasts submitted as part of the Regional Earthquake Likelihood Models (RELM) project (Field, 2007a) assumed that every point in space exhibits a Gutenberg-Richter distribution of hypocenters, which is incompatible with the characteristic magnitude-frequency distribution for faults. Further research on how real faults behave is clearly warranted.

Predicted Rate of $M \geq 6.5$

5 year probability

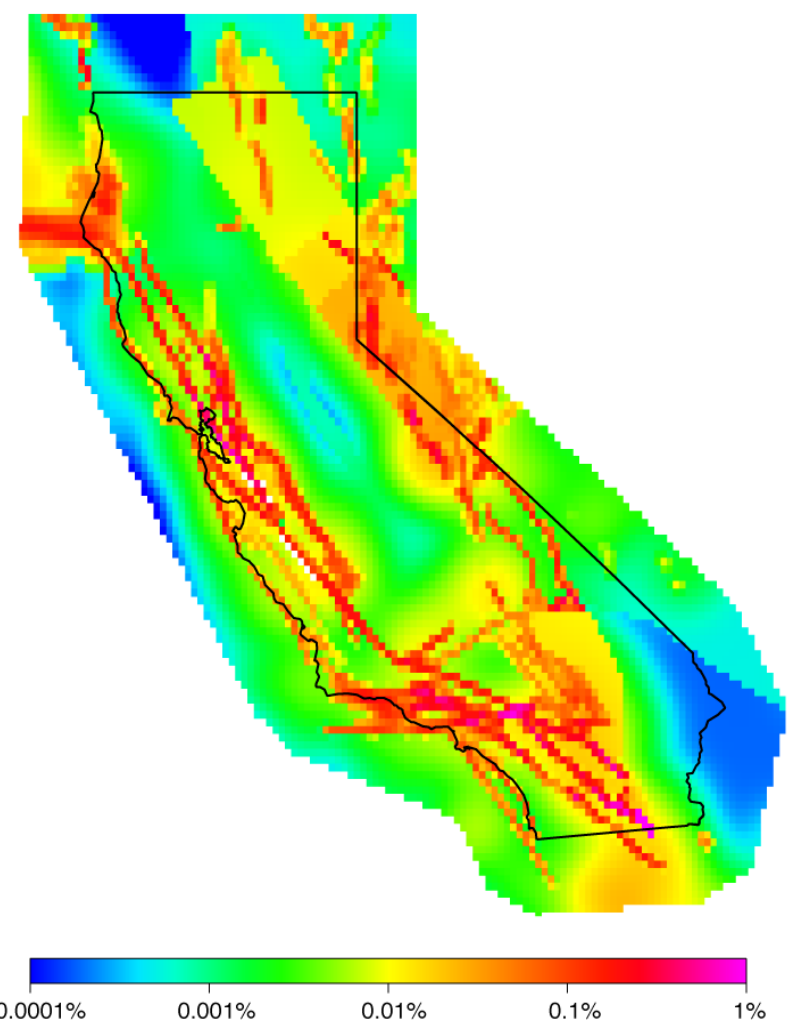

Ratio of Predicted Rate of $M \geq 6.5$ to

Extrapolated Rate from $M=5$

5 year probability

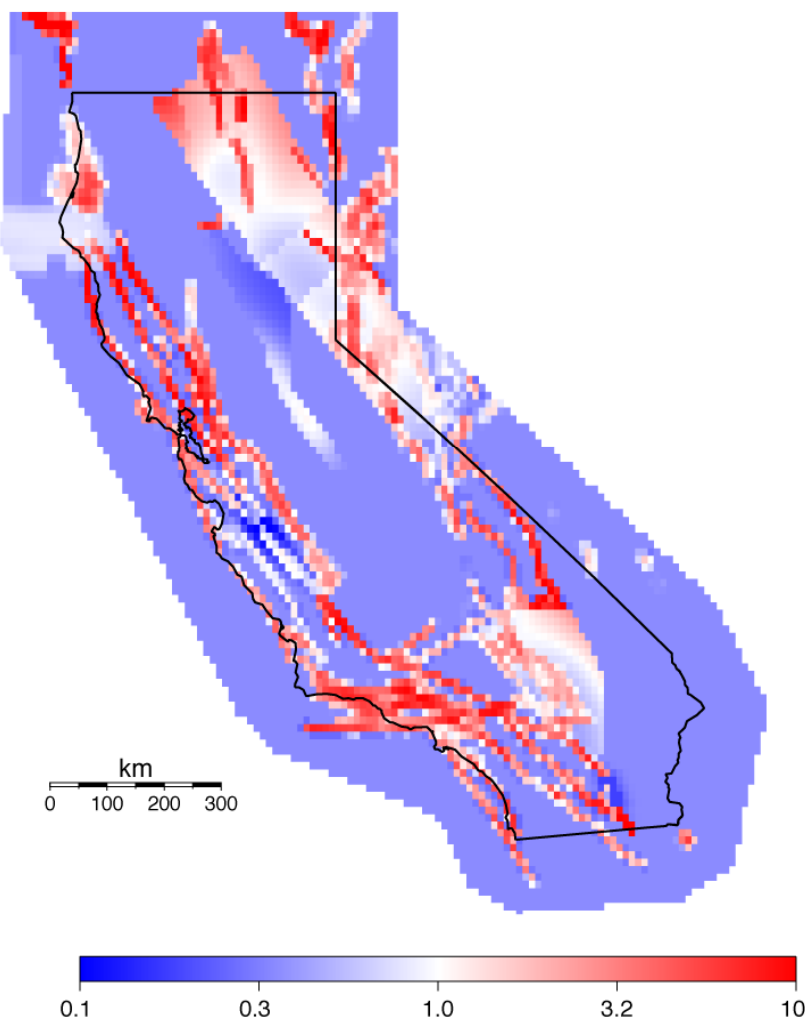

Figure 19. Map on the left shows the expected number of $M \bullet 6.5$ hypocenters in $0.1^{\circ} \times 0.1^{\circ}$ bins in a 5 year period, predicted by Earthquake Rate Model 2.3. Map on the right shows the ratio obtained by dividing this expected value by the number of $M \bullet 6.5$ events extrapolated from the expected number of $\mathrm{M} \bullet 5.0$ events using a b-value of 0.8 . The hot colors on the right therefore indicate areas that have a greater number of $\mathrm{M} \bullet 6.5$ events than predicted by the Gutenberg-Richter distribution; i.e., these areas contribute to the "bulge" discussed in the text. Cascadia is not included. 

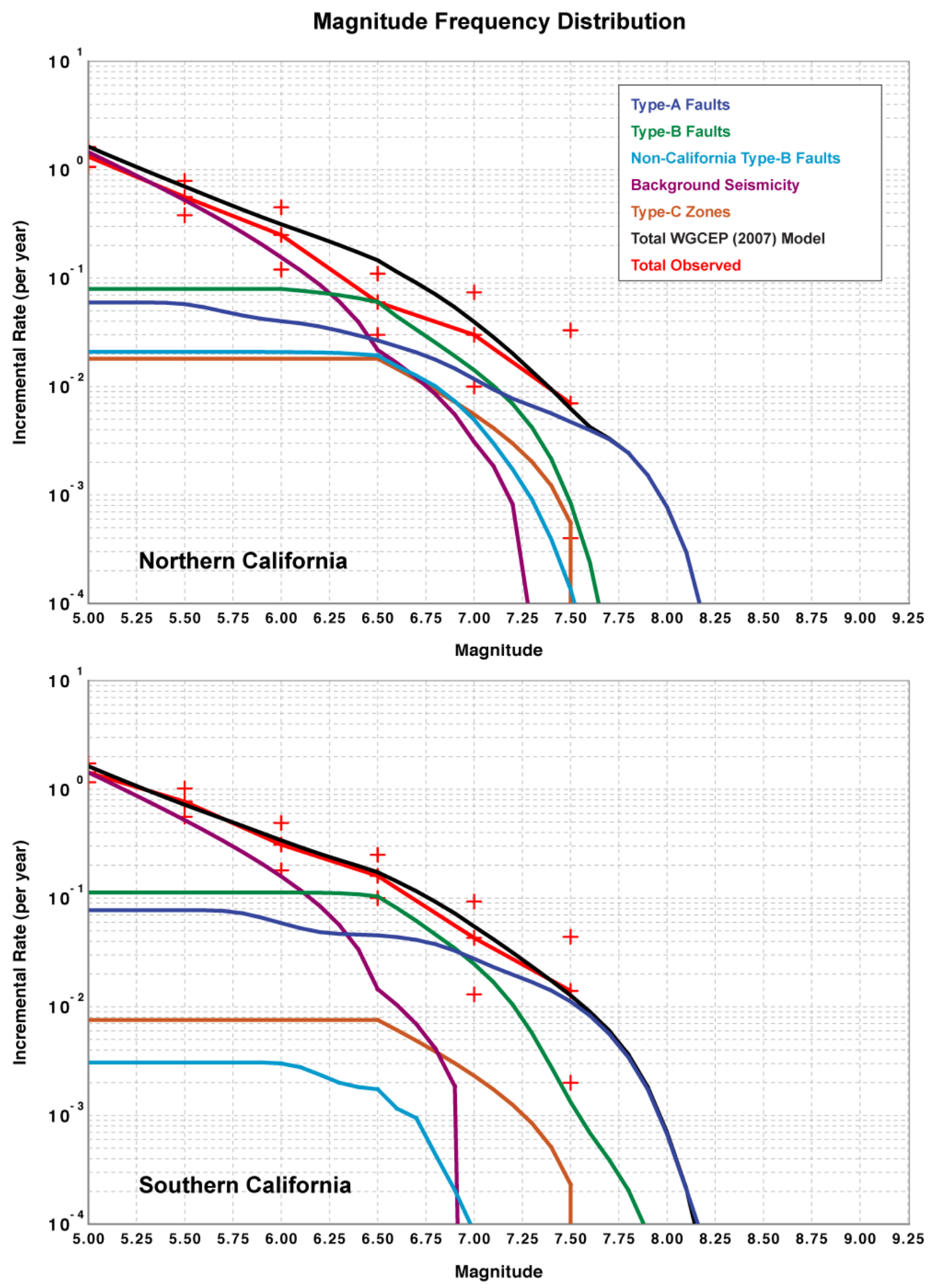

Figure 20. As Figure 15, but separated into northern California (A) versus southern California (B). Note here, however, that Type-B faults are not separated into their characteristic versus Gutenberg-Richter components. Cascadia is not included. 
Another culprit for the bulge could be fault-to-fault ruptures not represented in ERM 2.3. A (nonCalifornian) example is the 2002 Denali earthquake, which began on the Susitna Glacier fault, jumped onto the Denali fault, and then jumped off onto the Totschunda fault rather than taking an obvious extension of the Denali fault (Eberhart-Phillips et al., 2003). The 1992 Landers earthquake is another example that, until it happened, was not included in the NSHMP models. Allowing more fault-to-fault ruptures in the model would, to some extent, reduce the rate of intermediate sized events and increase the rate of larger events. Even if such fault-to-fault ruptures are rare, they may release enough seismic moment to significantly reduce the rate of events near M 6.5.

We also tested the magnitude-frequency distributions of the UCERF 2 model by dividing the state into the northern and southern regions shown in Figure 1 (Figure 20). The model fits the observed seismicity rates better in southern California, where the rate is higher. In comparison, the model rate for northern California region shows a bulge similar to the statewide distribution, exceeding the $95 \%$ confidence intervals on observed rates at $M \geq 6.5$. Contributing to this mismatch is an apparent decrease (anti-bulge) in the observed rate, though we note that a Gutenberg-Richter distribution can be adjusted to pass through the $95 \%$ confidence limits on the observed rates.

Integrated Strain Tensor Test. To test the UCERF 2 deformation and earthquake rate models, we constructed strain tensors for the model region and compared them to predictions from the far-field Pacific-North American plate motion. Conceptually, strain tensors measure the net change in shape of a box (3-D volume) associated with the deformation caused by all of the faults (in a deformation model) or earthquakes (in a source model) within the box. In this test, we compared the resulting magnitude and orientation of principal strain axes calculated from the strain tensors with the same values expected for the plate motion deforming equivalent volumes. We used the Kostrov (1974) method as presented in Aki and Richards (1980); details of our data input, calculations, results, references describing the limitations of the method, and additional discussion are included in Appendix P (Wisely et al., 2007). We have considered seven 3-D volumes oriented perpendicular to the plate boundary (Figure 21); the results summarized in Table 9. Data input include the slip rates of all Type-A and Type-B faults and the shear across Type-C zones, the rate of background seismicity (assumed to have the same style as the faults or modeled earthquakes in the same volume), the depths of the faults, and the thickness of the block being deformed.

For the entire region, our deformation model accounts for 90 to $96 \%$ of the plate motion (depending upon average fault depths, Table 9) and is consistent with simple shear parallel to the plate boundary (i.e. has calculated principal strain axes oriented only $5.9^{\circ}$ from those produced by plate motion and minimal, $3.8 \%$, crustal thickening, Table 9). The 5-10\% differences between our model and values expected for the plate boundary are almost certainly within the combined uncertainties (see Appendix P for discussion of uncertainty ranges). If significant, the additional strain implied by the slightly greater plate motion $(\sim 10 \%)$ may be accommodated aseismically. The results agree quite well with the line integrals discussed above, especially for regions dominated by long, highly active strike slip faults aligned sub-parallel to the plate boundary. Interestingly, in the Los Angeles region (represented by the Transverse Ranges path integral, Figure 8) the strain tensor approach appears to capture the entire plate motion, whereas the line 
integral does not. This is probably because a 3-D volume is a better way to characterize the many discontinuous faults in this region than attempting to draw a representative path across a subset of them.

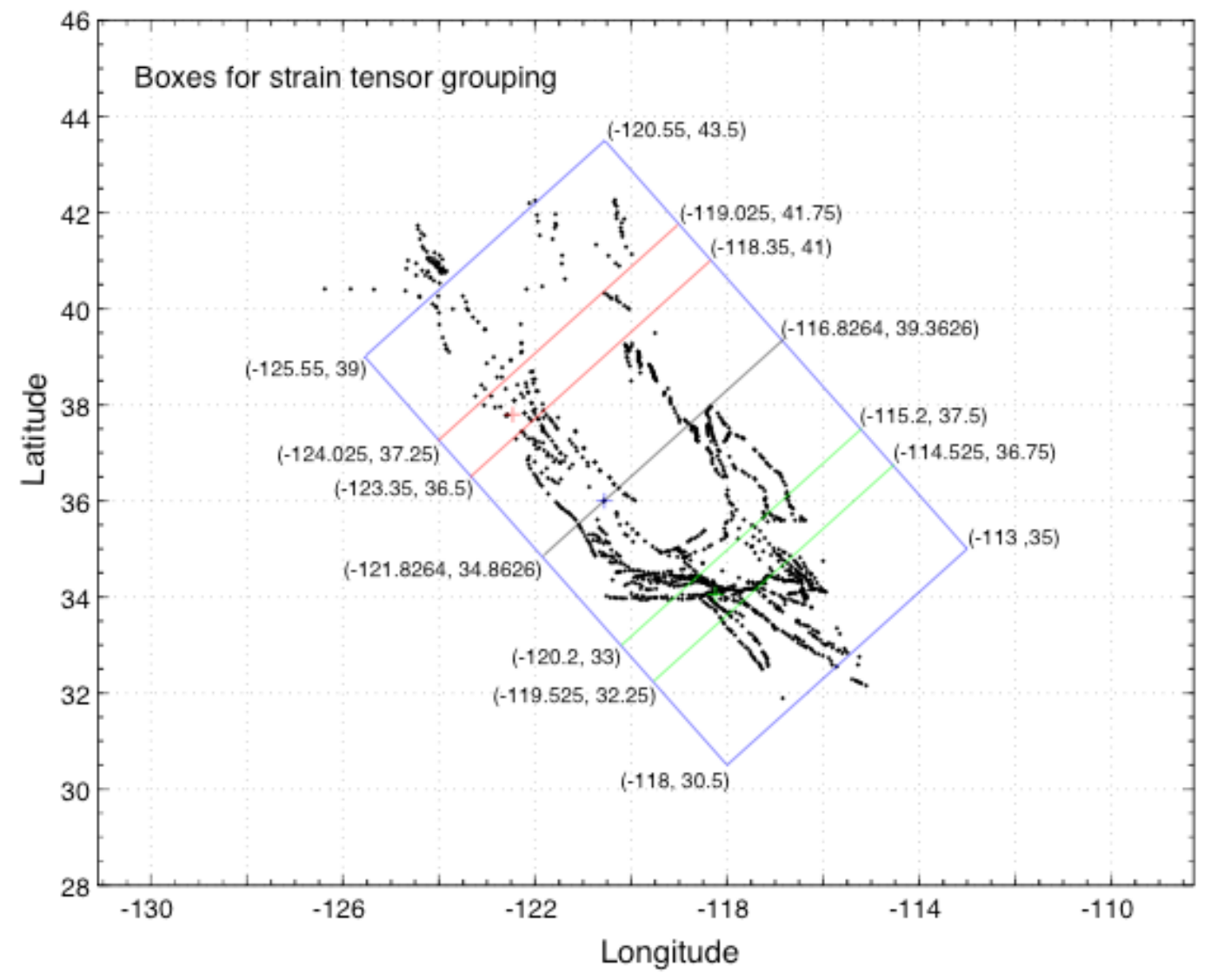

Figure 21. Locations of crustal volumes used for strain tensor analysis; depths of each volume included in Table 4 of Appendix P (Wisely et al., 2007). Black dots are boundaries between linear sections of included faults. Blue box is the extent of the Pacific/North America boundary within the US; black line splits the region into north and south at the northern end of the Parkfield section and the southern end of the Creeping section of the San Andreas fault (blue +); red is a box centered on the Bay Area and green a box centered on Los Angeles.

To explore the difference between northern and southern California, we split the region in half, perpendicular to the plate boundary, through the northern end of the Parkfield section of the San Andreas fault (southern end of the Creeping section), and considered $\sim 100 \mathrm{~km}$ wide boxes centered on San Francisco and Los Angeles (Figure 21). All subregions approximate the plate motion in strain rate, the orientation of calculated principal strain axes, and the small fraction of thickening or thinning of the boxes consistent with the transform plate margin (Table 9).

We also calculated how much strain is accounted for by earthquakes within our model (i.e. excluding aseismic slip that contributes to our deformation model and the plate rate). For the entire region, our seismic source model accounts for $\sim 70 \%$ of the plate motion $(64.6 \%$ plus an estimated $5 \%$ for aftershocks that are not included in the model). This is very consistent with the global average seismic component of strike-slip plate boundaries (Bird \& Kagan, 2004). 
Table 9. Integrated strain tensor test of the ERM 2.3 Model.

\begin{tabular}{|l|c|c|c|c|c|c|}
\hline \multirow{2}{*}{ Block } & \multicolumn{3}{|c|}{ Deformation Model } & \multicolumn{3}{c|}{ Source Model } \\
\cline { 2 - 7 } & $\begin{array}{l}\text { Accommodated } \\
\text { by Model (1) }\end{array}$ & $\begin{array}{l}\text { Angular } \\
\text { Difference } \\
(2)\end{array}$ & $\begin{array}{l}\text { Vertical } \\
(3)\end{array}$ & $\begin{array}{l}\text { Angular } \\
\text { Accommodated } \\
\text { by Model (1) }\end{array}$ & $\begin{array}{l}\text { Angfference } \\
\text { (2) }\end{array}$ & $\begin{array}{l}\text { Vertical } \\
(3)\end{array}$ \\
\hline $\begin{array}{l}\text { Entire } \\
\text { Region }\end{array}$ & $90.8 \%$ & $-5.9^{\circ}$ & $3.8 \%$ & $64.6 \%$ & $-6.7^{\circ}$ & $3.5 \%$ \\
\hline North 1/2 & $95.9 \%(4)$ & $-3.0^{\circ}$ & $-1.6 \%$ & $56.7 \%$ & $-1.3^{\circ}$ & $-1.6 \%$ \\
\hline South 1/2 & $95.2 \%(4)$ & $-10.2^{\circ}$ & $8.6 \%$ & $78.4 \%$ & $-10.7^{\circ}$ & $7.9 \%$ \\
\hline $\begin{array}{l}\text { San } \text { Francisco } \\
\text { North of } \\
\text { Bay Area }\end{array}$ & $90.9 \%$ & $-2.3^{\circ}$ & $1.9 \%$ & $67.1 \%$ & $-1.9^{\circ}$ & $1.9 \%$ \\
\hline $\begin{array}{l}\text { Los } \\
\text { Angeles }\end{array}$ & $101.0 \%$ & $-13.5^{\circ}$ & $16.5 \%$ & $84.4 \%$ & $-12.6^{\circ}$ & $14.9 \%$ \\
\hline $\begin{array}{l}\text { South of } \\
\text { LA area }\end{array}$ & $85.7 \%(5)$ & $-5.5^{\circ}$ & $0.6 \%$ & $68.8 \%(5)$ & $-6.8^{\circ}$ & $0.6 \%$ \\
\hline
\end{tabular}

(1) Percentage of Pacific - North America plate motion accommodated by the model (calculated as the ratio of the maximum principal strain axes presented in Appendix P (Wisely et al., 2007)).

(2) Angular difference between the orientation of principal strain axes of the model and average Pacific North America plate motion; positive is more northerly and negative more westerly.

(3) Percentage of thickening (positive) or thinning (negative) of the block relative to the simple shear component (ideal Pacific - North America plate motion has only simple shear and thus should have zero block thickening or thinning).

(4) These values do not average to the State total because each box is calculated with the average depth of all of the faults in the box. If one fixes the thickness of the boxes to the State average $(\sim 13 \mathrm{~km})$ one would calculate $88.7 \%$ for the northern $1 / 2$ and $98.7 \%$ for the southern $1 / 2$. Since the average depth of faulting is a real difference between northern and southern California it is more appropriate to use the different average depths of each half to compare to the plate boundary total.

(5) This value is very sensitive to the rate and orientation of shear applied to the Imperial C-zone and the spatial cut off of the block being considered (since the density of mapped faults drops dramatically into Mexico). An early calculation using the Imperial C-zone of Rate Model 2.2 and a slightly different spatial cut off yielded 115\%. Because the Imperial C-zone is given zero value in our current source model, the percent of shear in our source model is as accurate as other boxes.

Several detailed differences are worth noting. The San Francisco region matches the regional rates very closely and shear is almost exactly aligned with the plate motion, suggesting that this region is very well modeled. The regions north of San Francisco and south of Los Angeles are a bit high and low, respectively (Table 9). As discussed in Appendix P (Wisely et al., 2007), these regions are very sensitive to where the model is cut off, due to the transition to Cascadia to the north and the lack of mapped faults in Mexico to the south. Alternative choices lead to significantly different results. The Los Angeles region is slightly higher than expected, probably due to the detailed location of the box, which captures most of the thrust faults in the Transverse Ranges and the major regional strike slip faults. The seismic components for northern and southern California are $56.7 \%$ and $78.4 \%$ respectively. This difference is almost certainly significant and is due to the fact that the northern California block contains the creeping section of the San Andreas fault, major faults in the Bay Area have significant aseismicity factors, and the rapidly slipping eastern California Type-C zone is given a $50 \%$ aseismicity factor. In addition, the 
southern California block has many more Type-B faults that are reverse in style; owing to their low dip and lack of aseismicity, they contribute significantly to the seismic component of the strain. We conclude that the difference between northern and southern California represents real differences in the seismic component of the strain across the plate boundary and not a bias in the model.

In summary, our deformation model is remarkably consistent along the entire length of the plate boundary in California and very consistent in both magnitude and style with the plate motion that drives it. Our source model contains about the right fraction of the plate motion, based on comparison with global averages for strike slip boundaries (Bird \& Kagan, 2004), and contains variations along strike that are consistent with known variations in fault styles and their creep rates across the State.

Historical Seismicity Test of Source-Type Distribution. We compared the rates of historic $M \geq 6.5$ earthquakes assigned to Type-A, B, C, and background sources with those expected by the UCERF 2 earthquake rate model. In the 157 years since the catalog start date, there have been 41 earthquakes plus 5 probable foreshocks or aftershocks with $\mathrm{M} \geq 6.5$ in the study region, which compares with 50 predicted for the next 157-year period from UCERF 2.

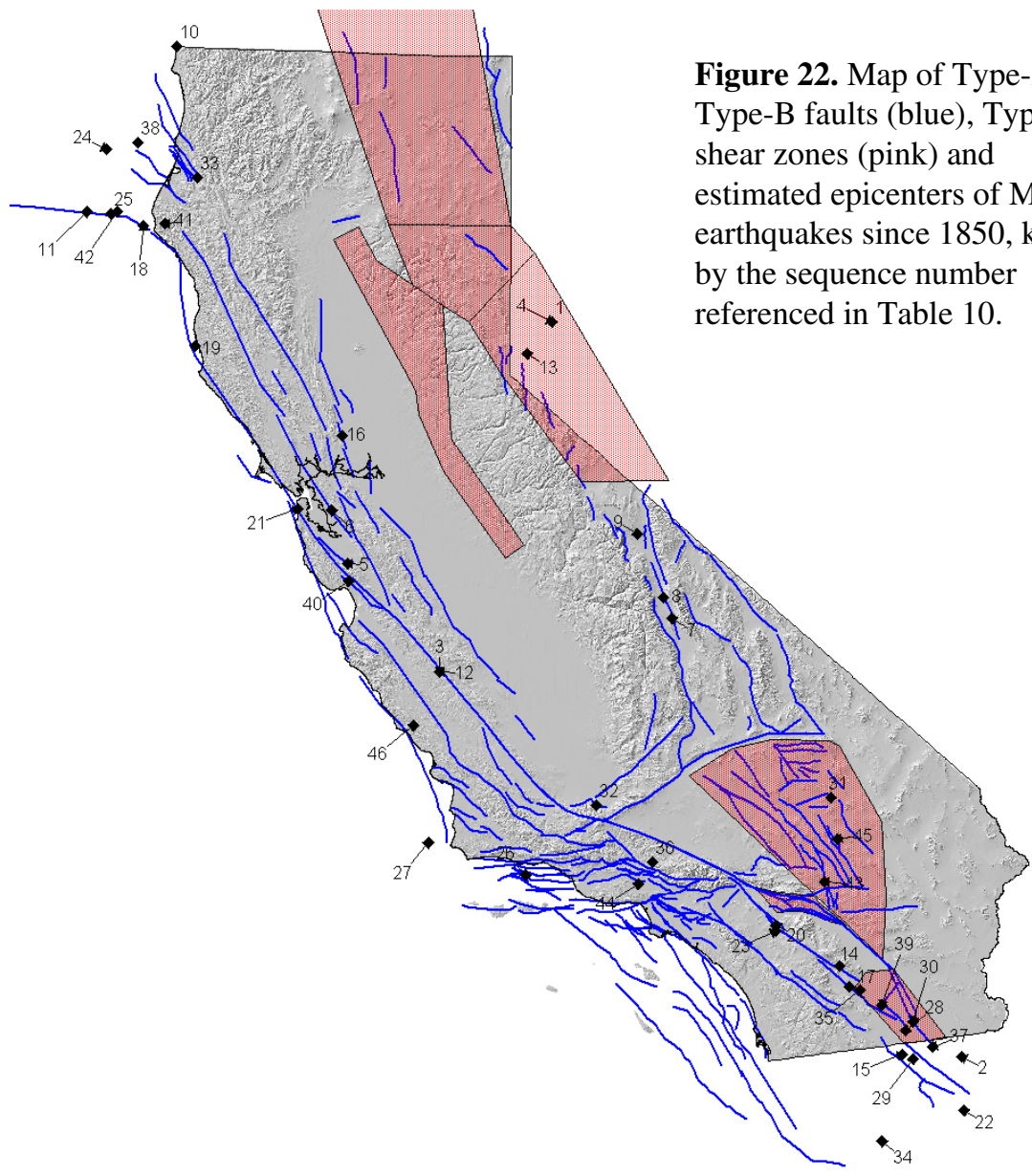

Although the location uncertainties make the assignments difficult, especially for the older events, we estimated that 10 were Type-A sources, 17 were Type-B, 3.5 were Type-C, and 15.5 were background ( 7 
from the special Gorda Plate background zone). If an earthquake is attributed to multiple sources, we split its contribution to these totals. From Table 8, we can calculate that the corresponding UCERF 2 expected numbers are approximately $11,26,4$, and 6 , respectively. The largest discrepancy is the over-prediction of Type-B sources by the model; however, given the uncertainties and small-sample statistics, its significance can be questioned.

Table 10. Assignment of likely source faults to the historic $\mathrm{M} \bullet 6.5$ California earthquakes.

\begin{tabular}{|c|c|c|c|c|c|c|c|}
\hline ID & Date & Lat & Lon & Mag & Loc Err & Fault & Source Type \\
\hline 1 & January 1,1852 & 39.5 & -119.5 & 7.3 & NA & & $\mathrm{B}$ or $\mathrm{C} ?$ \\
\hline 2 & November 29, 1852 & 32.5 & -115 & 6.5 & 100 & & $\mathrm{~B}$ ? \\
\hline 3 & January 9,1857 & 36.2 & -120.8 & 7.9 & 25 & San Andreas & A \\
\hline 4 & March 15, 1860 & 39.5 & -119.5 & 6.5 & 100 & Olinghouse? & $\mathrm{B}$ or $\mathrm{C}$ ? \\
\hline 5 & October 8, 1865 & 37.2 & -121.9 & 6.5 & 25 & & $\begin{array}{l}\text { background, } \\
\text { possibly A }\end{array}$ \\
\hline 6 & October 21,1868 & 37.7 & -122.1 & 7 & 25 & Hayward & A \\
\hline 7 & March 26, 1872 & 36.7 & -118.1 & 7.6 & 25 & Owens Valley & B \\
\hline 8 & March 26, 1872* & 36.9 & -118.2 & 6.8 & 100 & Owens Valley & B \\
\hline 9 & April 11, 1872* & 37.5 & -118.5 & 6.8 & 100 & & B \\
\hline 10 & November 23, 1873 & 42 & -124.2 & 6.9 & 100 & & $\begin{array}{l}\text { Gorda plate } \\
\text { background }\end{array}$ \\
\hline 11 & May 9, 1878 & 40.4 & -125.2 & 7 & 100 & & background \\
\hline 12 & April 12, 1885 & 36.2 & -120.8 & 6.5 & 100 & San Andreas & A \\
\hline 13 & June 3, 1887 & 39.2 & -119.8 & 6.5 & 50 & & $\mathrm{~B}$ or $\mathrm{C}$ ? \\
\hline 14 & February 9, 1890 & 33.4 & -116.3 & 6.8 & NA & & $\mathrm{B}$ or $\mathrm{C}$ ? \\
\hline 15 & February 24, 1892 & 32.55 & -115.65 & 7.3 & 50 & Laguna Salada? & B \\
\hline 16 & April 19, 1892 & 38.4 & -122 & 6.6 & 25 & Great Valley? & B \\
\hline 17 & May $28,1892 *$ & 33.2 & -116.2 & 6.5 & NA & & A or $\mathrm{C}$ ? \\
\hline 18 & September 30, 1894 & 40.3 & -124.5 & 6.5 & 100 & & $\begin{array}{l}\text { Gorda plate } \\
\text { background }\end{array}$ \\
\hline 19 & April 15, 1898 & 39.2 & -123.8 & 6.7 & 50 & San Andreas? & A or background \\
\hline 20 & December 25, 1899 & 33.8 & -117 & 6.7 & 25 & San Jacinto? & A \\
\hline 21 & April 18, 1906 & 37.7 & -122.5 & 7.8 & 25 & San Andreas & A \\
\hline 22 & November 21, 1915 & 32 & -115 & 6.6 & NA & Cerro Prieto? & background \\
\hline 23 & April 21, 1918 & 33.75 & -117 & 6.8 & 25 & San Jacinto? & A \\
\hline 24 & July 15,1918 & 41 & -125 & 6.5 & NA & & $\begin{array}{l}\text { Gorda plate } \\
\text { background }\end{array}$ \\
\hline 25 & January 22, 1923 & 40.4 & -124.9 & 7.2 & NA & & $\begin{array}{l}\text { Gorda plate } \\
\text { background }\end{array}$ \\
\hline 26 & June 29,1925 & 34.3 & -119.8 & 6.8 & 25 & & B \\
\hline 27 & November 4, 1927 & 34.6 & -120.9 & 7.1 & 30 & & background \\
\hline 28 & December $30,1934^{+}$ & 32.77 & -115.604 & 6.5 & 25 & Cerro Prieto? & B or background \\
\hline 29 & December 31, 1934 & 32.51 & -115.533 & 7 & 5 & Cerro Prieto? & B or background \\
\hline 30 & May 19,1940 & 32.85 & -115.52 & 6.9 & 5 & Imperial & B \\
\hline 31 & April 10, 1947 & 34.983 & -116.331 & 6.5 & 5 & Manix & $\mathrm{C}$ \\
\hline 32 & July 21,1952 & 34.958 & -118.998 & 7.5 & 5 & White Wolf & B \\
\hline 33 & December 21, 1954 & 40.78 & -123.87 & 6.6 & NA & & background \\
\hline 34 & February 9, 1956 & 31.75 & -115.917 & 6.5 & 25 & San Miguel & background \\
\hline 35 & April 9, 1968 & 33.17 & -116.087 & 6.6 & 5 & San Jacinto - Borrego section & A \\
\hline 36 & February 9, 1971 & 34.42 & -118.37 & 6.6 & 5 & Sierra Madre San Fernando & $\mathrm{B}$ \\
\hline ID & Date & Lat & Lon & Mag & Loc Err & Fault & Source Type \\
\hline 37 & October 15,1979 & 32.61 & -115.318 & 6.51 & 5 & Imperial & $\mathrm{B}$ \\
\hline
\end{tabular}




\begin{tabular}{|c|c|c|c|c|c|c|c|}
\hline 38 & November 8, 1980 & 41.08 & -124.62 & 7.3 & 5 & & $\begin{array}{l}\text { Gorda plate } \\
\text { background }\end{array}$ \\
\hline 39 & November 24, 1987 & 33.02 & -115.852 & 6.51 & 1 & $\begin{array}{l}\text { San Jacinto - Superstition } \\
\text { Hills section }\end{array}$ & A \\
\hline 40 & October 18,1989 & 37.04 & -121.88 & 6.89 & 1 & San Andreas? & background or A \\
\hline 41 & April 25, 1992 & 40.33 & -124.23 & 7.15 & 5 & Cascadia? & $\begin{array}{l}\text { Gorda plate } \\
\text { background }\end{array}$ \\
\hline 42 & April 26, 1992* & 40.42 & -124.832 & 6.6 & 5 & & $\begin{array}{l}\text { Gorda plate } \\
\text { background }\end{array}$ \\
\hline 43 & June 28, 1992 & 34.2 & -116.437 & 7.29 & 1 & $\begin{array}{l}\text { Johnson Valley, Homestead } \\
\text { Valley, Emerson, Camp Rock }\end{array}$ & $\mathrm{B}$ \\
\hline 44 & January 17, 1994 & 34.21 & -118.537 & 6.65 & 1 & Northridge & B \\
\hline 45 & October 16, 1999 & 34.59 & -116.271 & 7.12 & 1 & Lavic Lake, Bullion & B \\
\hline 46 & December 22, 2003 & 35.7 & -121.097 & 6.55 & 2 & & background \\
\hline
\end{tabular}

\footnotetext{
* Probable aftershock

+ Probable foreshock
} 


\section{E. Probability Models}

Our model development up to this point was tightly coordinated with NSHMP, so that both the 2007 revisions of national seismic hazard maps and UCERF 2 are based on the same long-term earthquake rate model for California, ERM 2.3. To create an earthquake rupture forecast from ERM 2.3, we must add a probability model that specifies how events are distributed in time (see Figure 4). The simplest assumption is that earthquakes occur randomly in time at a constant rate; i.e., they obey Poisson statistics. This model, which is used in constructing the national seismic hazard maps, is "time independent" in the sense that the probability of each earthquake rupture is completely independent of the timing of all others.

Here we depart from the NSHMP (2007) conventions by considering "time-dependent" earthquake rupture forecasts that condition the event probabilities for the Type-A fault segments on the date of the last major rupture. Such models, which have been the focus of the previous WGCEP studies, are motivated by the elastic rebound theory of the earthquake cycle (Reid, 1911; NRC, 2003); they are based on stress-renewal models, in which probabilities drop immediately after a large earthquake releases tectonic stress on a fault and rise as the stress re-accumulates due to constant tectonic loading of the fault.

The earthquake probability models we explored included the five used by the WGCEP (2003), the two general classes of models applied to southern California faults in UCERF 1 (Petersen et al., 2007a), and a few other candidates. This section briefly discusses each of these options and justifies the weights assigned to the time-dependent branches of the UCERF 2 logic tree, which are shown in Figure 4d. We also summarize the time-dependent model developed for the Cascadia subduction zone by Frankel and Petersen (2007; Appendix L).

\section{E.1. WGCEP (2003) Probability Models}

WGCEP (2003) applied five types of probability models: (1) the Poisson model; (2) the Brownian Passage Time (BPT) model, also know as the inverse Gaussian model (Kagan and Knopoff, 1987; Matthews et al., 2002); (3) a "BPT-Step" model that accounted for Coulomb stress change effects of a previous earthquake; (4) a "Time-Predictable" model, and (5) an "Empirical" model (Reasenberg et al., 2003) based on historic changes in seismicity rates. These are discussed by WGCEP (2003) and summarized by Field (2007a).

The Poisson model computes the probability of one or more events as $1-\mathrm{e}^{-R \Delta T}$, where $\Delta T$ is the forecast duration and $R$ is the long-term rate of the earthquake rupture. The BPT models and the TimePredictable models are stress-renewal models that involve computing the probability each segment will rupture, conditioned on the date of last event, and then mapping these probabilities onto the various possible ruptures according to the relative frequency of each (from the long-term rate model) and the probability that each segment will nucleate each event. Further details are given in Appendix N (Field and Gupta, 2007), where it is shown that there exists a self-consistency problem with the WGCEP (2003) methodology for converting segment probabilities into both single and multi-segment rupture probabilities. Specifically, the distribution of segment recurrence intervals assumed by the model, $a$ priori, does not agree with that produced by simulating events using the model. As long as there are a small number of segments, however, the method does not drastically bias event or moment rates, and does 
honor the overall intent of elastic rebound theory. A few promising alternative approaches are discussed in Appendix N (Field and Gupta, 2007), but none are vetted enough for application at this time. Therefore, we place the WGCEP (2003) methodology, and their BPT model in particular, in the category of best-available science.

The BPT-Step model included a modification of segment probabilities based on Coulomb stresschange calculations of up to one previous event on each fault. We do not feel that application of the BPTStep model is warranted for UCERF 2 for the following reasons: (1) there are large uncertainties associated with such calculations (Hardebeck, 2004; Parsons, 2005), and nowhere in California do we believe present results would rise above these uncertainties; (2) this model did not significantly impact the mean earthquake probabilities given by WGCEP (2003); and (3) there exists an alternative hypothesis that dynamic stress changes, rather than static, are responsible for triggering earthquakes (e.g., Hill et al., 1993; Belardinelli et al., 1999; Kilb et al., 2000; Gomberg et al., 2003). Our low priority for this model was also influenced by a straw poll taken among distinguished colleagues at a workshop on timedependent earthquake probabilities in March 2007 (Table 2). If a large earthquake struck in California, we would revisit this decision, and the calculated Coulomb effects might be more pronounced.

The WGCEP (2003) applied their time-predictable model only to the northern San Andreas fault, the only fault in their study area where the average slip on each segment in the previous event could be estimated. Segment probabilities were computed according to the "time-predictable" hypothesis in which the expected time of the next event is equal to the slip of the last event divided by the slip rate (Shimazaki $\&$ Nakata, 1980). This calculation used the BPT-step model (including the correction for Coulomb stress change), and then partitioned the segment probabilities among ruptures. However, because insufficient time had elapsed to accumulate the slip necessary for the magnitude of a full northern San Andreas rupture, WGCEP (2003) multiplied the earthquake-rupture probabilities by the probability that enough slip had accumulated to produce that event. This is a version of the slip-predictable model of Shimazaki \& Nakata (1980). All the earthquake probabilities were then normalized so that the total probability of an event was unchanged.

We have chosen not to apply the WGCEP (2003) Time-Predictable model for the following reasons: (1) as discussed in Appendix N (Field and Gupta, 2007), Monte Carlo simulations revealed that slippredictable methods for computing earthquake probabilities from long-term rates significantly overpredict event rates and moment rates; and (2) data on the average slip in previous events is sparse and uncertain (Appendix B, Dawson et al., 2007a), preventing a robust application of the model.

The WGCEP (2003) empirical model was developed to explain a persistent seismicity lull following the 1906 earthquake (a factor of $\sim 4$ fewer $M \geq 5.5$ earthquakes after 1906 compared to the period beforehand). For example, elastic dislocation models (like that used in the BPT-step distribution) predict that the region should have emerged from Coulomb stress shadow caused by the 1906 event by about 1965 (WGCEP, 2003; Figures 4.5 \& 5.6), and a three-dimensional, viscoelastic model developed by Parsons (2002) predicted a stress-shadow emergence date of 1980. Thus, given the absence of an adequate physical model for the observed seismicity lull, the WGCEP (2003) Empirical model simply scaled the forecasted rate of earthquake ruptures by the ratio of recently observed seismicity rates to observed long-term rates (Reasenberg et al., 2003). They applied the following three values for these 
ratios (as logic-tree branches): $0.392,0.541$, and 0.665 , with weights of $0.1,0.5$, and 0.4 , respectively, and then computed probabilities using a Poisson model. We have developed and applied a similar model, statewide, as discussed below.

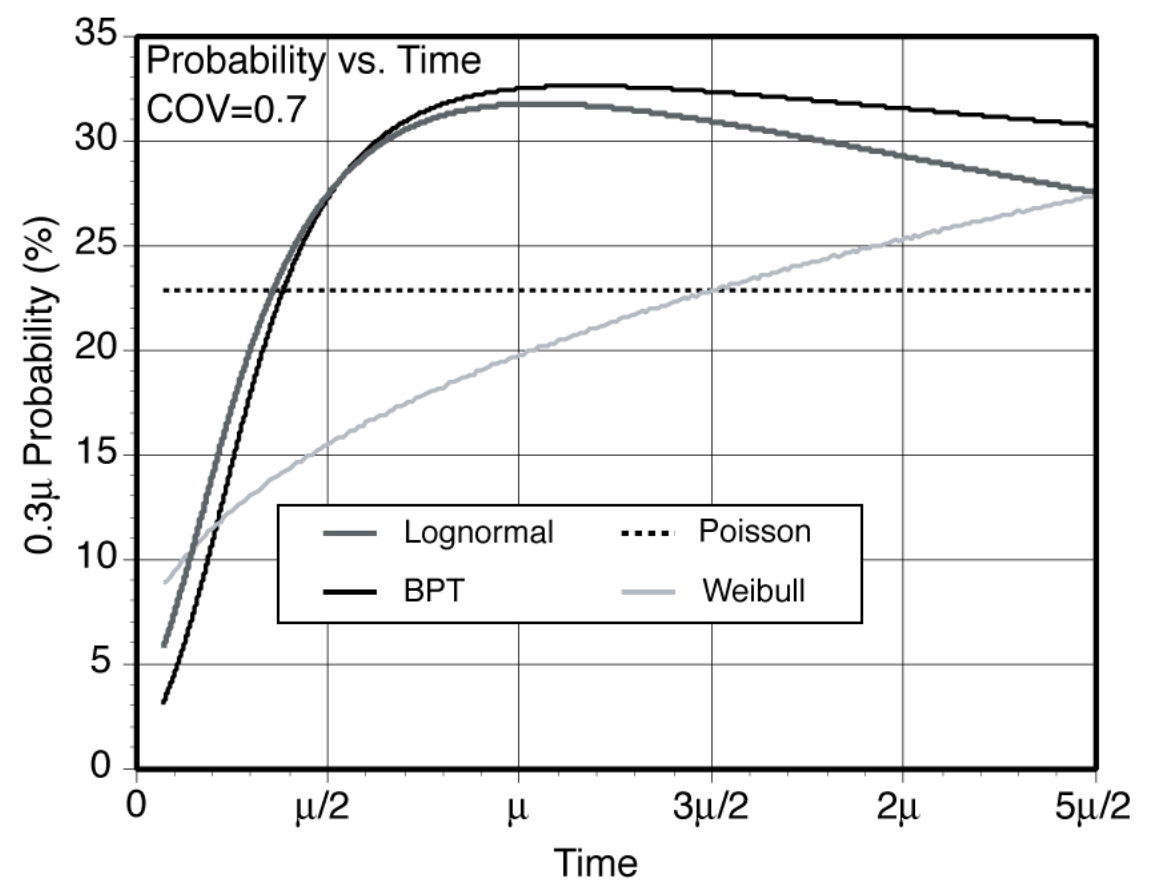

Figure 23. Comparison of conditional earthquake probability vs. time (expressed as a function of interevent time $\mu$ ) for four probability density functions.

\section{E.2. Selection of Probability Models}

In addition to the models adopted by WGCEP (2003), we considered other probability models such as the lognormal distribution (e.g., Nishenko and Buland, 1987) and the Weibull distribution (Hagiwara, 1974). The latter has been recently advocated by Rundle et al. (2006) on the basis of earthquake simulation models. The conditional probabilities derived from these models are compared with those of the Poisson and BPT models in Figure 23. We concluded that these alternatives are not warranted given the fact that overall observational and methodological uncertainties are large compared to differences in the results that would be obtained.

After careful review of available probability models, and further examination of those that have important implications on results, we have chosen the Poisson, the Brownian Passage Time (BPT) model, and a statewide empirical model. All Type- $\mathrm{C}$ zones and background seismicity are treated with the Poisson model. The WGCEP (2003) BPT model is applied only to the segmented Type-A faults, and the unsegmented model for Type-A faults is treated as Poisson because we lack a justifiable method to calculate conditional probability on unsegmented faults. Thus, $10 \%$ unsegmented and $90 \%$ segmented weight are given to the Poisson versus BPT models on Type-A faults (Figure 4d). This weighting is consistent with UCERF 1 and our expectation that unsegmented faults are more likely to exhibit Poisson 
behavior rather than renewal-type behavior. Finally, an empirical model option, described more in the next section, is applied to the Type-A and -B sources as well.

\section{E.3. Statewide Empirical Model}

This model, described in detail in Appendix M (Felzer, 2007b), provides an empirical, catalog-based measure of the current seismicity rate that can be compared to the long term average within each of 8 subregions shown in Figure 24. Following in part the WGCEP (2003) precedent, the current seismicity rate is defined as the arithmetic average of seismicity rates observed from 1906-2006, 1942-2006, and 1984-2006. The long-term rate is defined as the 1850-2006 rate, or more accurately, as the 1850-2006 rate corrected via Epidemic Type Aftershock Sequence (ETAS) simulations for the possibility of occasional events as large as $\mathrm{M}=8.3$ (because their aftershocks could significantly influence perceived rates). The ratios of the current rates to the long-term rates for the full and declustered catalogs are given in Table 11. The seismicity rate calculations for the empirical model use the methods, magnitude completeness thresholds, b-values, and magnitude error and rounding corrections presented in Appendix I (Felzer, 2007a).

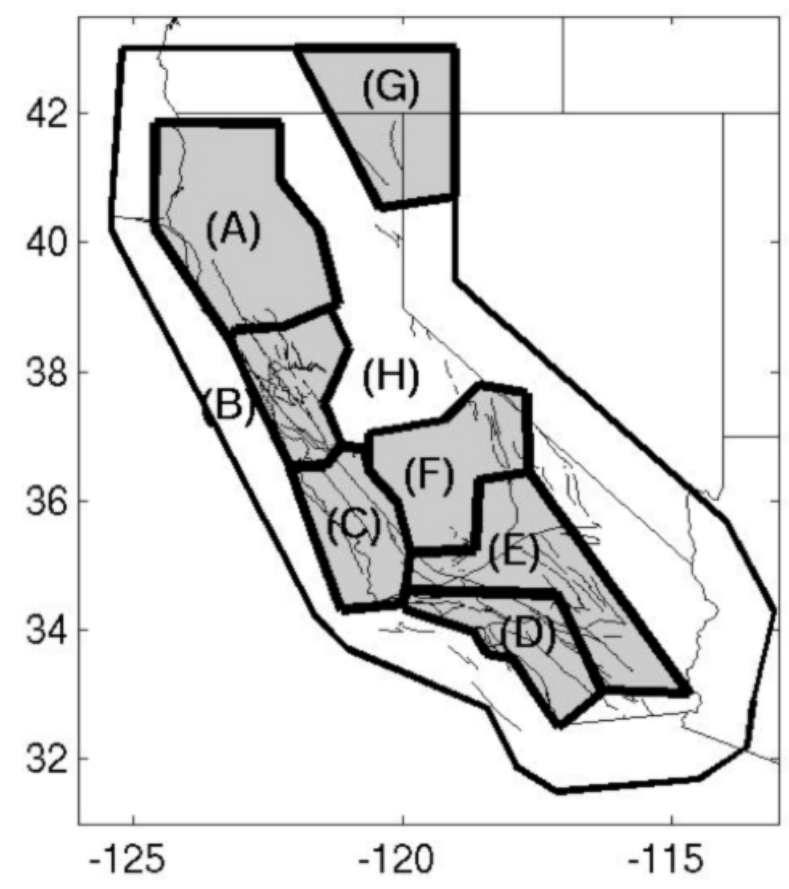

Figure 24. Map of the regions (shaded in gray) for which regional short-term and long-term rates of $\mathrm{M} \bullet 5$ events are calculated. From the top, the regions are (A) North region, (B) San Francisco region, (C) Central Coast Region, (D) Los Angeles region, (E) Mojave region, (F) Mid region, and (G) Northeast region. The rest of the area (H, unshaded) is processed as the "rest of the state". Boundaries of these regions come from Appendix I (Felzer, 2007a), where they were set to enclose areas of similar catalog magnitude completeness thresholds (which improves the rate calculation within a region). The magnitude of completeness is primarily determined by population (pre-1932) and instrumental (post-1932) density (see Appendix I). 
The empirical corrections we applied are spatially variable (Figure 24; Table 11). Thus, to make empirical probability calculations, we modified the rate of each rupture in the long-term model by the mean observed empirical rate change fractions given in Table 11 for the declustered catalog. Rates of ruptures that crossed polygon boundaries were modified by a rupture-area weighted average of the empirical rate adjustment factors from those polygons. It is important to note that this empirical model was applied only to Type-A and Type-B fault sources, because the background seismicity was already more consistent with the short-term rates and the Type-C sources already had a $50 \%$ moment rate reduction, as discussed above. Poisson probabilities were then calculated from the adjusted rates for all earthquake sources. WGCEP (2003) weighted the empirical probability models on a fault-by-fault basis, but the mean weighting of the empirical model was 0.29 . We see no clear basis for strongly altering this weight, so the empirical probability model was given a $30 \%$ weight (Figure 4 ).

Table 11. Best estimate of the ratio between current and long term seismicity rates in the different regions.*

\begin{tabular}{|l|l|l|}
\hline Region & Full catalog & Declustered catalog \\
\hline A. North & $0.71 \pm 0.52$ & $0.81 \pm 0.63$ \\
\hline B. San Francisco & $0.42 \pm 0.11$ & $0.57 \pm 0.25$ \\
\hline C. Central Coast & $0.58,-0.38,+0.62$ & $0.69,-0.41,+0.90$ \\
\hline D. Los Angeles & $0.60 \pm 0.27$ & $0.55 \pm 0.29$ \\
\hline E. Mojave & - & - \\
\hline F. Mid & $0.58 \pm 0.38$ & $0.61 \pm 0.45$ \\
\hline G. Northeast & - & - \\
\hline H. Rest of state & $0.70,-0.36,+0.58$ & $0.86,-0.34,+0.61$ \\
\hline
\end{tabular}

* The first column gives the region letter and name shown in Figure 24. The second column gives values for the full catalog and the third column for the declustered catalog. These calculations are done with our preferred $\mathrm{b}$ values of 1.0 and 0.8 for the full and declustered catalogs, respectively, and with the long term rates corrected for the possibility of maximum magnitude (M 8.3) earthquakes in California. The values to calculate these ratios were taken from Tables 5-12 of Appendix M (Felzer, 2007b). Errors on the fractional changes are given at the $98 \%$ confidence level; these are relatively large in many areas because of the significant uncertainty associated with the historic catalog rates. Ratios are not provided for the Mojave or Northeastern regions owing to the lack of long-term data.

The empirical model used in UCERF 2 differs from the WGCEP (2003) empirical model in several aspects: (1) We used catalog magnitude completeness thresholds that were more sophisticated and varied more in space and time. (2) We made corrections for magnitude error and rounding in calculating seismicity rates. (3) We made rate calculations for regions throughout the state, and for the state as whole, rather than just for the San Francisco Bay Area. (4) We used catalog data only to estimate current and future short-term seismicity rates, thus avoiding curve fitting (as in WGCEP, 2003, Figure 5.6).

WGCEP (2003) interpreted the seismicity lull embodied in their empirical model as representing a stress shadow cast in the bay area by the 1906 earthquake. It is interesting to note that the Los Angeles region has a commensurate seismicity rate change. In fact, one cannot rule out the possibility that the entire state has experienced a single, uniform drop in seismicity, raising the question of whether some 
other process is at work. We do not have a preferred interpretation, but nonetheless believe the empirical model is an important option to include at this time (regardless of the ultimate cause).

\section{E.4. Cascadia Probability Model}

The Cascadia subduction zone was treated separately from the faults inside the California state boundaries. The probability model was based on the two scenarios described in §D.7. For the M 8.0-8.7 scenario, a Poisson (time-independent) model was applied. For the M 8.8-9.2 scenario, we used a timedependent BPT distribution with an average recurrence interval of 500 years and an aperiodicity of 0.5 determined by Petersen et al. (2002) directly from the dates of coastal subsidence events at Willapa Bay reported by Atwater and Hemphill-Haley (1997). The last large M 9.0 earthquake is thought to have occurred in January, 1700, or 307 years ago (Satake et al., 2003). The resulting time-dependent probability is $8.0 \%$ for a M 9.0 earthquake in the next 30 years, somewhat higher than the $5.8 \%$ Poisson (time-independent) probability. Note that $8.0 \%$ is not the final probability for full-subduction-zone ruptures due to some fraction of the moment rate being put into the smaller, floating ruptures (as discussed above). In fact, given the inclusion of these smaller ruptures, the final model recurrence interval for the full-fault ruptures is actually 750 years, which if used would correspond to a timedependent probability of $2.6 \%$. The issue of which recurrence interval to use relates to the selfconsistency problem discussed above for the case where both single- and multi-segment ruptures are included. Appendix L (Frankel and Petersen, 2007) provides a more complete description of the timedependent model for Cascadia. 


\section{F. Results of Probability Calculations}

Here we present some representative calculations of the earthquake probabilities obtained from UCERF 2. This earthquake-rupture forecast gives the probability and magnitude of every possible $M \geq 5$ earthquake in the region for a specified time span. Each of the 480 final branches of the logic tree (Figure 4 ) is a viable forecast with an assigned probability of being the "correct" model, computed as the product of the weights of all branches associated with the forecast.

\section{F.1. Probability of What?}

Hazard and loss estimation seeks to quantify the probability of exceeding some specified ground motion, damage state, or loss metric. Technically speaking, such estimates should be computed for each logic-tree branch separately, leading to a probability distribution of possible hazard or loss estimates, from which practical decisions can be made. Doing such calculations requires coupling an earthquakerupture forecast with some ground-motion model (for hazard) and subsequently with a vulnerability or fragility function (for loss). Quantifying the loss implications of our various models is clearly beyond present scope because non-proprietary tools for doing such calculations do not yet exist. Hazard calculations are within reach, but would be limited to a narrow range of ground motion models (which were evolving rapidly during the course of this study) and intensity-measures of interest. Such studies are therefore left to future publications.

Following previous WGCEPs, we use the probability of experiencing earthquakes of various magnitudes as the "peril of merit" in quantifying the implications of UCERF 2. Specifically, in addition to giving the probability and magnitude of each discrete rupture, we cite the aggregate probability of having events greater than or equal to specified magnitudes in different regions throughout the state, on various source types, on specific faults, and on Type-A fault segments. We also calculate "participation probability" maps, which display the probabilities that an individual $0.1^{\circ} \times 0.1^{\circ}$ cell in the statewide grid will be traversed by a fault rupture (of any source type) above a specified magnitude threshold.

In these calculations, we generally cite the mean probability obtained from the 480 logic-tree branches (or interesting subsets of branches), computed using the final branch weights. We also cite the minimum and maximum probabilities obtained from the total set of branches as a measure of the spread. We emphasize that these extreme values do not represent any particular confidence level, nor do they represent absolute limits, owing to inherent limitations of the model, which does not implement every type of epistemic uncertainty. Rather, the maximum and minimum values represent extreme values within the context of our particular logic tree. All time-dependent probabilities cited here are for a start-year of 2007, and unless otherwise noted, for a forecast duration of 30 years. Detailed listings of probabilities, including those for a 5-year forecast and comparisons with results of previous studies, are given in the Supplementary Materials.

Except where otherwise stated, the probabilities of earthquakes on the Cascadia megathrust are not included in our probability calculations to order to distinguish the contributions. Cascadia probabilities have been calculated using the probability model described in §E.4 and Appendix L (Frankel and Petersen, 2007), and are presented separately (e.g., in Figure 32). 


\section{F.2. Regional Probabilities}

As a validation step, we first make a direct comparison with the main results of WGCEP (2003). Figure 25 shows the UCERF 2 cumulative "magnitude-probability distribution" for the Bay Area box considered by WGCEP (2003); i.e., the probability of having events greater than or equal to a specified magnitude within this region. The most widely cited number from the WGCEP (2002) report is a total probability of 0.62 for an $M \geq 6.7$ event in the Bay Area. As shown in Figure 25, our mean probability of 0.63 is consistent with their number; moreover, our minimum and maximum probabilities $(0.41$ and 0.84 , respectively) agree very well with their $2.5 \%$ and $97.5 \%$ confidence bounds ( 0.38 and 0.85 , respectively). The same good agreement is found with the WGCEP (2003) probabilities for $M \geq 7$ and $M \geq 7.5$ events, which are also plotted in Figure 25. The UCERF 2 logic tree has 80 branches in this region (a factor of 6 less than 480 because none of our alternative deformation models influence Bay Area ruptures), whereas WGCEP (2003) constructed a logic tree with many more branches, which they sampled by a Monte Carlo method 10,000 times to generate a full probability distribution. The agreement in Figure 25 implies that we succeeded in capturing their most important epistemic uncertainties, in part because we were guided by the comprehensive uncertainty analysis of the WGCEP (2003) report.

\section{Magnitude Probability Distribution from All Sources WGCEP (2003) Region}

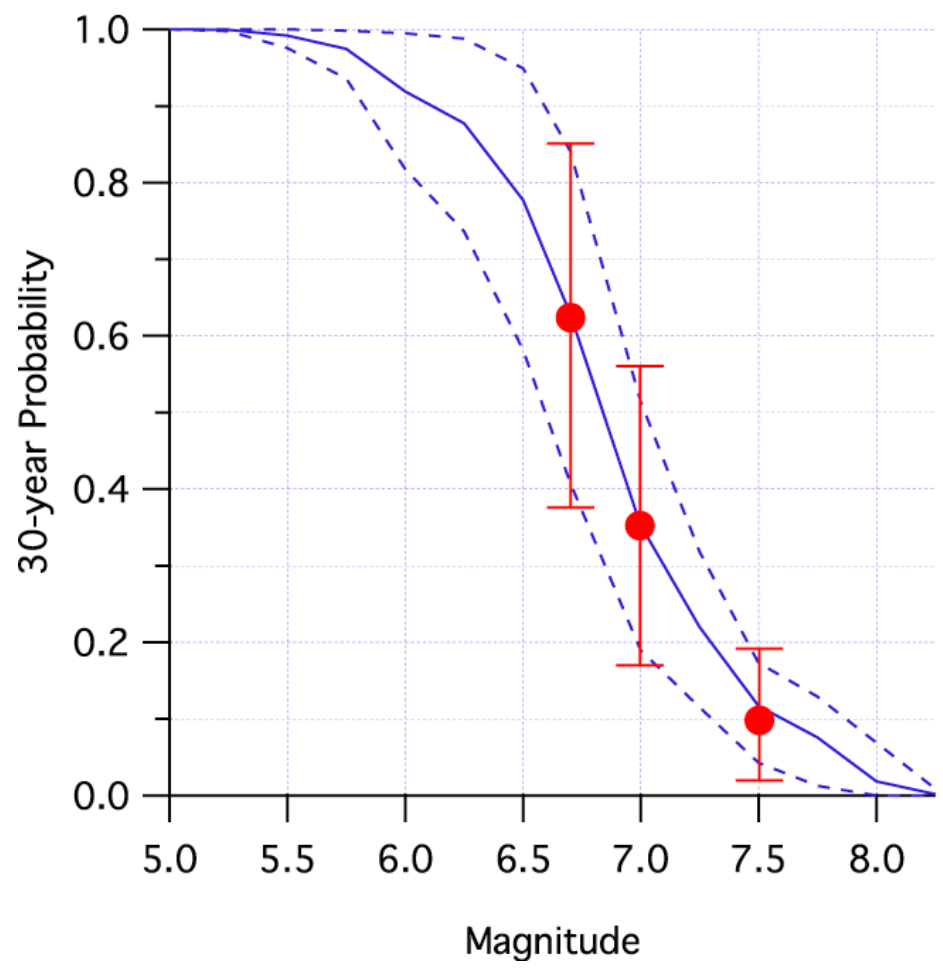

Figure 25. A comparison of the mean UCERF 2 cumulative magnitude-probability distribution for all events in the Bay Area study region (blue line) with the results of WGCEP (2003) (red symbols). The dashed blue lines represent the minimum and maximum values sampled from the UCERF 2 logic tree branches. The red error bars represent the 95\% confidence bounds computed by WGCEP (2003). The boundaries of the WGCEP (2003) study region are shown in Figure 1. 
Figure 26 gives the 30-year magnitude-probability distribution for the entire study region (excluding Cascadia earthquakes). Considering all sources, Californians can be nearly certain of having an earthquake of $M \geq 6.5$ during the next 30-year period; indeed, the odds of an $M \geq 6.7$ event reach $99.7 \%$. The mean probability of an $\mathrm{M} \geq 7.0$ event is about $94 \%$, with a minimum of $85 \%$ and a maximum of $99 \%$. The chance of an earthquake of $M \geq 7.5$ is $46 \%$, with a minimum of $29 \%$ and a maximum of $65 \%$.

For $\mathrm{M} \geq 8.0$, the mean probability is $4.5 \%$ with a minimum of zero and a maximum of $11 \%$. The probabilities calculated for the largest magnitude events should be used with caution, because they depend critically on rupture scenarios that involve fault lengths longer than historically observed rupture events, as well as an extrapolation of scaling relationships beyond the limits of the empirical data.

\section{Magnitude Probability Distribution by Source Type All of California (except Cascadia)}
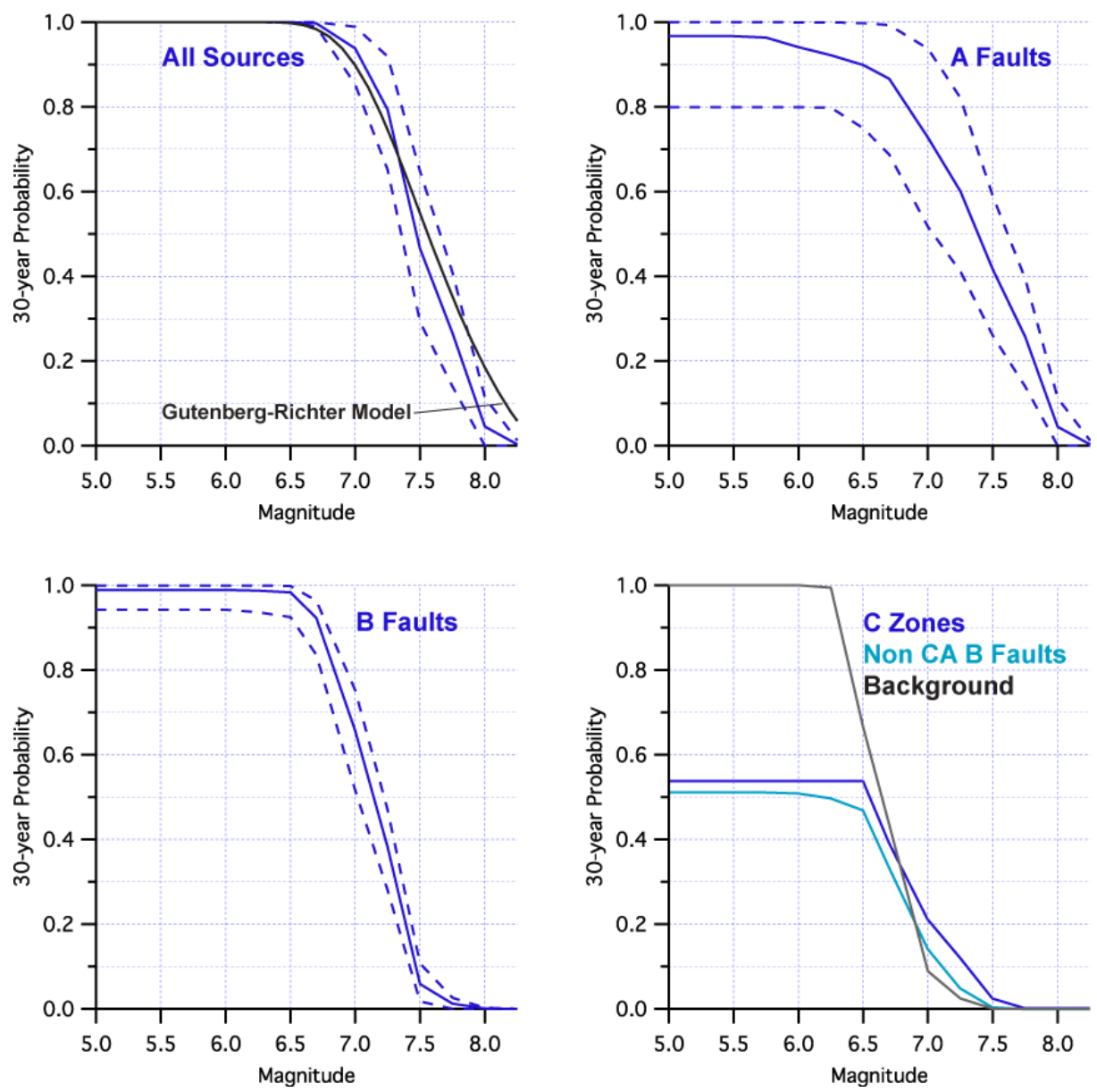

Figure 26. The first panel is the mean UCERF 2 cumulative magnitude-probability distribution for all of California, excluding Cascadia. The other panels show the magnitude-probability distributions for each source type. No maxima and minima are plotted for the Type-C zones and background seismicity, because only one logic-tree branch influences these sources; the maxima and minima for non-California Type-B Faults are not shown to avoid clutter. The black line in the All Sources plot represents the magnitude-probability distribution for the theoretical Gutenberg-Richter distribution described in the text. 
For comparison, Figure 26 includes a plot for a theoretical Gutenberg-Richter distribution with a bvalue of 0.8 , a rate of $M \geq 5.0$ events equal to that predicted by our model, and maximum magnitude of 8.3 (with truncation applied to the incremental distribution, not the cumulative distribution). The comparison shows that UCERF 2 has relatively high probabilities between M 6.5 and 7.3 and relatively low probabilities above 7.3 compared with the Gutenberg-Richter model. This result is consistent with our observation that ERM 2.3 appears to over-predict the rate of events near M 6.5 (the "bulge"), and it illustrates the possibility that UCERF 2 under-predicts the probability of very large events, owing to the exclusion of many fault-to-fault rupture possibilities, as discussed in $\S \mathrm{D} .8$.

Figure 26 also gives the total regional probabilities associated with the different types of sources. The probabilities of generating an $\mathrm{M} \geq 6.8$ earthquake are approximately equal between Type- $\mathrm{A}$ and Type- $\mathrm{B}$ faults (80\%), with Type-A faults dominating for larger events and Type-B faults dominating at lower magnitudes. The total probability for an $\mathrm{M} \geq 6.5$ earthquake on a Type-B fault is $98 \%$. The background seismicity dominates below $M 6.25$, with virtual certainty of producing an $M \geq 5.75$ event in 30 years.

\section{Magnitude Probability Distribution All of California (except Cascadia)}
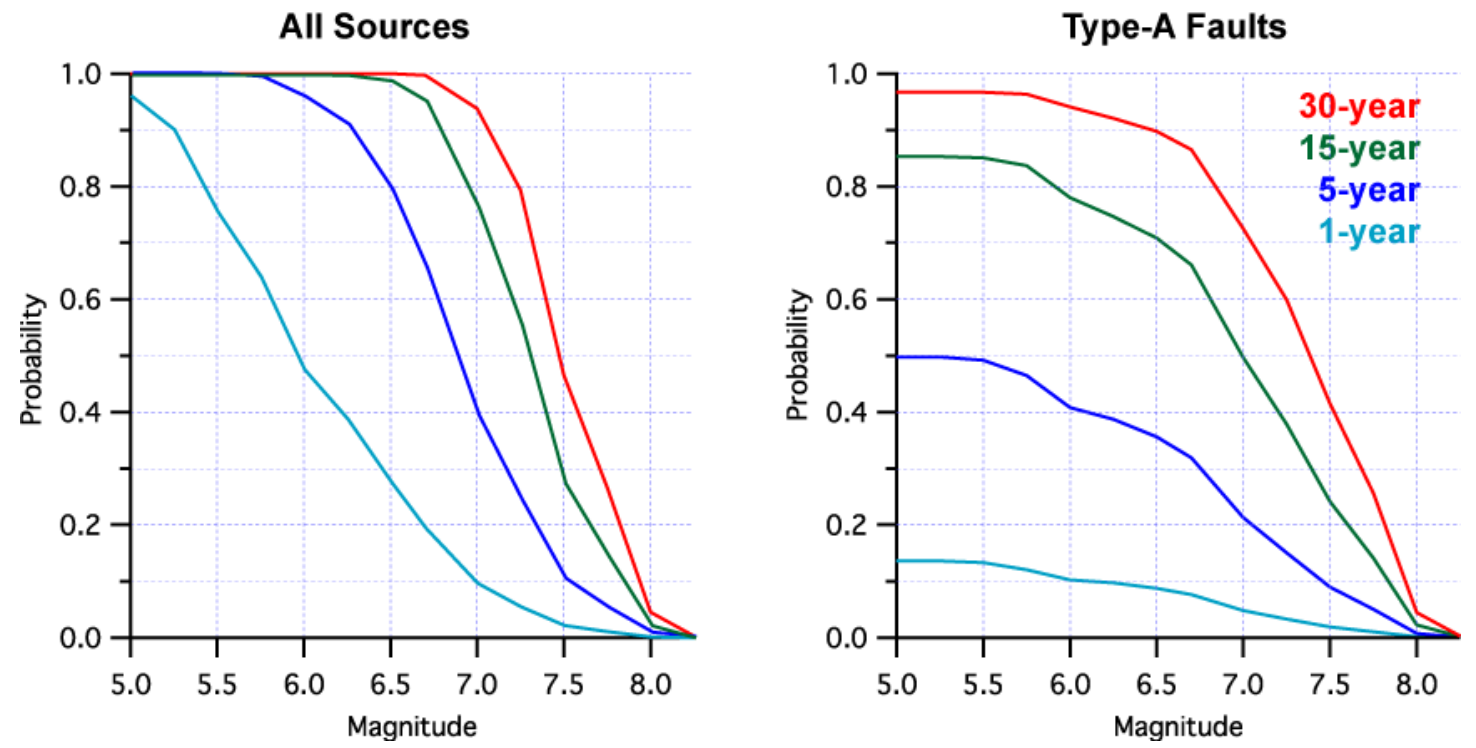

Figure 27. Mean UCERF 2 cumulative magnitude-probability distributions for all California sources (excluding Cascadia) and for all Type-A Faults for forecast durations of 1, 5, 15, and 30 years.

Figure 27 displays the mean magnitude-probability distributions for forecast durations of 1, 5, 15, and 30 years for all sources (excluding Cascadia) and for Type-A faults alone. The magnitude threshold for which there is a $50 \%$ probability of occurrence is 5.9 for the one-year forecast, 6.75 for 5 years, 7.35 for 15 years, and about 7.5 for 30 years. Figure 28 compares the total regional magnitude-probability distribution for the UCERF 2 time-dependent model with that for a purely time-independent (Poisson) version of our model. This plot implies maximum regional probability gains of about $2 \%$ to $3 \%$ near M 7.5, which are insignificant given overall uncertainties. Thus, there is no evidence that California, as a whole, is particularly overdue for a large earthquake compared to long-term model. 


\section{Magnitude Probability Distribution All of California (except Cascadia), All Sources}

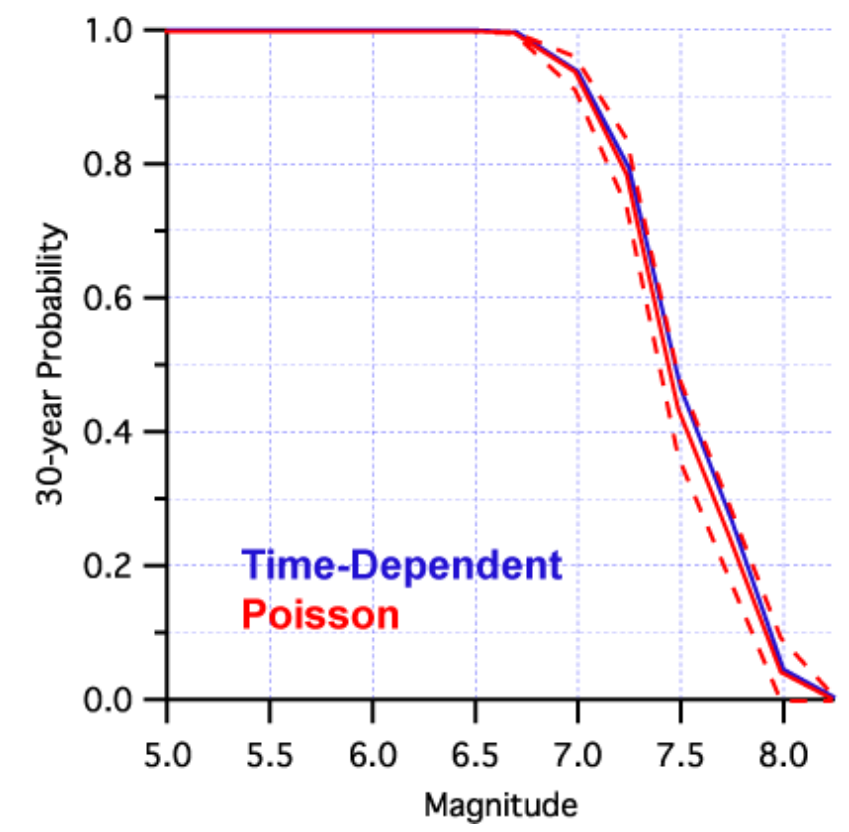

Figure 28. Comparison of the mean UCERF 2 cumulative magnitude-probability distribution for all of California excluding Cascadia (blue line) with the time-independent (Poisson) version of the model (red line with maxima and minima plotted with dashes).

Figures 29 and 30 show the magnitude-probability distributions for the northern versus southern California regions (the dividing line is shown in Figure 1). Probabilities are uniformly higher in southern California, even though the two areas are approximately equal in size. For example, the average probability for $M \geq 6.7$ is $97 \%$ in southern California, whereas it is $93 \%$ in northern California. At $\mathrm{M} \geq 7.5$, the difference between the two regions is greater than a factor of two (37\% vs. 15\%). These relative probability differences apply to both Type-A and Type-B faults. The probabilities from Type-C zones and Non-California Type-B faults are lower in southern California because such sources are fewer in this region.

WGCEP (1995) cited a probability of $80 \%$ to $90 \%$ for an $M \geq 7$ event in southern California, which is consistent with our mean of $81 \%$ and our range of $63 \%$ to $95 \%$ (Figure 30 ). Their probability for $\mathrm{M} \geq 7.8$ was $6 \%$ to $9 \%$, whereas our mean is $16 \%$ with a range of $6 \%$ to $32 \%$. It should be noted that our definition of southern California differs from that of WGCEP (1995), which can be seen by comparing the boundary in Figure 1 with boundary in the third panel of Figure 2. 


\section{Magnitude Probability Distribution by Source Type Northern California}
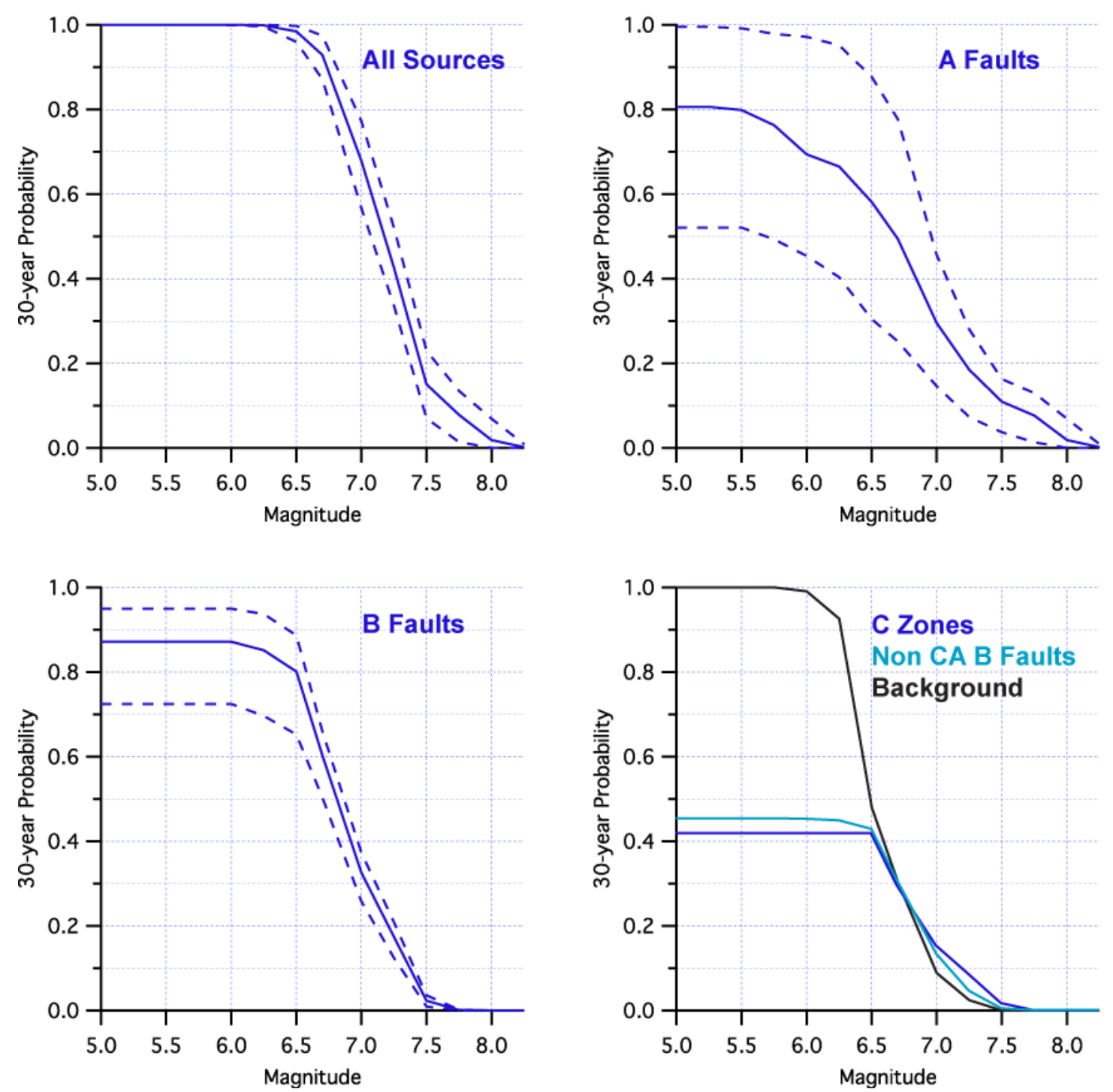

Figure 29. Cumulative magnitude-probability distributions for different source types in northern California (excluding Cascadia). 


\section{Magnitude Probability Distribution by Source Type Southern California}
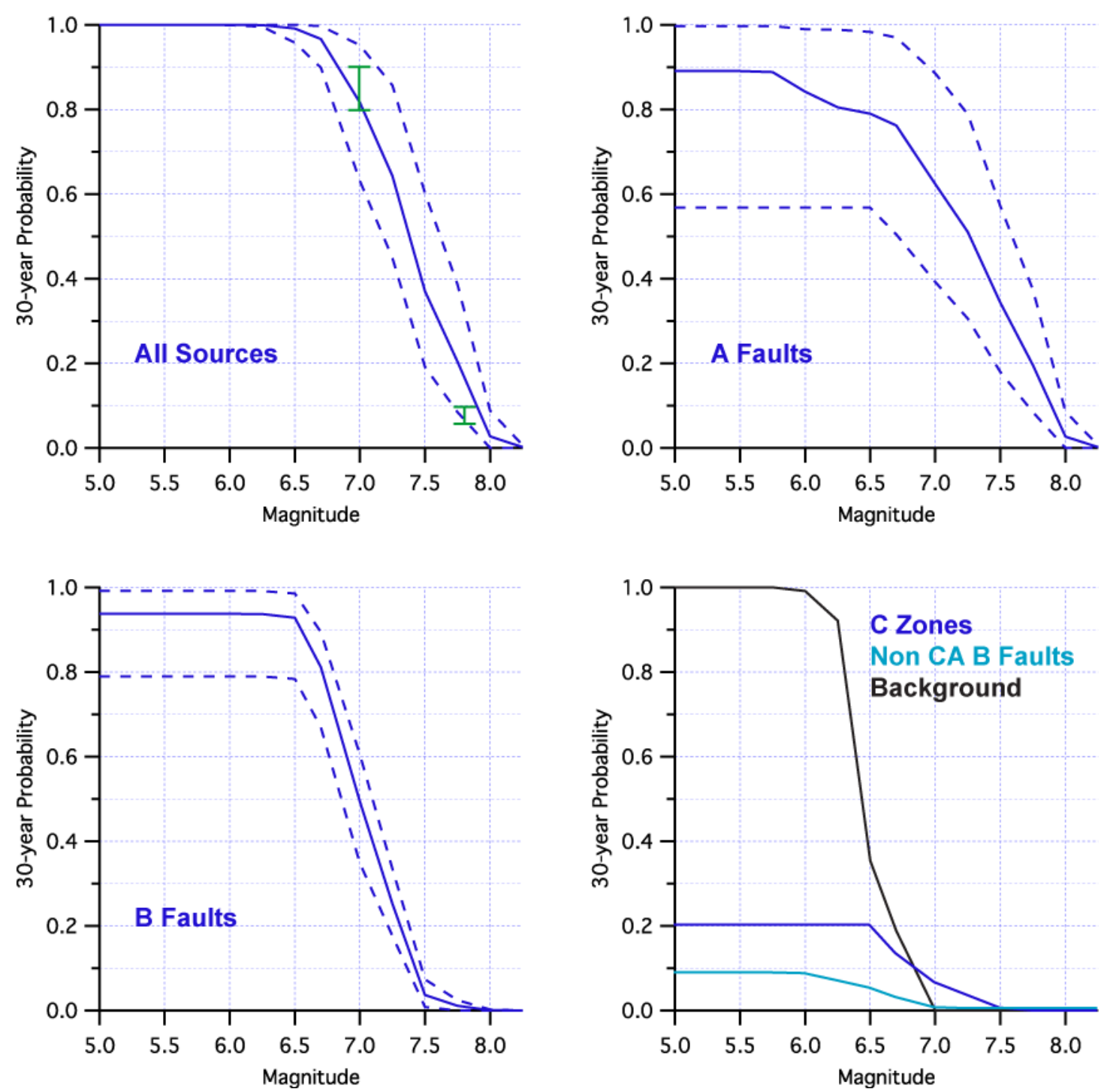

Figure 30. Cumulative magnitude-probability distributions for different source types in southern California. The range of probabilities cited by WGCEP (1995) is shown in green.

\section{F.3. Probabilities for Faults}

Type-A Fault Probabilities. Figure 31 shows the total magnitude-probability distributions for the individual Type-A faults, compared to previous working group results. These plots only include probabilities for segment-filling events (or earthquakes larger than M 6.5 for the unsegmented models), whereas smaller events are treated as part of the background seismicity. The southern San Andreas has the highest probabilities for all magnitudes up to about 8.0, above which the northern San Andreas probabilities become comparable. The Calaveras also stands out in terms of high probabilities, although only at smaller magnitudes, owing to the relatively high aseismic slip factor on this fault. Table 12 lists aggregate $M \geq 6.7$ probabilities for each fault in descending order; the Calaveras falls near the bottom of 
the list, and the Hayward and San Jacinto faults are runners up to the southern San Andreas. Also listed in Table 12 are the mean probabilities and $95 \%$ confidence bounds for those faults considered by WGCEP (2003); all are in good agreement with our results. The $M \geq 6.7$ probabilities for the San Jacinto and Elsinore faults show a factor-of-two difference between the WGCEP (1995) and WGCEP (2007) estimates, which reflect our inclusion of multi-segment ruptures and other new data for these faults in the present study. 


\section{Magnitude Probability Distribution of Type-A Faults 30-year Probability}
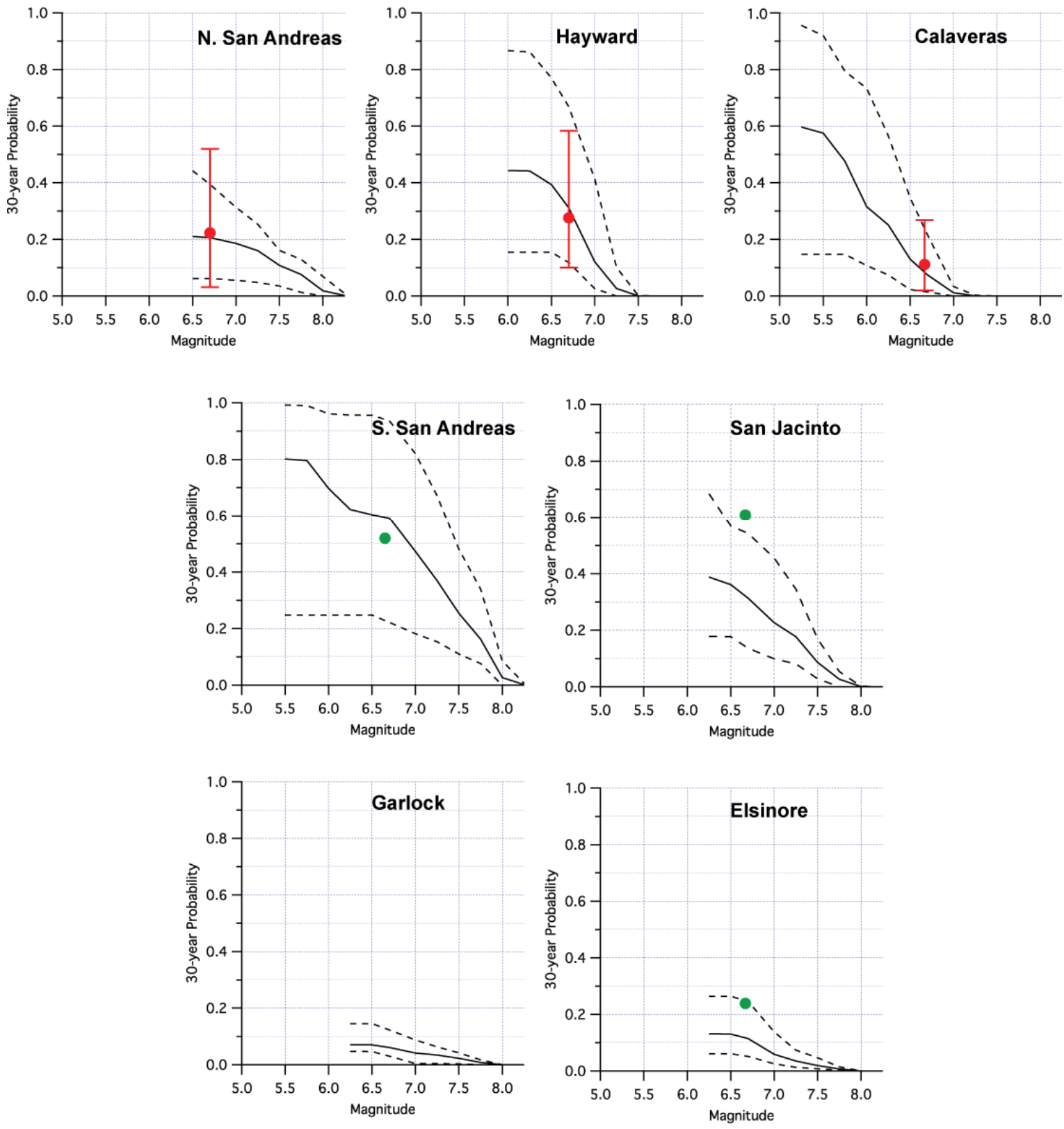

Figure 31. Cumulative magnitude-probability distributions for each Type-A fault. WGCEP (1995) results are shown in green and WGCEP (2003) in red. See Table 12 for values. 
Table 12. 30-year probability of $M \geq 6.7$ events on the Type-A faults and the four faults considered by WGCEP (2003) but categorized as Type-B in this study. All probabilities have been rounded to the nearest percent. Names in parentheses are those used by WGCEP (2003).

\begin{tabular}{|c|c|c|c|c|}
\hline & Fault & $\begin{array}{l}\text { WGCEP (2007) Mean } \\
\text { [Min-Max] }\end{array}$ & $\begin{array}{l}\text { WGCEP (2003) Mean } \\
\text { [2.5\% and } 97.5 \%]\end{array}$ & WGCEP (1995) Mean \\
\hline \multirow{7}{*}{ 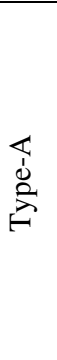 } & S. San Andreas & $59 \%$ [22-94] & & $53 \%$ \\
\hline & Hayward-Rodgers Creek & $31 \%$ [12-67] & $27 \%[10-58]$ & \\
\hline & San Jacinto & $31 \%[14-54]$ & & $61 \%$ \\
\hline & N. San Andreas & $21 \%[6-39]$ & $23 \%[3-52]$ & \\
\hline & Elsinore & $11 \%[5-25]$ & & $24 \%$ \\
\hline & Calaveras & $7 \%[1-22]$ & $11 \%[3-27]$ & \\
\hline & Garlock & $6 \%[3-12]$ & & \\
\hline \multirow{4}{*}{ 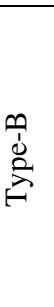 } & $\begin{array}{l}\text { San Gregorio Connected } \\
\text { (San Gregorio) }\end{array}$ & $6 \%[4-9]$ & $10 \%[2-28]$ & \\
\hline & $\begin{array}{l}\text { Green Valley Connected } \\
\text { (Concord/Green Valley) }\end{array}$ & $3 \%[1-6]$ & $4 \%[0-12]$ & \\
\hline & $\begin{array}{l}\text { Greenville Connected } \\
\text { (Greenville) }\end{array}$ & $3 \%[2-4]$ & $3 \%[0-8]$ & \\
\hline & $\begin{array}{l}\text { Mount Diablo Thrust } \\
\text { (Mt. Diablo Thrust) }\end{array}$ & $1 \%[0-1]$ & $2 \%[0-8]$ & \\
\hline
\end{tabular}

Table 13. The maximum magnitudes and $M \geq 6.7,30$-year probability for all Type-B faults for which the mean probability is $\geq 5 \%$. Min and max values represent limits from the logic tree and do not correspond to a particular confidence level. All probabilities are rounded to the nearest percent. Maximum magnitudes represent the upper magnitude of the Gutenberg Richter distribution and the average magnitude of characteristic events.

\begin{tabular}{|l|c|c|c|}
\hline \multirow{2}{*}{ Fault Name } & \multicolumn{2}{|c|}{ Maximum Magnitude } & \multirow{2}{*}{$\begin{array}{c}\text { M 6.7 Probability (\%) } \\
\text { Mean [Min-Max] }\end{array}$} \\
\cline { 2 - 3 } & Ellsworth-B & Hanks \& Bakun & $27 \%[21-31]$ \\
\hline Imperial & 7.0 & 6.8 & $13 \%[9-15]$ \\
\hline Maacama-Garberville & 7.4 & 7.3 & $9 \%[7-11]$ \\
\hline Bartlett Springs & 7.3 & 7.2 & $9 \%[5-12]$ \\
\hline Hunting Creek-Berryessa & 7.1 & 6.9 & $8 \%[6-10]$ \\
\hline Little Salmon (Onshore) & 7.1 & 7.0 & $8 \%[5-11]$ \\
\hline San Cayetano & 7.2 & 7.1 & $7 \%[6-8]$ \\
\hline Death Valley (No) & 7.3 & 7.3 & $7 \%[5-9]$ \\
\hline Death Valley (No of Cucamongo) & 7.2 & 7.1 & $7 \%[4-9]$ \\
\hline San Gregorio Connected & 7.5 & 7.4 & $6 \%[4-8]$ \\
\hline Death Valley (Black Mtns Frontal) & 7.3 & 7.1 & $6 \%[4-6]$ \\
\hline Laguna Salada & 7.3 & 7.2 & $5 \%[3-7]$ \\
\hline Oak Ridge (Onshore) & 7.2 & 7.1 & $5 \%[3-8]$ \\
\hline Santa Susana, alt 1 & 6.9 & 6.7 & $5 \%[3-7]$ \\
\hline Death Valley Connected & 7.8 & 7.9 & $5 \%[4-6]$ \\
\hline Anacapa-Dume, alt 1 & 7.2 & 7.1 & $5 \%[4-6]$ \\
\hline Death Valley (So) & 6.9 & 6.7 & $5 \%[3-6]$ \\
\hline Oak Ridge Connected & 7.4 & 7.3 & $5 \%[3-6]$ \\
\hline Palos Verdes & 7.3 & 7.2 & $5 \%[3-5]$ \\
\hline Anacapa-Dume, alt 2 & 7.2 & 7.1 & $5 \%[3-5]$ \\
\hline Coronado Bank & 7.4 & 7.3 & \\
\hline
\end{tabular}


Total Type-B Fault Probabilities. Table 13 lists all Type-B faults for which the average 30-year probability of $M \geq 6.7$ is greater than $5 \%$ (along with the maximum magnitudes).

Cascadia Probabilities. The total magnitude-probability distribution for Cascadia is shown in Figure 32. The 30-year probability of an $\mathrm{M} \geq 8.0$ event is $12 \%$, and the probability of a full-subduction-zone event $(\mathrm{M} \geq 8.8)$ is $5.4 \%$.

\section{Magnitude Probability Distribution All of California and Cascadia Subduction Zone}

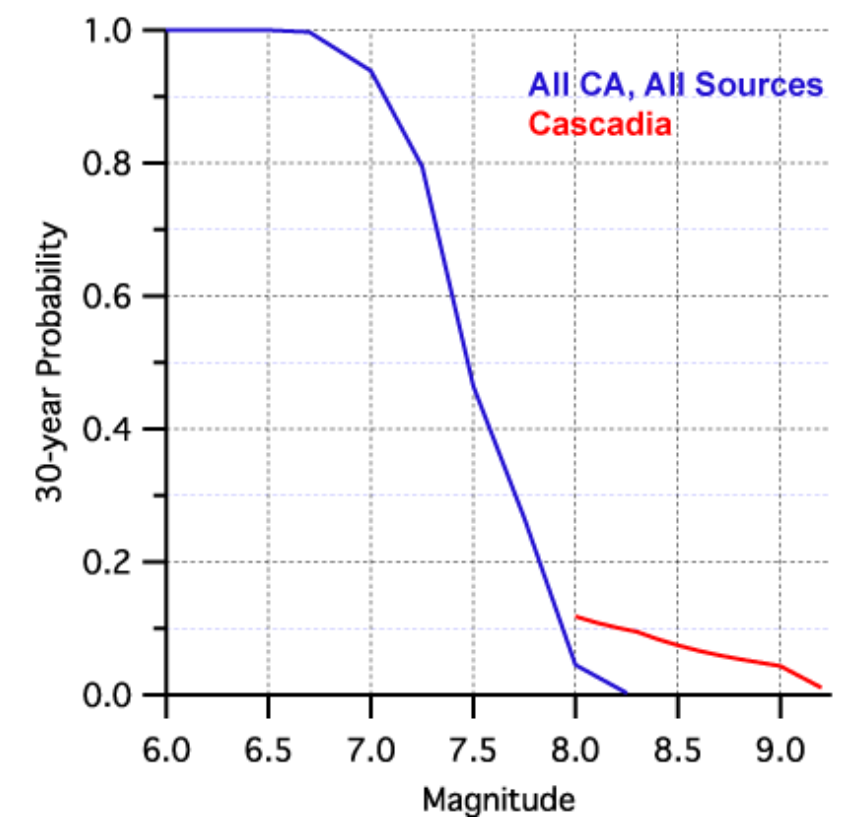

Figure 32. The mean UCERF 2 cumulative magnitude-probability distribution for all of California and the Cascadia subduction zone.

Rupture Probabilities. Individual UCERF 2 rupture probabilities for every branch of the logic tree are tabulated in Appendix N (Field and Gupta, 2007) for the segmented Type-A faults. Sheets 2-4 of the Supplementary Spreadsheet lists logic-tree average probabilities for each rupture on each Type-A fault, as well as other information such as comparisons with time-independent probabilities and the results of previous studies (e.g., WGCEP, 1995, 2003) where possible. Note that probability gains, defined as the time-dependent probability divided by the time-independent probability, can vary between the 5-year and 30-year forecasts. The largest differences are for ruptures that have shorter recurrence intervals. A good example is the Parkfield rupture, which has a recurrence interval of about 30 years; the gain for a 5-year forecast is 0.39 while that for a 30 -year forecast is 0.96 .

All UCERF 2 mean-rupture probabilities are within the 95\% confidence bounds defined by WGCEP (2003), except for those ruptures that were given a zero probability on all branches in their model. A difficulty in comparing UCERF 2 rupture probabilities in southern California with previous studies comes 
from our changes to segmentation models; e.g., the increased number of segments on the southern San Andreas means there are more rupture probabilities, so the probability of any one event has consequently gone down. We therefore move on to discussing segment probabilities because they represent an aggregate over all ruptures, and as such are a more practical measure because both single and multisegment events pose significant hazard.

Segment Probabilities. The total probability for a rupture of a given Type-A fault segment was computed by aggregating the probabilities of all ruptures that involve that segment (and therefore represent a "participation probability"). In these computations, we have excluded the unsegmented branches of our logic tree, because segment probabilities are undefined. Nevertheless, these segment probabilities are generally representative, since the unsegmented branches are only given $10 \%$ weight. Mean segment rates, mean recurrence intervals, and average time-dependent probabilities (as well as other information) are listed in Sheets 5-8 of the Supplementary Spreadsheet. Figure 33 is a "fence diagram" showing the segment probabilities for the northern California Type-A faults, along with the UCERF 2 timeindependent (Poisson) probabilities and the results of WGCEP (2003). We note that these probabilities are for $M \geq 6.7$ events only, in keeping with the results highlighted by WGCEP (2003). There is generally good agreement between our time-dependent results and those of WGCEP (2003).

Probabilities for the North Coast and Peninsula segments of the San Andreas (SAN and SAP, respectively) are about 25\% lower than those of WGCEP (2003) because we did not include their timepredictable model. For example, the average slip on the SAP segment from the 1906 event was $3.65 \mathrm{~m}$ in the WGCEP (2003) model, taken from Thatcher et al. (1997). Dividing by the average slip rate of 0.017 $\mathrm{m} / \mathrm{yr}$ yields a recurrence interval 215 years according to the WGCEP (2003) time-predictable model, 13\% less than our average recurrence interval of 246 years.

Our probabilities for the Hayward-Rodgers Creek segments are about 25\% greater than those of WGCEP (2003), which results from our exclusion of the Poisson (unsegmented) model in the numbers cited here; Table 12, which includes the unsegmented model, shows that the total UCERF 2 probability of $M \geq 6.7$ events for this fault is only about 15-percent greater than in WGCEP (2003). The Hayward Rodgers Creek fault exhibits some probability gain relative to our time-independent Poisson model. Our probability for the Northern Calaveras segment is lower than that of WGCEP (2003) by about 32-percent, due to the fact that our mean recurrence interval went up by a factor two to be consistent with the 484year paleoseismic recurrence interval of Kelson et al. (1996; see also Appendix K). The factor of 1.78 increase for the Southern Calaveras segment is due to a reduction of the recurrence interval; the mean dropped from 75 to 51 years, primarily from our use of the tapered slip model. The probability for the Central segment of the Calaveras increased by about $50 \%$ owing to an increased rate of full-fault ruptures, which resulted from differences in how floating/unsegmented events were handled and moment-balancing with respect to our chosen magnitude-area relationships and tapered-slip model. It should be noted that none of segment-probability differences with respect to WGCEP (2003) are significant, given the uncertainties cited in each study.

Figure 34 compares our time-dependent segment probabilities for southern California Type-A faults with our time independent (Poisson) probabilities and those of WGCEP (1995). Here, the probability of 
all segmented-model events is included, to be consistent with WGCEP (1995). The most dramatic observation from this figure is that all segments of the southern San Andreas appear overdue compared to our time-independent model. The Parkfield segment has the highest average probability of occurrence (75\%), even though such an event occurred in 2004; this results from the short recurrence interval (24 years in our long-term model) compared to the forecast duration of 30 years. The Cholame segment has the second highest probability (37\%), owing to the high rate of events there, and the Coachella segment comes in third (34\%). The low probabilities for the San Gorgonio and San Bernardino South segments, compared to WGCEP (1995), result from lower event rates, which ultimately result from lower estimated slip rates on this part of the fault. Our mean recurrence interval of 156 years for the Coachella Valley segment is consistent with the 160-year value used by WGCEP (1995) in their "Time-predictable" and "Renewal" models. However, they also included a "Dates" model, based on paleoseismic observations, for which the recurrence interval was 220 years, which caused their total average probability to be 0.22 , compared to our value of 0.34 .

\section{Segment Rupture Probability}

Northern California

Comparison with WGCEP (2003)

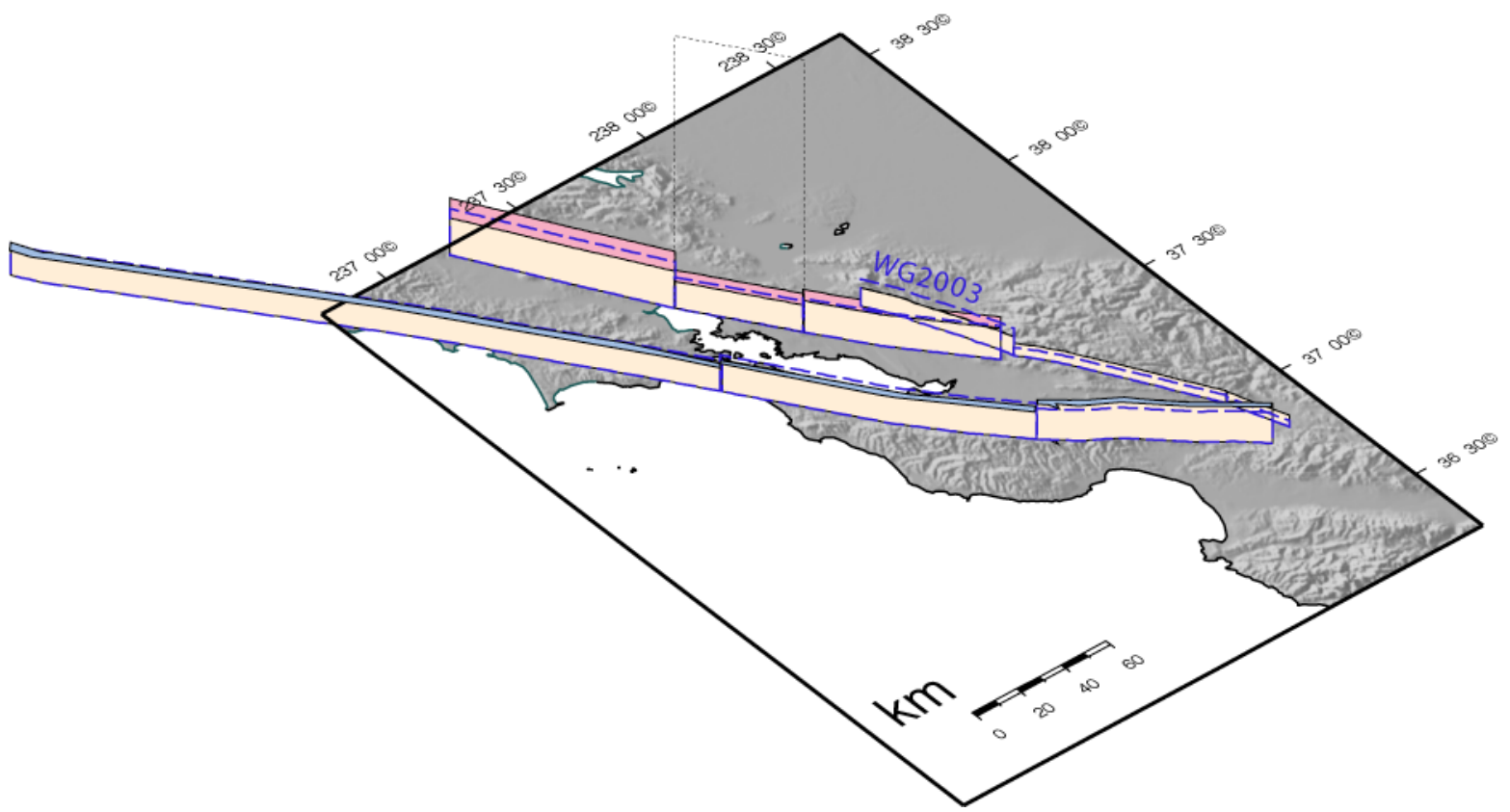

Figure 33. Fence diagram of 30-year segment probabilities for $M \bullet 6.7$ events on Type-A Faults in northern California, where the height of each fence is proportional to the probability (with the dotted line representing 100\%). Pink and blue shading indicate the degree to which our segment probabilities are above or below, respectively, the long-term (Poisson) probabilities. The dashed lines represent the 30-year probabilities from WGCEP (2003), for which the start year was 2002.

The most dramatic changes for the San Jacinto fault are drastically reduced probabilities for the San Bernardino Valley (SBV) and San Jacinto Valley (SJV) segments. The reduced probability on SBV 
results from a factor of two reduction of the slip rate, as described in the deformation-model section, and the inclusion of many more multi-segment ruptures. The reduction for SBV would have been even greater if the date of last event had not been changed from 1890 to 1769 (see Appendix B). The reduced probability for SJV results from an approximate factor-of-three increase in the slip per event assumed for this segment. Our probabilities for the Glen Ivy and Temecula segments of the Elsinore fault are also significantly reduced compared to WGCEP (1995) due to our inclusion of multi-segment ruptures.

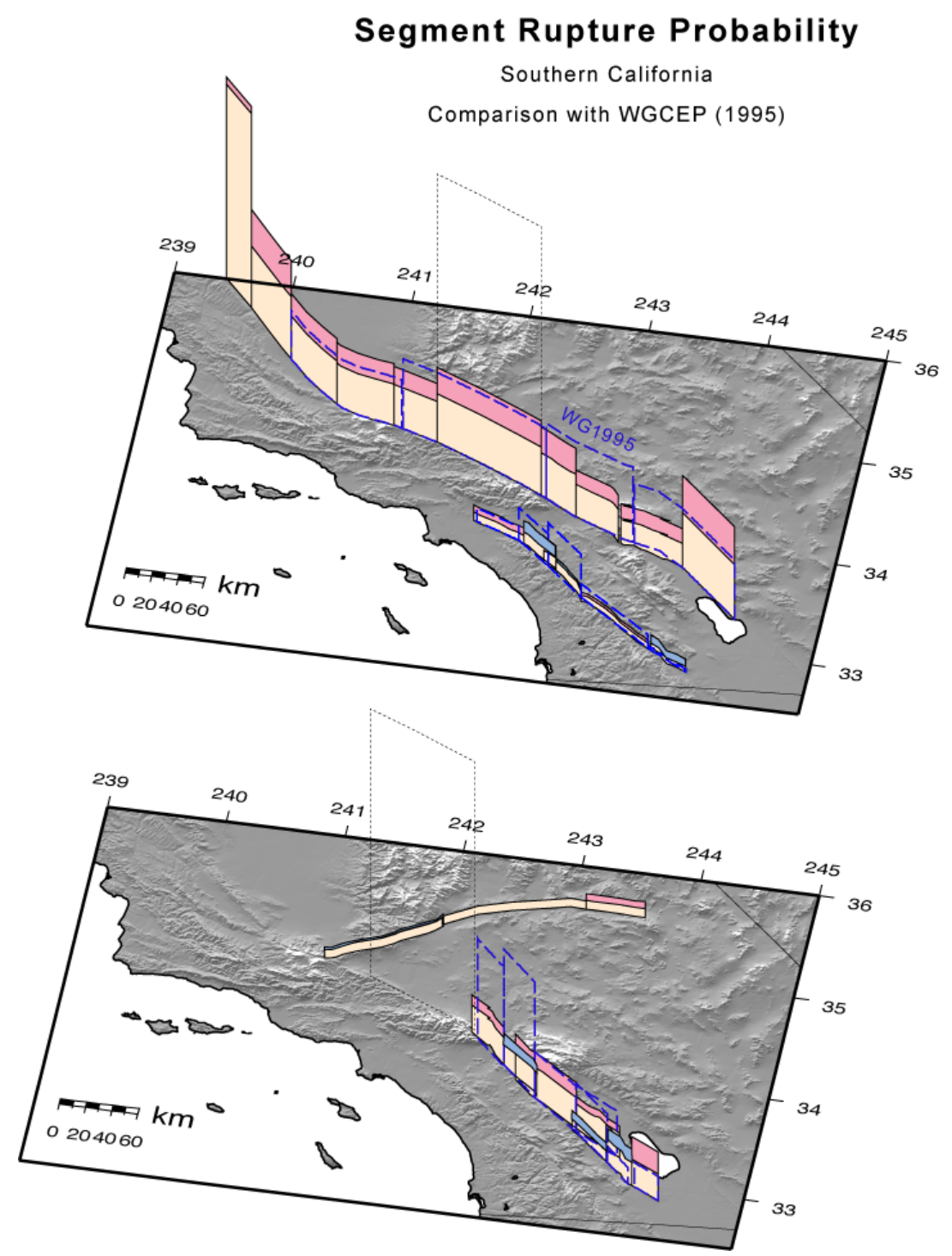

Figure 34. Same as Figure 32, but for the San Andreas and Whittier Elsinore faults (top) and San Jacinto and Garlock faults (bottom) in southern California. All segmented-model events are included (i.e., no magnitude 6.7 threshold has been applied). Here the dashed lines represent probabilities from WGCEP (1995).

Participation Probability Maps. The UCERF 2 earthquake rupture forecast can be visualized by mapping the mean probability that an element of area on a statewide grid will include a fault rupture of any source 
type above a specified magnitude threshold during the next 30 years. Figure 35 presents these "participation probability" maps for three magnitude thresholds. For events with $M \geq 5.0$, the areas where the participation probabilities exceed $1 \%$ (yellow or warmer in color) include over half the state, reflecting the widespread distribution of California seismicity, much of which is represented in the model as "background." At $M \geq 6.7$, this same probability level is confined to the major faults, and at $M \geq 7.7$, it is generally restricted to the longer strike-slip strands of the San Andreas fault system.

Figure 36 shows the ratio of the time-dependent map for $M \geq 6.7$ in Figure 35 to an equivalent timeindependent map (where all sources in UCERF 2 are treated as Poissonian). The influence of the empirical model is clear in this figure, causing the vast majority of cells to have lower time-dependent probabilities. The exceptions are the Type-A faults that have large probability gains according to the BPT model, such as the southern San Andreas, and the Cascadia megathrust.

\section{Participation Probabilities}
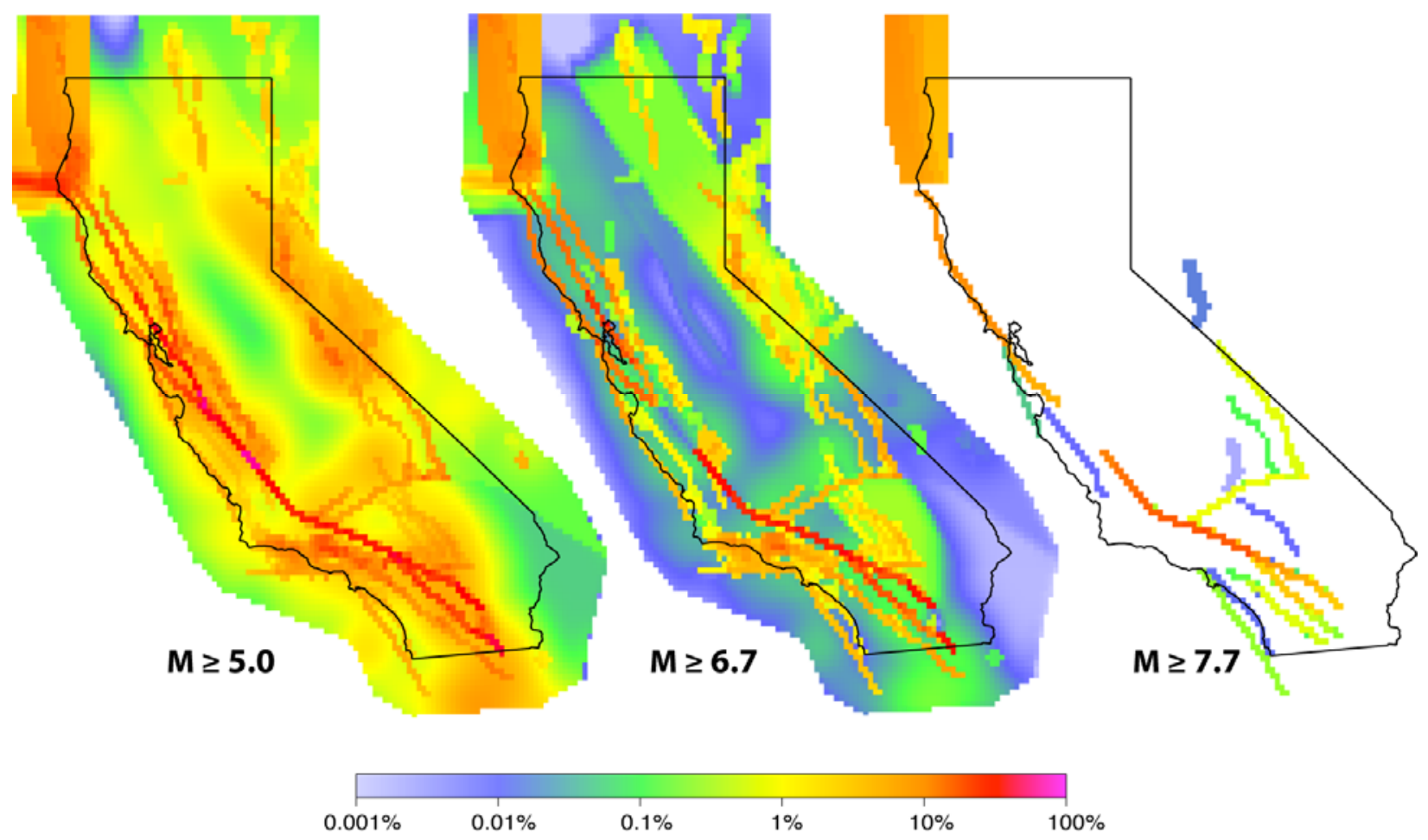

Figure 35. Participation probability maps, displaying the mean UCERF 2 probabilities that an individual $0.1^{\circ} \times 0.1^{\circ}$ cell in the statewide grid will be involved in a fault rupture of any source type above the specified magnitude threshold during the next 30 years. The magnitude thresholds shown here are $\mathrm{M} \bullet 5.0$, 6.7, and 7.7. Probability color scale is logarithmic; i.e. each decrement unit represents a 10-fold decrease in probability. These maps include ruptures on the Casacdia megathrust beneath northwestern California. 


\section{Ratio of Time-Dependent to Time-Independent Participation Probabilities for $M \geq 6.7$}

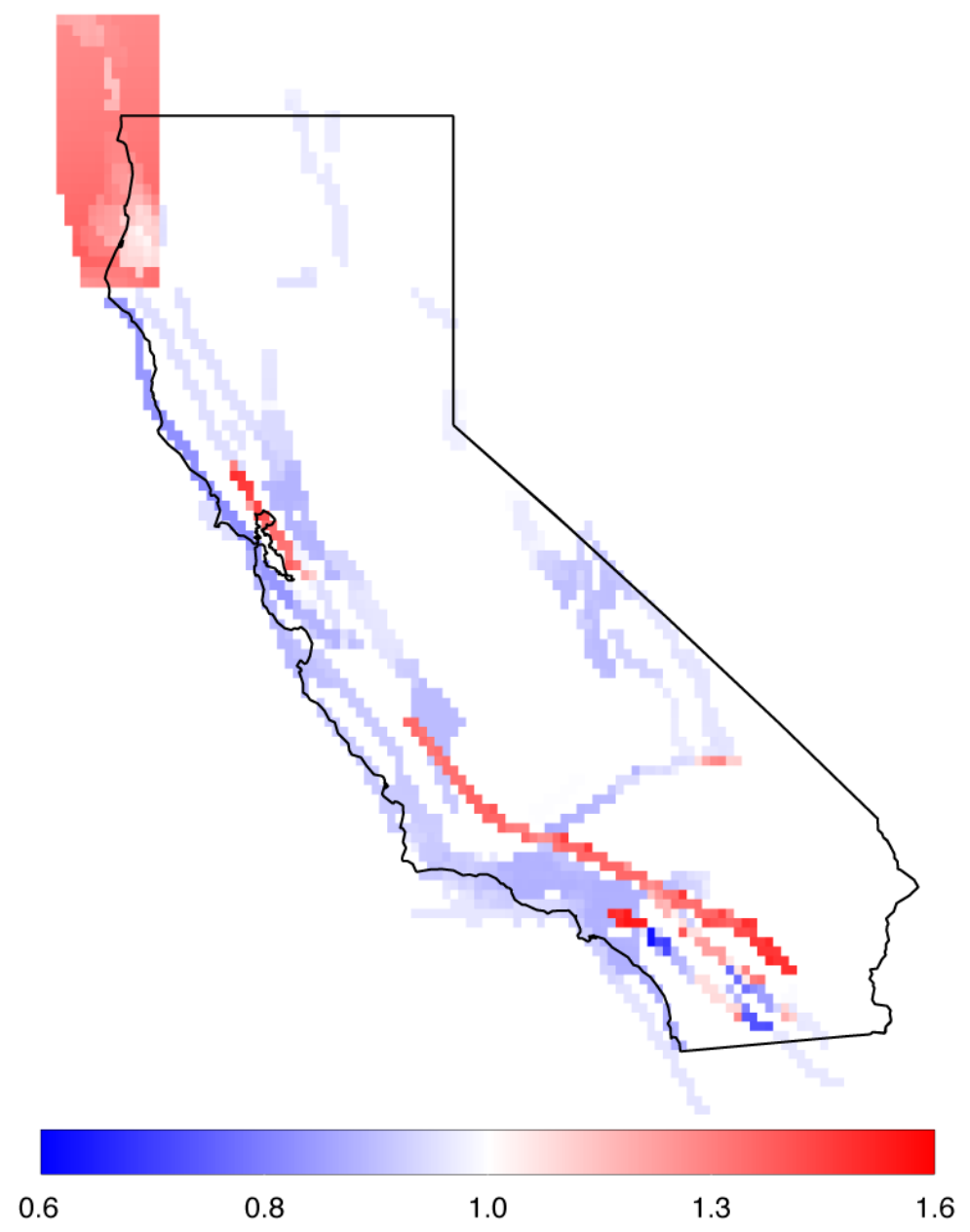

Figure 36. Map showing the 30 -year time-dependent UCERF 2 participation probabilities for $M \bullet 6.7$ ruptures (middle panel of Figure 35) divided by the corresponding time-independent (Poisson) probabilities.

\section{F.4. Probability Sensitivity Analysis}

To understand the epistemic uncertainties, we need to know which logic-tree branches exert the most influence on the mean probabilities. Figure 37a shows a histogram of probabilities of $M \geq 6.7$ events inside the WGCEP (2003) region obtained from all branches of the logic tree. The histogram bars in maroon give the contribution from the Empirical model and the blue bars give the contribution from the BPT/Poisson branches. The mean for the Empirical model is $46 \%$ whereas that of the BPT/Poisson branches is $70 \%$, very consistent with the results of WGCEP (2003) model, which obtained regional values of $44 \%$ for their Empirical model and $60 \%$ and $72 \%$ for their Poisson and BPT models, respectively. Figure $37 \mathrm{~b}$ shows a similar trend for $\mathrm{M} \geq 7.5$ events throughout the entire study region; the Empirical model average is $35 \%$ and the BPT/Poisson average is $51 \%$. The Empirical versus BPT/Poisson probability-model branch is by far the most influential in our logic tree. 


\section{Probability Contribution of Probability Model}

(a) $M \geq 6.7$ Earthquakes, All Sources

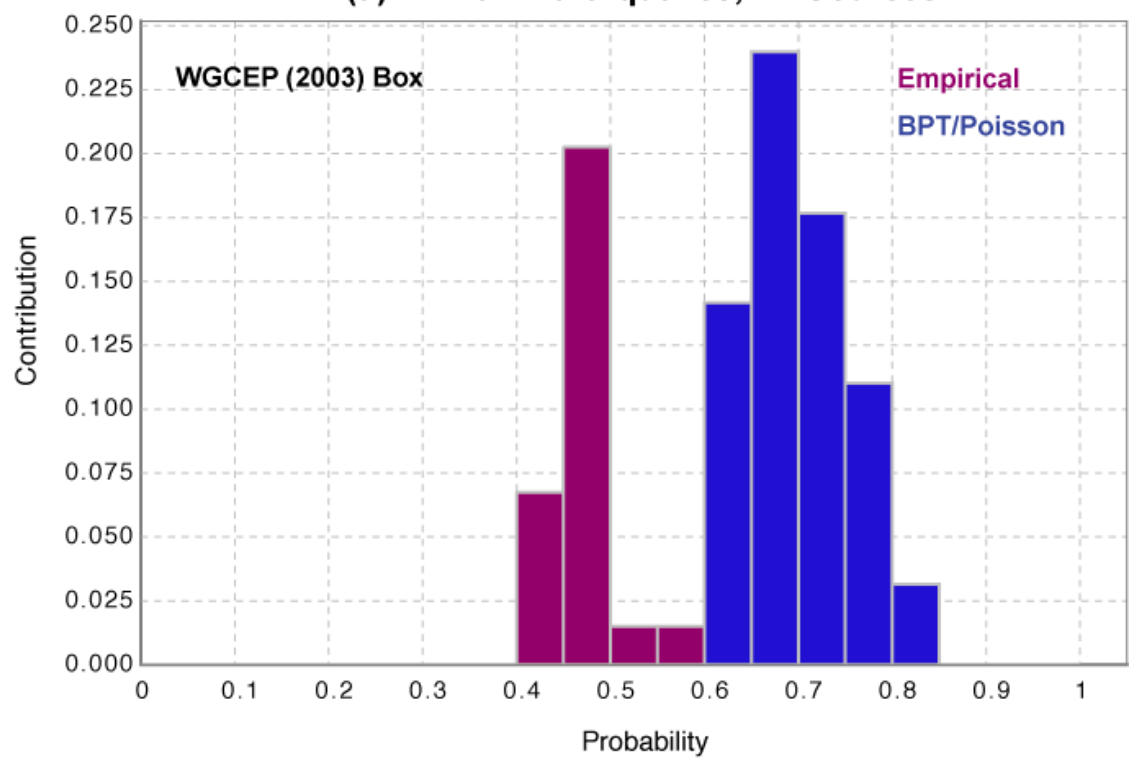

(b) $M \geq 7.5$ Earthquakes, All Sources

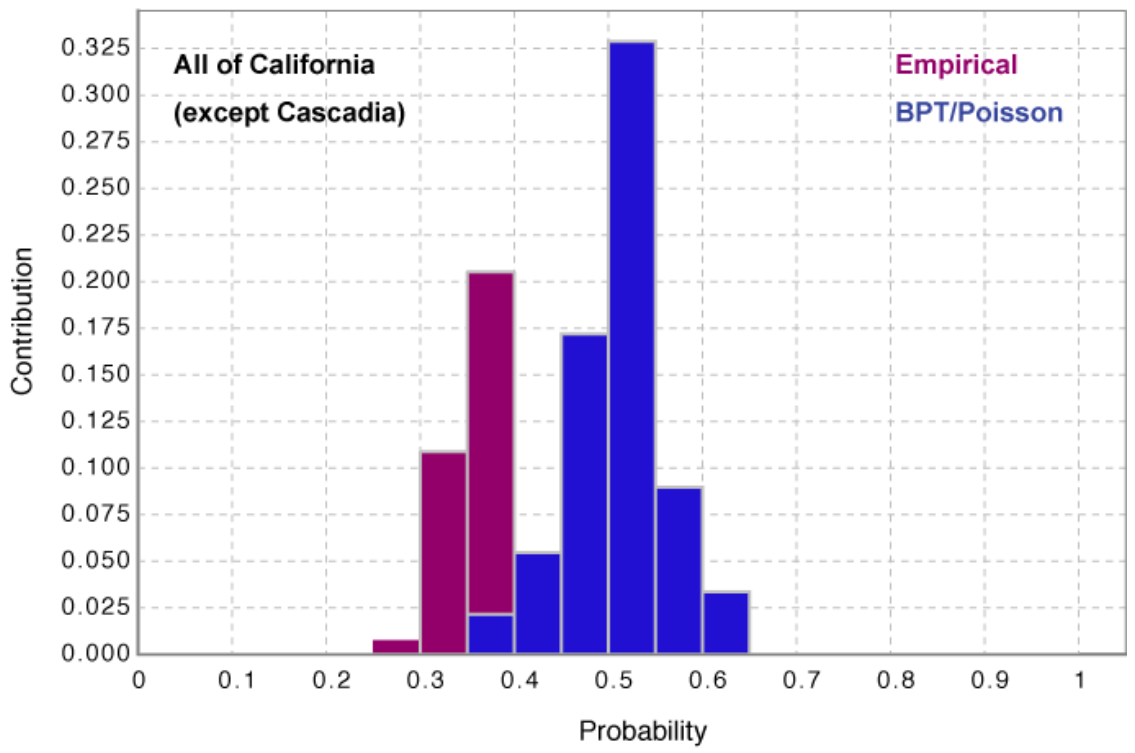

Figure 37. These histograms show the probability-weight contributions from the Empirical (maroon) versus BPT/Poisson (blue) probability-model branches of the logic tree. The top applies to M•6.7 events in the WGCEP (2003) study region and the bottom applies to M•7.5 events in the entire region. Note that the maroon bins stack on top of the blue (rather than behind). These plots reveal that Empirical model branches lead to systematically lower probabilities than the BPT/Poisson branches. Total area (blue and red) integrates to unity. Cascadia is not included in this figure. 


\section{Probability Contribution of Magnitude-Area Relationship}

(a) $M \geq 6.7$ Earthquakes, All Sources

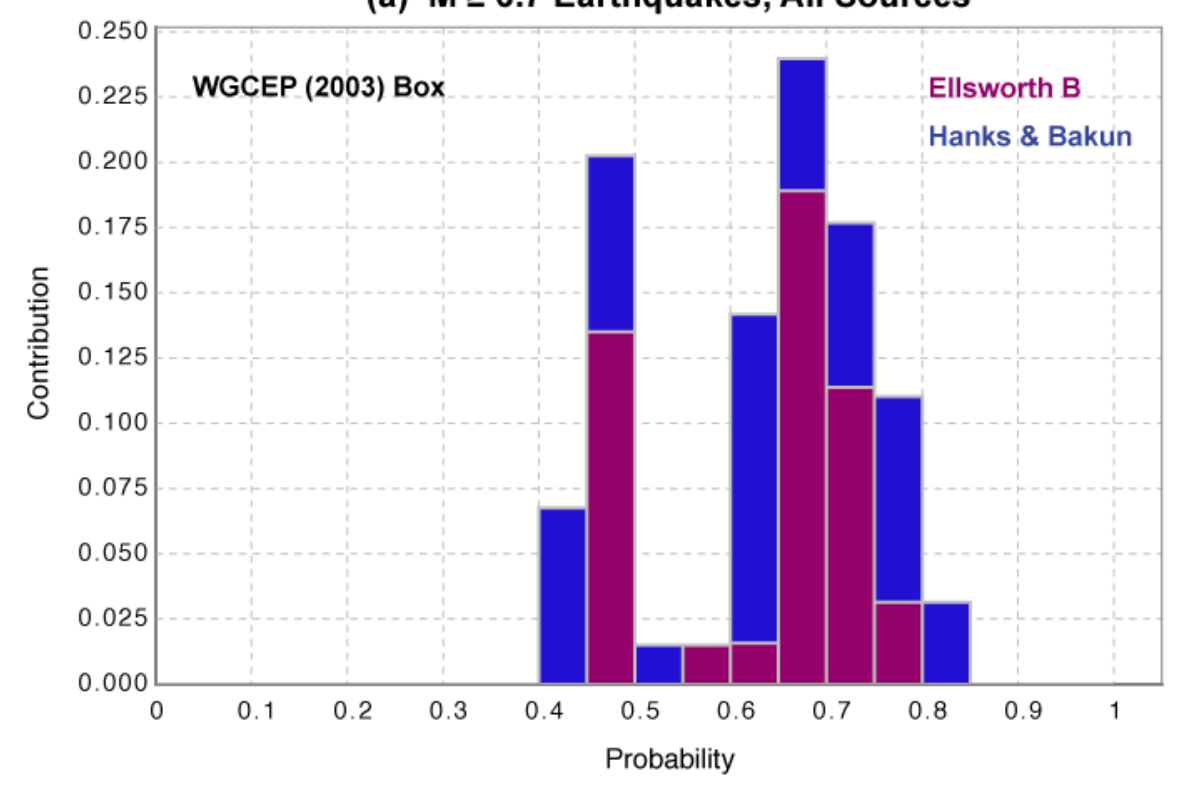

(b) $M \geq 7.5$ Earthquakes, All Sources

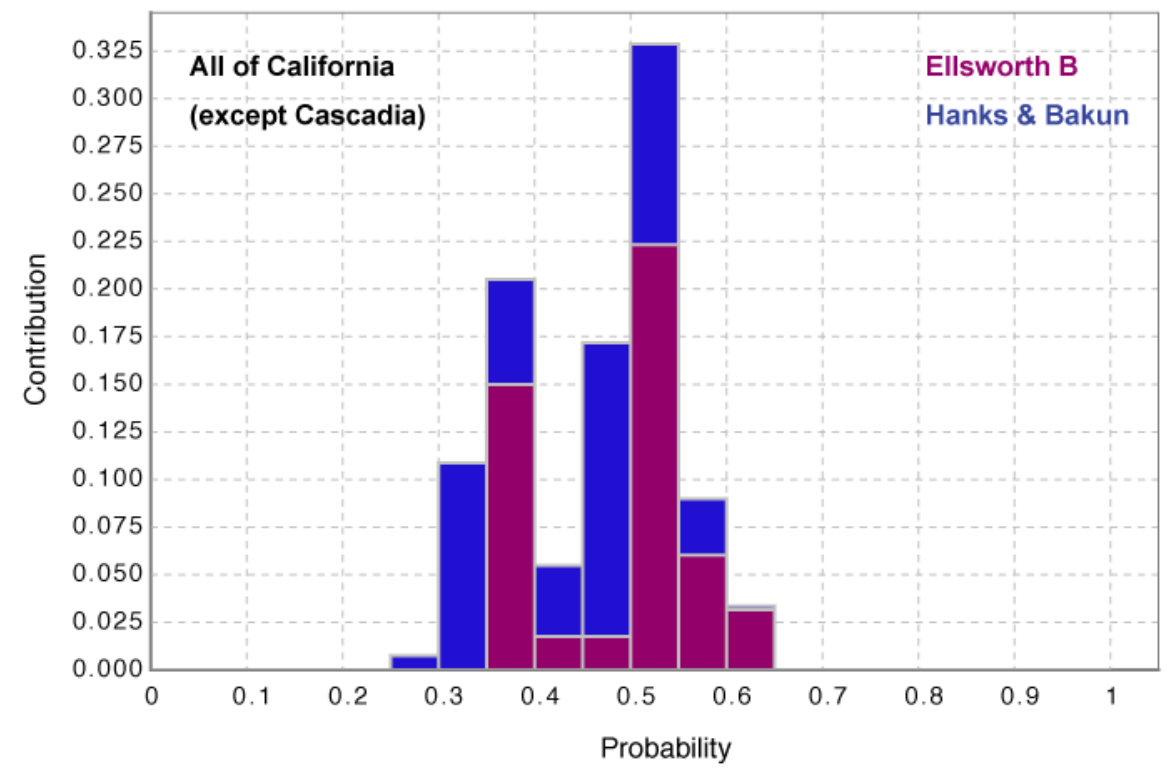

Figure 38. Same as Figure 36, but for the Ellsworth-B versus Hanks and Bakun magnitude-area relationships. Cascadia is not included in this figure.

Figure $38 \mathrm{~b}$ shows the influence of magnitude-area relationship on the probability of all $\mathrm{M} \geq 7.5$ events in the study region. The Ellsworth-B relationship has an average probability of $49 \%$, whereas Hanks and Bakun has an average of $44 \%$; this is consistent with the latter relationships having higher magnitudes for given rupture areas and therefore lower rates in a moment-balanced model. Figure 38a 
shows the same plot for all $M \geq 6.7$ in the WGCEP (2003) region, where the interpretation is not so simple. The mean probabilities for these two cases are nearly identical, but the Hanks and Bakun relationship shows a wider spread due to the fact that it predicts both lower and higher magnitudes, compared to Ellsworth-B, at lower and higher rupture areas, respectively (the moment-balanced versus apriori branches may be influential as well).

Figure 39 shows the influence of aperiodicity on the probability of $M \geq 7.0$ events on segmented Type-A faults, the only branch that utilizes the BPT model. There is a perceptible influence, with lower aperiodicities producing higher probabilities, but the effect is relatively small and does not influence final mean probabilities.

\section{Probability Contribution of Aperiodicity}

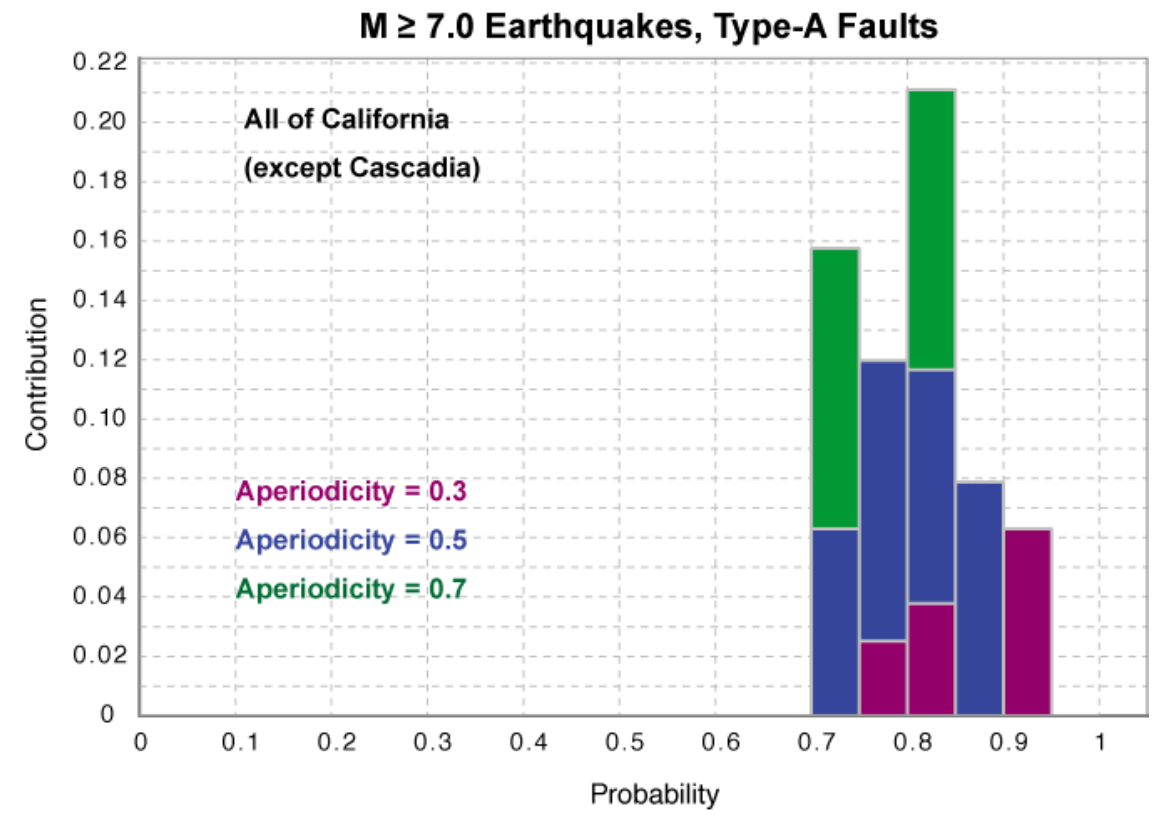

Figure 39. The influence of aperiodicity on $\mathrm{M} \bullet 7$ probabilities for BPT branches aggregated over all TypeA faults. Note that the bins stack on top of each other rather than being plotted behind. Cascadia is not included in this figure. 


\section{G. Discussion}

\section{G.1. Model Limitations and Opportunities for Future Improvements}

It is important to note that not all epistemic uncertainties have been accounted for in UCERF 2. Those available but given zero weight in our final logic tree, include alternatives for the following: (1) alternative moment-rate reductions on faults (e.g., for smaller earthquakes and aftershocks); (2) the fraction of characteristic versus Gutenberg-Righter magnitude-frequency distribution for Type-B and unsegmented Type-A fault models, as well as the particular parameter values assigned to these distributions; (3) alternative magnitude-area relations; (4) alternative slip-distributions for the segmented models; (5) the minimum- and maximum-rate a-priori models for Type-A faults; (6) the weights assigned to Type-C sources; and (7) the weights assigned to the various probability models.

Logic-tree branches included by WGCEP (2003), but currently left out in our framework, include epistemic uncertainties for segment endpoints, upper and lower seismogenic depths, aseismicity factors, slip rates, and the alternative BPT-step and time-predictable" probability models. Indeed, we left these out specifically because the WGCEP (2003) sensitivity analyses showed them to be of lower-order importance, which is confirmed by the fact that our final overall uncertainties agree well with theirs. Nevertheless, the uncertainty bounds cited for UCERF 2 do not include all the aforementioned potential contributions, which is why we have not assigned them specific confidence levels.

As stated repeatedly in this report, our goal has been to provide a reliable basis for quantifying mean hazard and loss, and we believe we have done so within our model framework. However, there are inherent limits to our overall framework that warrant disclosure. In what follows we discuss several that we believe should be addressed as soon as possible.

Relax segmentation and include fault-to-fault ruptures. Following previous working groups, we have applied a segmented model on those faults that we think we understand the best (Type-A). This proves convenient in not only constructing the long-term earthquake rate model, but also in computing conditional, time-dependent probabilities (addressed in the next section). However, recent interpretations of paleoseismic data on the southern San Andreas, arguably the most extensively studied fault in the word, include the possibility that no persistent rupture boundaries exist (Weldon et al., 2005).

Furthermore, our model does not allow several neighboring faults to ever rupture together, in spite of their close proximity. For example, a Calaveras rupture might branch onto the Hayward fault (Manaker et al., 2005), and a northern San Jacinto fault might rupture with the Mojave section of the San Andreas. Another example is the Great Valley fault, which in the model has been divided into 14 distinct Type-B sources that can never rupture together. This potential problem was pointed out by Jackson (1996) in an opinion paper regarding WGCEP (1995). It was also dramatically exemplified by the 2002 Denali earthquake in Alaska, where rupture began on the Susitna Glacier Fault, jumped onto the Denali fault, and then jumped off onto the Totschunda fault (Eberhart-Phillips et al., 2003). Anderson et al. (2003) subsequently published a paper stating that "a large northern San Jacinto fault earthquake could trigger a cascading rupture of the Sierra Madre-Cucamonga system, potentially causing a moment magnitude 7.5 
to 7.8 earthquake on the edge of the Los Angeles metropolitan region". A related issue is that our model implies that earthquakes greater than magnitude 7.0 will not occur in much of California.

Most working group members agree that these limitations should be addressed in future studies, and that some of the things our model precludes will eventually happen. In fact, some believe that segmentation and lack of fault-to-fault ruptures is the likely culprit of the over-prediction of earthquake rates near M 6.5; although our model is now within the $95 \%$ confidence bounds of the observations, it is still well above the best estimate. The significant challenge will be in constructing such a model that honors what we know about faults - where they are, their slip rates, and paleoseismic constraints on recurrence intervals - and also what we know about the ability of rupture to jump from one fault to another (e.g., Harris and Day, 1993; Wesnousky, 2006).

Self-consistent elastic-rebound-theory-motivated renewal models. We have demonstrated a selfconsistency problem with the WGCEP (2003) methodology for computing conditional time-dependent probabilities when both single and multi-segment ruptures are allowed. We applied it nonetheless, because it remains our best available model for honoring the intent of elastic rebound theory, which working group members felt was important. Unfortunately this self-consistency problem gets worse as segmentation assumptions are relaxed, so alternative approaches will be needed in the future.

Earthquake triggering and clustering. Some have argued that earthquake-clustering effects are more consistent with worldwide data than traditional elastic-rebound-theory-motivated renewal models (e.g., Kagan and Jackson, 1999). Does the interactive complexity of a fault system effectively erase, or at least significantly reduce, any predictability implied by elastic rebound theory? Are earthquake triggering effects, as implied by aftershock statistics, equally or more relevant than renewal models at large magnitudes? The present working group acknowledges that the answers to these questions may be yes. Even WGCEP (1990) addressed this possibility by noting a number of suggestive earthquake pairings in the nineteenth century. More recent, proximal sets of events in California include: (1) the 1971 San Fernando and 1994 Northridge earthquakes; (2) the 1991 Joshua Tree, 1992 Landers, 1992 Big Bear, and 1999 Hector Mine earthquakes; and (3) the 2003 San Simeon and 2005 Parkfield earthquakes.

The USGS recently went public with a CEPEC-endorsed Short Term Earthquake Probability (STEP) model that produces 24-hour forecasts based on empirical aftershock statistics (Gerstenberger et al., 2005). An interesting implication of this model is that the highest probability for a large event on the southern SAF, for example, will be the moment after it actually happens. Many advocates of elasticrebound theory would take issue with this behavior. However, the two overall perspectives are not necessarily incompatible, as a renewal model might be most appropriate for the patch of fault that has just ruptured, whereas a triggering model might be more appropriate for those in the general vicinity. We believe a high priority should be placed on the implementation of such clustering models, especially to the extent that user communities are interested in shorter-term forecasts. As we noted, we do not believe that accounting for potential triggering effects from any recent earthquakes would have significantly changed our findings, especially if all uncertainties associated with such calculations were accounted for. Nevertheless, this could change with the occurrence of one sizable earthquake. 
Extent of earthquake rupture surfaces. Inconsistencies among currently published magnitude-area relationships need to be resolved. Our choices were based in part on the influence they had on our overprediction of earthquake rates near M 6.5. Interestingly, the relationships we preferred on this basis are precisely those that physics-based waveform modelers find problematic (because the implied high stress drops map into unrealistically high ground motions). Related to this issue is our definition of average upper- and lower-seismogenic depth, as well as our aseismicity factors and coupling coefficients. In reality, faults do not transition from seismic to aseismic at any one particular depth, and indeed there is likely a conditionally stable zone implying these depths may be magnitude dependent. We need consilience on the inter-relationship of all these physical attributes.

Model complexity. Our models have become more and more complex with each working group. One manifestation is that the volume of model documentation has seemingly followed a power-law increase with time (known informally as "Dieterich's law"). This obviously makes the models more difficult to review, but also makes them more prone to error with respect to implementation. Is increased complexity endemic to the development of system-level models, or is it a reflection of a patchwork approach taken in improving the models?

In our current framework, considerable time and effort goes into deciding whether a fault is Type-A or Type-B, identifying where one fault ends and another begins, and in adding Type-C shear zones in areas where the faults and background seismicity don't seem to add up. If Nature doesn't honor such distinctions, by virtue of exhibiting a fractal distribution of faults, for example, then perhaps we should be looking for a model that doesn't need them.

We believe that simpler, system-level earthquake models need to be developed. One promising approach includes physics-based earthquake simulators (e.g., Ward, 2000; Rundle et al., 2006). In fact, these models appear to solve many of the problems we face, including the relaxation of segmentation assumptions, allowing fault-to-fault ruptures, exhibiting self-consistent elastic-rebound behavior, and including clustering and triggering effects. Significant issues exist with such simulators, however, such as how to adequately represent epistemic uncertainties given so many free parameters, and how to forecast future events when you can't directly impose recent earthquake history. At the very least, earthquake simulators should prove valuable in terms of guiding the development of alternative approaches, just as waveform modeling has helped guide the functional form of empirical attenuation relationships.

Other issues. We need more quantitative and objective ways of assigning logic-tree branches; e.g., systematic procedures based on Bayesian methods. We also need earthquake loss evaluation tools for the purpose of identifying and trimming unimportant logic-tree branches. Further development of kinematically consistent deformation models could have a significant impact on future models. Progress on the age-old debate on whether faults exhibit Gutenberg-Richter or characteristic magnitude-frequency distributions would be very helpful. Part of the problem has been differences in how "the fault" is defined, which is perhaps inevitable given the fractal nature of the system. The more relevant question is whether each patch (or small volume) on a fault exhibits a Gutenberg-Richter or characteristic distribution of hypocenters. Finally, a better understanding of the empirical probability model is in order, especially 
given the fact that that "stress shadow" interpretation of WGCEP (2003) is called into question by the fact that most of the state appears to be in an seismicity lull.

Most of the above issues were recognized at the beginning of the project. However, project deadlines impeded their resolution, as did the specific needs of the user community. As an example of the latter, the current building code development relies on defining an "average" deterministic event for each fault source. In a model where segmentation is relaxed and faults are allowed to rupture together, it is not clear whether a meaningful definition of an "average" event exists. It was also made clear to us that, due to computational demands, loss modelers would not have been able to process the much larger number of ruptures that would exist in such a model. From an earthquake insurance policy perspective, including triggered events and clustering will also raise questions about how, or even if, such events can be distinguished from "ordinary" aftershocks (which is important with respect to how policy deductibles are handled). We look forward to working in tandem with these user groups as we develop more sophisticated models in the future.

\section{G.2. Accomplishments and Key Differences From Previous Studies}

The overarching accomplishment of the present working group has been the development of a statewide model that uses consistent methodologies, data-handling standards, and uncertainty treatment in all regions. This was no trivial task given budget limitations, time constraints, and the need to form consensus among several different groups of scientists that traditionally have not had to collaborate. Of particular note is the fact that the earthquake rate model underpinning our time-dependent UCERF 2, which will presumably influence insurance rates, is identical to that used in the 2007 USGS national hazard maps, which will influence building codes.

The entire development process of UCERF 2 was open and broadly exhibited to all specialists who cared to voice a viewpoint. Each step was reviewed by a standing review panel, as well as by other top scientists, and the final model was evaluated by NEPEC and CEPEC.

Considerable effort was put into data compilation, evaluation, and analysis. This included: (1) developing a new, statewide earthquake catalog; (2) utilization of the comprehensive SCEC Community Fault Model; (3) revision of fault slip rates, and inclusion on new distributed shear zones, based on GPS data and kinematic-consistency considerations; (4) compilation of paleoseismic trench data and Monte Carlo analysis thereof in terms of implied recurrence interval distributions; and (5) reassessment of creep observations.

Important improvements for Type-A faults include more objective and quantitative methods for constructing expert opinion (a-priori) models using paleoseismic constraints, with that applied to the southern San Andreas fault being particularly exemplary. We also provide a more general, inversion methodology for adjusting these models to be consistent with slip-rate data (moment balancing) and, optionally, paleoseismic event-rate data. An unsegmented model options was also provided for Type-A faults.

Any earthquake rate model can be tested for consistency with a variety of data covering different areas and different time scales. For the entire area over a long time, the earthquake rate model should reproduce the strain related to the relative motion of the Pacific and North American Plates. On shorter 
time scales and in smaller areas the model should be consistent with geologic slip rates on faults, paleoseismic earthquake rates, measured geodetic strain, and historic seismicity. A number of these data sets are used in creating UCERF2, then others are used to check the model. It is encouraging that a model based on fault slip rates, paleoseismology and geodetics can be made consistent with both the large-scale motion of the Pacific-North American plate boundary and with historic seismicity.

Another noteworthy contribution was a much more careful analysis of the historical earthquake catalog. Corrections made for magnitude uncertainties, rounding effects, and variations in magnitude completeness led to a magnitude frequency distribution that is significantly different than that predicted by the NSHMP (2002) model. A large proportion of our time went to resolving this discrepancy, or more specifically, bringing our prediction to within the $95 \%$ confidence bounds of the observations. Attributes of the model that were different from NSHMP 2002 and lessened the bulge included the following: (1) a statewide $10 \%$ moment-rate reduction on faults to account for the contribution of smaller events and aftershocks; (2) the option to connect more Type-B faults; (3) the zero b-value option for the GutenbergRichter contribution of Type-B faults; and (4) a threefold reduction in the rate of background seismicity at $\mathrm{M}>6.5$.

In addition to comparing our forecast with observed seismicity rates, the model was evaluated for consistency with the Pacific-North American plate-boundary motion. UCERF 2 captures these motions and their spatial distribution quite closely. This is true when we compare the expected strain in large blocks of crust with observations, and when we examine slip rates on individual faults. These tests are particularly important because they give an independent means of assessing and validating spatial variations in hazard in UCERF 2.

We highlight the consistency between UCERF 2 and the WGCEP (2003) study as particularly noteworthy. The WGCEP (2003) state-of-the-art approach to forecasting was a breakthrough in many respects, and it was possibly the most complex and involved earthquake forecast ever attempted. UCERF 2 was necessarily less complex in approach because of the larger scope and time limits. Nonetheless, our agreement gives us confidence that we succeeded in capturing the important aspects of WGCEP (2003) in our statewide application.

Perhaps the most valuable result from UCERF 2 is that the relative time-dependent hazard from region to region, and from fault to fault, can be compared in meaningful ways. We have compared, for example, the probability of earthquakes across all damaging magnitudes striking in either northern or southern California, and have provided quantitative epistemic uncertainties in the process.

Finally, the entire model was implemented in the open-source, modular, and extensible framework provided by the OpenSHA platform (Field et al., 2003) and utilized distributed electronic databases, which will make future improvement and modifications easier. We have also provided graphical-userinterface based analysis tools that others can use to verify our results and/or to explore other model options (e.g., logic-tree branches that have been given zero weight). 


\section{Acknowledgments}

The authors are grateful to the members of the Scientific Review Panel-W. Ellsworth (chair), M. Blanpied, L. Cluff, A. Cornell, A. Frankel, D. Jackson, D. Schwartz, and S. Wesnousky-who reviewed all aspects of this study and provided innumerable suggestions for its improvement. Generous advice and reviews were also provided by the National Earthquake Prediction Evaluation Committee (J. Dieterich, chair), the California Earthquake Prediction Evaluation Committee (J. Parrish, chair), the California Earthquake Authority Multidisciplinary Research Team (R. Anderson, B. Rowshandel), and a number of individual reviewers of the report's many appendices. Tran Huynh cheerfully assisted all of the authors throughout the report production and handled the many technical issues with great skill. Bill Ellsworth guided the entire publication process through the USGS labyrinth. This study was sponsored by the California Earthquake Authority, the U.S. Geological Survey, the California Geological Survey, and the Southern California Earthquake Center; SCEC acknowledges the support of the National Science Foundation under Cooperative Agreement EAR-0529922 and the USGS under Cooperative Agreement 07HQAG0008. This document is registered as USGS Open File Report 2007-1437, CGS Special Report \#203, and SCEC Contribution \#1138. 


\section{References}

Aki, K., and Richards, P. G. (1980). Quantitative Seismology: Theory and Methods, W. H. Freeman and Co., New York, 932 pp.

Algermissen, S. T., and D. M. Perkins (1982). A Probabilistic Estimate of Maximum Acceleration in Rock in the Contiguous United States, U.S. Geol. Surv. Open File Report 76-416.

Anderson, G., B. Aagaard, and K. Hudnut (2003). Fault Interactions and Large Complex Earthquakes in the Los Angeles Area, Science, 302, 1946-1949; doi: 10.1126/science.1090747.

Atwater, B., and E. Hemphill-Haley (1997) Recurrence Intervals for Great Earthquakes of the Past 3,500 Years at Northeastern Willapa Bay, Washington, U.S. Geol. Surv. Prof. Paper. 1576, 108 pp.

Bakun, W. H. (2000). Seismicity of California's North Coast. Bull. Seismol. Soc. Am. 90, 797-812.

Belardinelli, M. E., M. Cocco, O. Coutant, and F. Cotton (1999). Redistribution of dynamic stress during coseismic ruptures; evidence for fault interaction and earthquake triggering, J. Geophys. Res., 104, $14,925-14,945$.

Bennett, R. A., A. M. Friedrich, and K. P. Furlong (2004). Codependent histories of the San Andreas and San Jacinto fault zones from inversion of fault displacement rates, Geology, 32, 961-964.

Biasi, G. P., and Weldon, R. J. (2006). Estimating surface rupture length and magnitude of paleoearthquakes from point measurements of rupture displacement, Bull. Seismol. Soc. Am., 96, $1612-1623$.

Bird, P. (2003). An updated digital model of plate boundaries, Geochem. Geophys. Geosystems, 4, 1027, doi:10.1029/2001GC000252.

Bird, P., and Y. Y. Kagan (2004). Plate-Tectonic Analysis of Shallow Seismicity: Apparent Boundary Width, Beta, Corner Magnitude, Coupled Lithosphere Thickness, and Coupling in Seven Tectonic Settings, Bull. Seismol. Soc. Am., 94, 2380-2399; doi:2310.1785/0120030107.

Cao, T., Bryant, W.A., Rowshandel, B., Branum, D., and Wills, C. J., 2003, The Revised 2002 California Probabilistic Seismic Hazard Maps June 2003: California Geological Survey Web Page http://www.consrv.ca.gov/cgs/rghm/psha/fault_parameters/pdf/2002_CA_Hazard_Maps.pdf.

Cornell, C. A. (1968). Engineering seismic risk analysis, Bull. Seismol. Soc. Am., 58, 1583-1606.

Dawson, T., R. J. Weldon II, and G. Biasi (2007a). Recurrence interval and event age data for type A faults, U. S. Geol. Surv. Open File Rep. 2007-1437-B.

Dawson, T., T. Rockwell, R. J. Weldon II, and C. Wills (2007b). Summary of geologic data and development of a priori rupture models for the Elsinore, San Jacinto and Garlock faults, $U$. S. Geol. Surv. Open File Rep. 2007-1437-F.

DeMets, C., R. G. Gordon, D. F. Argus, and S. Stein (1994). Effect of recent revisions to the geomagnetic reversal time-scale on estimates of current plate motions, Geophys. Res. Lett., 21, 2191-2194, doi:10.1029/94GL02118.

Dorsey, R. J. (2003). Late Pleistocene slip rate on the Coachella Valley segment of the San Andreas Fault and implications for regional slip partitioning, Geol. Soc. Am. Abstracts with Programs, 35(4), 22.

Eberhart-Phillips, D., P. J. Haeussler, J. T. Freymueller, A. D. Frankel, C. M. Rubin, P. Craw, N. A. Ratchkovski, G. Anderson, G. A. Carver, A. J. Crone, T. E. Dawson, H. Fletcher, R. Hansen, E, L. Harp, R. A. Harris, D. P. Hill, S. Hreinsdóttir, R. W. Jibson, L. M. Jones, R. Kayen, D. K. Keefer, C. F. Larsen, S. C. Moran, S. F. Personius, G. Plafker, B. Sherrod, K. Sieh, N. Sitar, W. K. Wallace (2003). The 2002 Denali Fault Earthquake, Alaska: A large-magnitude, slippartitioned event, Science, 300, 1113-1118.

Fault Section Database 2.0, USGS-CGS-SCEC California Reference Geologic Fault Parameter Database, http://www.wgcep.org; with online database documentation at http://gravity.usc.edu/WGCEP/resources/documents/CA_RefFaultParams_v4.6.pdf

Fay, N. P., and E.D. Humphreys (2005). Fault slip rates, effects of elastic heterogeneity on geodetic data, and the strength of the lower crust in the Salton Trough region, southern California, J. Geophys. Res., 110, B09401, doi:10.1029/2004JB003548. 
FEMA, Federal Emergency Management Agency (2000). HAZUS 99, Estimated Annualized Earthquake Losses for the United States, Federal Emergency Management Agency Report 366, Washington, D.C., September, 2000, 32 pp.

Felzer, K. R. (2007a). Calculating California seismicity rates, U.S. Geol. Surv. Open-File Rep., 20071437-I.

Felzer, K. R. (2007b), Empirical Estimation of Regional Time Variation in Seismicity, U.S. Geol. Surv. Open-File Rep., 2007-1437-M.

Felzer, K. R., and T. Cao (2007). WGCEP historical California earthquake catalog, U.S. Geol. Surv. Open-File Rep., 2007-1437-H.

Fialko, Y., (2006). Interseismic strain accumulation and the earthquake potential on the southern San Andreas fault system, Nature, in press.

Field, E. H. (2007a). Overview of the Working Group for the Development of Regional Earthquake Likelihood Models (RELM), Seismol. Res. Lett. 78, 7-16.

Field, E. H. (2007b), A summary of previous Working Groups on California Earthquake Probabilities, Bull. Seismol. Soc. Am., 97, p. 1033-1053, doi:10.1785/0120060048.

Field, E. H., and V. Gupta (2007). Conditional, Time-Dependent Probabilities for Segmented Type-A Faults in the WGCEP UCERF 2, U. S. Geol. Surv. Open File Rep. 2007-1437-N.

Field, E. H., N. Gupta, V. Gupta, M. Blanpied, P. Maechling, and T. H. Jordan (2005). Hazard Calculations for the WGCEP-2002 Earthquake Forecast Using Distributed Object Technologies, Seismol. Res. Lett. 76, 161-167.

Field, E. H., D. D. Jackson, and J. F. Dolan (1999). A Mutually Consistent Seismic-Hazard Source Model for Southern California, Bull. Seismol. Soc. Am. 89, 559-578.

Field, E.H., T.H. Jordan, and C.A. Cornell (2003). OpenSHA: A developing community-modeling environment for seismic hazard analysis, Seismol. Res. Lett., 74, 406-419.

Field, E. H., R. J. Weldon II, V. Gupta, T. Parsons, C. J. Wills, T. E. Dawson, R. S. Stein, and M. D. Petersen (2007). Development of Final A-Fault Rupture Models for WGCEP/NSHMP Earthquake Rate Model 2.3, U. S. Geol. Surv. Open File Rep. 2007-1437-G.

Flück, P., R. D. Hyndman, and K. Wang (1997). Three-dimensional dislocation model for great earthquakes of the Cascadia Subduction Zone, J. Geophys. Res., 102, 20,539-20,550.

Frankel, A., C. Mueller, T. Barnhard, D. Perkins, E. Leyendecker, N. Dickman, S. Hanson, and M. Hopper (1996). National seismic-hazard maps: documentation June 1996, U.S. Geol. Surv. Openfile Rept. 1996-532.

Frankel, A.D., and M.D. Petersen (2007). Cascadia Subduction Zone, U. S. Geol. Surv. Open File Rep. 2007-1437-L.

Frankel, A. D., M. D. Petersen, C. S. Mueller, K. M. Haller, R. L. Wheeler, E. V. Leyendecker, R. L. Wesson, S. C. Harmsen, C. H. Cramer, D. M. Perkins, K. S. Rukstales (2002). Documentation for the 2002 update of the national seismic hazard map, U.S. Geol. Surv. Open-file Report 2002-420.

Gardner, J. K., and L. Knopoff (1974). Is the sequence of earthquakes in southern California with aftershocks removed Poissonian?, Bull. Seismol. Soc. Am. 64, 1363-1367.

Gerstenberger, M., S. Wiemer, L.M. Jones, and P.A. Reasenberg (2005). Real-time forecast of tomorrow's earthquakes in California, Nature, 435, 328-331.

Gomberg, J., P. Bodin, and P. A. Reasenberg (2003). Observing earthquakes triggered in the near field by dynamic deformations, Bull. Seismol. Soc. Am., 93, 118-138.

Goldfinger, C., A. E. Morey, C. H. Nelson, J. Gutierrez-Pastor, J. E. Johnson, E. Karabanov, J. Chaytor, and A. Eriksson (2007). Rupture lengths and temporal history of significant earthquakes on the offshore and north coast segments of the northern San Andreas Fault based on turbidite stratigraphy, Earth Planet. Sci. Lett., 254, 9-27.

Gutenberg, B., and C. Richter (1944). Frequency of earthquakes in California Bull. Seismol. Soc. Am. 34, 185-188.

Hagiwara, Y. (1974). Probability of earthquake occurrence as obtained from a Weibull distribution analysis of crustal strain, Tectonophysics, 23, 323-318. 
Hanks, T. C., and W. H. Bakun (2002). A bilinear source-scaling model for $M$-log $A$ Observations of continental earthquakes, Bull. Seismol. Soc. Am., 92, 1841-1846.

Hanks, T. C., and W. H. Bakun (2007). $M$-log A observations for recent large earthquakes, Bull. Seismol. Soc. Am., in press , 2007.

Hanks, T. C., and H. Kanamori (1979). A moment magnitude scale, J. Geophys, Res., 84, 2348-2350.

Hardebeck J. L. 2004. Stress triggering and earthquake probability estimates, J. Geophys, Res., 109, B04310, doi:10.1029/2003JB002437.

Harris, R. A., and S. M. Day (1993). Dynamics of fault interaction: Parallel strike-slip faults, J. Geophys. Res., 98, 4461-4472.

Hemphill-Haley, M. A., and R. J. Weldon, II (1999). Estimating prehistoric earthquake magnitude from point measurements of surface rupture, Bull. Seismol. Soc. Am., 89, 1264-1279.

Hill, D. P., P. A. Reasenberg, A. Michael, W. J. Arabasz, G. Beroza, J. N. Brune, D. Brumbaugh, R. Castro, S. Davis, D. dePolo, W. L. Ellsworth, J. Gomberg, S. Harmsen, L. House, S. M. Jackson, M. Johnston, L. Jones, R. Keller, S. Malone, L. Munguia, S. Nava, J. C. Pechmann, A. Sanford, R. W. Simpson, R. S. Smith, M. Stark, M. Stickney, A. Vidal, S. Walter, V. Wong, and J. Zollweg (1993). Seismicity in the western United States remotely triggered by the M 7.4 Landers, California, earthquake of June 28, 1992, Science, 260, 1617-1623.

Hough, S. E. (1996). The case against huge earthquakes, Seismol. Res. Lett. 67, 3-4.

Humphreys, E. D., and R. J. Weldon II (1994). Deformation across the western United States: a local estimate of Pacific-North America transform deformation, J. Geophys. Res., 99, 19,975-20,010.

Jackson, D. D. (1996). The case for huge earthquakes, Seismol. Res. Lett. 67, 4-5.

Janecke, S. U., S. M. Kirby, V.E. Langenheim, A. N. Steely, R. J. Dorsey, B. Housen, and A. T. Lutz, (2005). High geologic slip rates on the San Jacinto fault zone in the SW Salton Trough, and possible near-surface slip deficit in sedimentary basins. GSA Abstr. w/ Progr., 37(7), 275.

Kagan, Y. Y. and D. D. Jackson (1999). Worldwide doublets of large shallow earthquakes, Bull. Seismol. Soc. Amer., 89, 1147-1155.

Kagan, Y. Y., and L. Knopoff (1987). Random stress and earthquake statistics: time dependence, Geophys. J. R. Astron. Soc., 88, 723-731.

Kelson, K. I., G. D. Simpson, W. R. Lettis, and C. C. Haraden (1996). Holocene slip rate and recurrence of the northern Calaveras fault at Leyden Creek, eastern San Francisco Bay region: Journal of Geophysical Research, 101, 5961-5975.

Kelson, K. I., A. R. Streig, R. D. Koehler, and K.-H. Kang (2006). Timing of late Holocene paleoearthquakes on the northern San Andreas fault at the Fort Ross Orchard site, Sonoma County, California, Bull. Seismol. Soc. Am., 96, 1012-1028.

Kendrick, K. J., D. M. Morton, S. G. Wells, and R. W. Simpson (2002). Spatial and temporal deformation along the northern San Jacinto fault, southern California; Implications for slip rates, Bull. Seismol. Soc. Am., 92(7), 2782-2802.

Kent, G. M., J. M. Babcock, N. W. Driscoll, A. J. Harding, J. A. Dingler, G. G. Seitz, J. V. Gardner, L. A. Mayer, C. R. Goldman, A. C. Heyvaert, R. C. Richards, R. Karlin, C. W. Morgan, P. T. Gayes, and L. A. Owen (2005). 60 k.y. record of extension across the western boundary of the Basin and Range province: Estimate of slip rates from offset shoreline terraces and a catastrophic slide beneath Lake Tahoe, Geology, 33(5), 365-368.

Kilb, D., J. S. Gomberg, and P. Bodin (2000). Triggering of earthquake aftershocks by dynamic stresses Nature, 408, 570-574,.

Kostrov V. V. (1974). Seismic moment and energy of earthquakes, and seismic flow of rocks, Izv. Acad. Sci. USSR Phys. Solid Earth, 1, Eng. Transl., 23-44,.

Lawson, C. L., and D. J. Hanson (1974). Solving Least Squares Problems, Prentice-Hall, Englewood Cliffs, New Jersey.

Lienkaemper, J. J., and P. L. Williams (2006). A 1650-Year Record of Large Earthquakes on the Southern Hayward Fault, Seismol. Res. Lett., 77, 229. 
Manaker, D. M., A. J. Michael, and R. Burgmann (2005). Subsurface Structure and Kinematics of the Calaveras-Hayward Fault Stepover from Three-Dimensional Vp and Seismicity, San Francisco Bay Regions, California, Bull. Seismol. Soc. Am., 95, 446-470.

Matthews, M. V., W. L. Ellsworth, and P. A. Reasenberg (2002). A Brownian Model for Recurrent Earthquakes, Bull. Seismol. Soc. Am., 92, 2233 - 2250,.

McCrory, P. A., J. L. Blair, D. H. Oppenheimer, and S. R. Walter (2004). Depth to the Juan de Fuca slab beneath the Cascadia subduction margin: a 3-D model for sorting earthquakes, U.S. Geol. Surv. Data Series, 91.

Meade, B. J., and B. H. Hagar (2005). Block models of crustal motion in southern California constrained by GPS measurements, J. Geophys. Res., 110, no. B03403.

Menke, W. (1989). Geophysical Data Analysis: Discrete Inverse Theory, Academic Press, 289 pp.

NRC, National Research Council (2003). Living on an Active Earth: Perspectives on Earthquake Science, Committee on the Science of Earthquakes (T. H. Jordan, chair), National Academies Press, Washington DC, 418 pp.

Nazareth, J. J., and E. Hauksson (2004). The seismogenic thickness of the southern California crust, Bull. Seismol. Soc. Am., 94, 940-960.

NSHMP, National Seismic Hazard Mapping Project (2002). Documentation for the 2002 Update of the National Seismic Hazard Maps, U. S. Geol. Surv. Open File Rep. 2002-420.

NSHMP, National Seismic Hazard Mapping Project (2007). Preliminary Documentation for the 2007 Update of the United States National Seismic Hazard Maps, U. S. Geol. Surv. Open File Rep. 2007-xxxx, submitted.

Nishenko, S. P., and R. Buland (1987). A generic recurrence interval distribution for earthquake forecasting, Bull. Seismol. Soc. Am., 77, 1382-1399.

Nishimura, C. E., D. S. Wilson, and R. N. Hey (1984), Pole of rotation analysis of present-day Juan de Fuca plate motion, J. Geophys. Res., 89, p. 10,283-10,290.

O'Connell, D. R. H., and J. R. Unruh (2000). Updated Seismotectonic Evaluation of faults within $10 \mathrm{~km}$ of Monticello Dam, Solano Project, California, U.S. Bureau of Reclamation, Geophysics, Paleohydrology and Seismotectonics Group, Geotechnical Services, Denver, 101 pp.

Oppenheimer, D., Beroza, G., Carver, C., Dengler, L., Eaton, J., Gee, L., Gonzalez, F., Jayko, A., Li, W. H., Lisowski, M., Magee, M., Marshall, G., Murray, M., McPherson, R., Romanowicz, B., Satake, K., Simpson, R., Somerville, P., Stein, R., and Valentine, D. (1993). The Cape Mendocino, California earthquake sequence of April 1992: subduction at the triple junction, Science, 261, 433-438.

Oskin, M., L. Perg, D. Blumentritt, S. Mukhopadhyay, and A. Iriondo (2007). Slip rate of the Calico fault: Implications for geologic versus geodetic rate discrepancy in the Eastern California shear zone, J. Geophys. Res., in press.

Page, M. T. and J. M. Carlson (2006). Methodologies for earthquake hazard assessment: model uncertainty and the WGCEP-2002 forecast, Bull. Seismol. Soc. Am. 96, 1624-1633.

Parsons, T. (2002). Post-1906 stress recovery of the San Andreas fault system from 3-D finite element analysis, J. Geophys. Res., 107, 2162, doi:10.1029/2001JB001051.

Parsons, T. (2005). Significance of stress transfer in time-dependent earthquake probability calculations, J. Geophys, Res. 110, doi:10.1029/2004JB003190.

Parsons, T. (2007a), Monte Carlo Method for Determining Earthquake Recurrence Parameters from Short Paleoseismic Catalogs: Example Calculations for California, U. S. Geol. Surv. Open File Rep. 2007-1437-C.

Parsons, T. (2007b). Monte Carlo method for determining earthquake recurrence parameters from short paleoseismic catalogs: Example calculations for California, J. Geophys. Res., in press.

Petersen, M. D., W. A. Bryant, C. H. Cramer, T. Cao, M. S. Reichle, A. D. Frankel, J. J. Lienkaemper, P. A. McCrory, and D. P. Schwartz (1996). Probabilistic Seismic Hazard Assessment for the State of California. California Division of Mines and Geology Open-File Report 96-08, USGS Open File Report 96-706. 
Petersen, M. D., T. Cao, K. W. Campbell, and A. D. Frankel (2007a). Time-independent and Timedependent Seismic Hazard Assessment for the State of California: Uniform California Earthquake Rupture Forecast Model 1.0, Seismol. Res. Lett., 78, 99-109.

Petersen, M. D., C. S. Mueller, A. Frankel, and Y. Zeng (2007b), Spatial seismicity rates and maximum magnitudes for background earthquakes, U. S. Geol. Surv. Open File Rep. 2007-1437-J.

Plesch, A., and J. H. Shaw (2003). SCEC CFM: a WWW accessible community fault model for Southern California, AGU Fall Meeting Proceedings and Abstracts, 84, S12B-0395.

Plesch, A., J. H. Shaw, C. Benson, W. A. Bryant, S. Carena, M. Cooke, J. Dolan, G. Fuis, E. Gath, L. Grant, E. Hauksson, T. H. Jordan, M. Kamerling, M. Legg, S. Lindvall, H. Magistrale, C. Nicholson, N. Niemi, M. Oskin, S. Perry, G. Planansky, T. Rockwell, P. Shearer, C. Sorlien, M. P. Süss, J. Suppe, J. Treiman, and R. Yeats (2007). Community Fault Model (CFM) for Southern California, Bull. Seismol. Soc. Am., 97, 1793-1802, doi:10.1785/0120050211.

Reasenberg, P. A., T. C. Hanks, and W. H. Bakun (2003). An empirical model for earthquake probabilities in San Francisco Bay Region, California, 2002-2031, Bull. Seismol. Soc. Am. 93, 113.

Reid, H. F. (1911). The elastic-rebound theory of earthquakes, Univ. Calif. Pub. Bull. Dept. Geol. Sci., 6, 413-444.

Rundle, P. B., J. B. Rundle, K. F. Tiampo, A. Donnellan and D. L. Turcotte (2006). Virtual California: fault model, frictional parameters, applications, Pure Appl. Geophys., 163(9), 1819-1846.

Satake, K., K. Wang, and B. Atwater (2003). Fault slip and seismic moment of the 1700 Cascadia earthquake inferred from Japanese tsunami descriptions, J. Geophys. Res., 108(B11), 2535, doi:10.1029/2003JB002521.

Savage, J. S., M. Lisowski, and W.H. Prescott (1990). An apparent shear zone trending north-northwest across the Mojave Desert into Owens Valley, eastern California, Geophys. Res. Lett., 17, 2113 2116.

Schorlemmer, D., M. C. Gerstenberger, S. Wiemer, D. D. Jackson, and D. A. Rhoades (2007). Earthquake Likelihood Model Testing, Seismol. Res. Lett. 78, 17-29.

Schwartz, D. P., and K. J. Coppersmith (1984). Fault behavior and characteristic earthquakes: Examples from the Wasatch and San Andreas fault zones, J. Geophys. Res., 89, 5,681-5,698.

Schwartz, D. P. (1996). Opinion Letter, Seismol. Res. Lett. 67, 5-6.

SSHAC, Senior Seismic Hazard Analysis Committee (1997). Recommendations for Probabilistic Seismic Hazard Analysis: Guidance on Uncertainty and Use of Experts, U.S. Nuclear Regulatory Commission, U.S. Dept. of Energy, Electric Power Research Institute; NUREG/CR-6372, UCRL-ID-122160, Vol. 1-2. Also a review of the document by National Academy Press, Washington, DC, 73 pp.

Sieh, K, E., and P. L. Williams (1990). Behavior of the southernmost San Andreas Fault during the past 300 years, Jour. Geophysical Research, 95, 6629-6645.

Shimazaki, K., and T. Nakata (1980). Time-predictable recurrence model for large earthquakes, Geophys. Res. Lett. 7, 279-282.

Schorlemmer, D., M. C. Gerstenberger, S. Wiemer, D. D. Jackson, and D. A. Rhoades (2007). Earthquake Likelihood Model Testing, Seismol. Res. Lett., 78, 17-29.

Somerville, P. (2006). Review of magnitude-area scaling of crustal earthquakes, Rep. to WGCE, URS Corp., Pasadena, 22 pp.

Stein, R. S. (2007). Earthquake rate model 2.2 of the 2007 Working Group for California Earthquake Probabilities, appendix D: magnitude-area relationships, U.S. Geol. Surv. Open-File Report 20071162 [http://pubs.usgs.gov/of/2007/1162/].

Stein, R. S. and T. C. Hanks (1998). M• 6 earthquakes in southern California during the twentieth century: no evidence for a seismicity or moment deficit. Bull. Seismol. Soc. Am., 88, 635-652.

Stirling, M. W., and S. G. Wesnousky (1997). Do historical rates of seismicity in southern California require the occurrence of earthquake magnitudes greater than would be predicted from fault length?, Bull. Seismol. Soc. Am., 87, 1662-1666. 
Thatcher, W., G. Marshall, and M. Lisowski (1997). Resolution of fault slip along the 470-km long rupture of the great 1906 San Francisco earthquake, J. Geophys. Res., 102, 5353-5367.

Toppozada, T. R., D. M. Branum, M. S. Reichle, and C. L. Hallstrom (2002). San Andreas fault zone, California: $\mathrm{m} \bullet 5.5$ earthquake history, Bull. Seismol. Soc. Am., 92, 2555-2601.

van der Woerd, J., Klinger Y., Sieh, K., Tapponnier P., Ryerson, F. J., and Meriaux A.S. (2006). Longterm slip rate of the southern San Andreas Fault from $10 \mathrm{Be}-26 \mathrm{Al}$ surface exposure dating of an offset alluvial fan, J. Geophys. Res., 111(1), B04407, doi:10.1029/2004JB003559

Ward, S. N. (2000). San Francisco Bay area earthquake simulations: A step toward a standard physical earthquake model, Bull. Seismol. Soc. Am., 90, 370-386.

Wdowinski, S. , Smith-Konter, B. , Bock, Y., and Sandwell, D. (2007). Diffuse interseismic deformation across the Pacific-North America plate boundary, Geology, 35, 311-314, doi:10.1130/G22938A.1.

Weldon II, R. J., G. P. Biasi, C. J. Wills, and T. E. Dawson (2007). Overview of the southern San Andreas fault model, U. S. Geol. Surv. Open File Rep. 2007-1437-E.

Weldon II, R. J., T. E. Fumal, G. P. Biasi, and K. M. Scharer (2005). Past and future earthquakes on the San Andreas fault, Science, 308, 966.

Weldon II, R. J., K. Scharer, T. Fumal, and G. Biasi (2004). Wrightwood and the earthquake cycle: what a long recurrence record tells us about how faults work, GSA Today, 14(9), 4-10.

Wells, D. L., and K. J. Coppersmith (1994). New empirical relationships among magnitude, rupture length, rupture width, rupture area, and surface displacement, Bull. Seismol. Soc. Am., 84, 9741002 .

Wesnousky, S. (2006). Predicting the endpoints of earthquake ruptures, Nature, 444, 358-360.

Wills C. J., R. J. Weldon II, and W. A. Bryant (2007a). California fault parameters for the National Seismic Hazard Maps and Working Group on California Earthquake Probabilities 2007, U. S. Geol. Surv. Open File Rep. 2007-1437-A.

Wills C. J., R. J. Weldon II, and E. H. Field (2007b). A-priori rupture models for Northern California Type-A faults, U. S. Geol. Surv. Open File Rep. 2007-1437-K.

Wisely, B. A., D. A. Schmidt, and R. J. Weldon II (2007). Compilation of surface creep on California faults and comparison of WG-07 deformation model to Pacific-North American plate motion, $U$. S. Geol. Surv. Open File Rep. 2007-1437-P.

Working Group on California Earthquake Probabilities (1988). Probabilities of large earthquakes occurring in California on the San Andreas fault, U.S. Geological Survey Open-File Report, p. 62.

Working Group on California Earthquake Probabilities (1990). Probabilities of large earthquakes in the San Francisco Bay Region, California, U.S. Geological Survey Circular, p. 51.

Working Group on California Earthquake Probabilities (1995). Seismic hazards in southern California: probable earthquakes, 1994-2024, Bull. Seismol. Soc. Am. 85, 379-439.

Working Group on California Earthquake Probabilities (2003). Earthquake Probabilities in the San Francisco Bay Region: 2002-2031, USGS Open-File Report 2003-214.

Yule, D., and K. Sieh (2003). Complexities of the San Andreas fault near San Gorgonio Pass: Implications for large earthquakes, J. Geophys. Res., 108(B11), 20 pp.

Zhang, H., T. Niemi, and T. Fumal (2006). A 3000-year record of earthquakes on the northern San Andreas fault at the Vedanta marsh site, Olema, California, Seismol. Res. Lett., 77, 176. 


\section{List of Acronyms}

BPT - Brownian Passage Time

CEA - California Earthquake Authority

CEPEC - California Earthquake Prediction Evaluation Council

CFM - Community Fault Model

CGS - California Geological Survey

ERM - Earthquake Rate Model

ERF - Earthquake Rupture Forecast

ETAS - Epidemic Type Aftershock Sequence

ExCom - Executive Committee

MOC - Management Oversight Committee

NEPEC - National Earthquake Prediction Evaluation Council

NSHMP - National Seismic Hazard Mapping Program

NUVEL-1A - Global plate motion model of DeMets et al. (1994)

RELM - Regional Earthquake Likelihood Models

SCEC - Southern California Earthquake Center

SRP - Scientific Review Panel

STEP - Short Term Earthquake Probability

UCERF - Uniform California Earthquake Rupture Forecast

USGS - United States Geological Survey

WGCEP - Working Group on California Earthquake Probabilities 